BIBLIOTECA VIRTUAL DE CIÊNCIAS HUMANAS

\title{
BIOTECHNOLOGY IN EUROPE
} AND LATIN AMERICA

PROSPECTS FOR CO-OPERATION

Bernardo Sorj Mark Cantley Karl Simpson Editors 


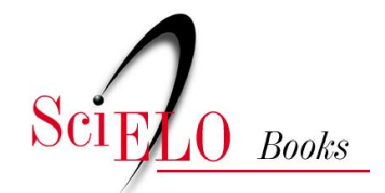

\title{
Biotechnology in Europe and Latin America \\ prospects for co-operation
}

\author{
Bernardo Sorj \\ Mark Cantley \\ Karl Simpson \\ (eds.)
}

SORJ, B., CANTLEY, M., and SIMPSON, K., eds. Biotechnology in Europe and Latin America: prospects for co-operation [online]. Rio de Janeiro: Centro Edelstein de Pesquisas Sociais, 2010. 219 p. ISBN: 978-85-7582-036-6. Available from SciELO Books $<$ http://books.scielo.org $>$.

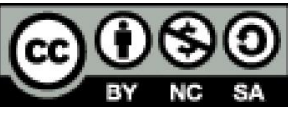

All the contents of this chapter, except where otherwise noted, is licensed under a Creative Commons Attribution-Non Commercial-ShareAlike 3.0 Unported.

Todo o conteúdo deste capítulo, exceto quando houver ressalva, é publicado sob a licença Creative Commons Atribuição Uso Não Comercial - Partilha nos Mesmos Termos 3.0 Não adaptada.

Todo el contenido de este capítulo, excepto donde se indique lo contrario, está bajo licencia de la licencia Creative Commons Reconocimento-NoComercial-CompartirIgual 3.0 Unported. 


\section{Bernardo Sorj \\ Mark Cantley \\ Karl Simpson \\ Editors}

\section{Biotechnology in Europe and Latin America \\ Prospects for co-operation}

Rio de Janeiro

$$
2010
$$

This publication is part of The Virtual Library of Social Sciences of The Edelstein Center for Social Research - www.bvce.org

Copyright (c) 2010, Mark Cantley, Karl Simpson, Bernardo Sorj

Copyright (c) 2010 of this on-line edition: The Edelstein Center for Social Research

No part of this publication may be reproduced or transmitted for commercial purposes in any form or by any means without permission in writing from the copyright holder at the address below. Parts of this publication may be reproduced for non commercial purposes so long as the authors and publisher are duly acknowledged.

ISBN 978-85-7582-036-6

The Edelstein Center for Social Research

http://www.centroedelstein.org.br/English/

Rua Visconde de Pirajá, 330/1205

Ipanema - Rio de Janeiro - RJ

CEP: 22410-000. Brazil

Contact: bvce@centroedelstein.org.br 


\section{SUMMARY}

Preface

Welcoming Speech Karl-Heinz Narjes

\section{Remarks.} Phili Viehoff

\section{Introduction} Karl Simpson

\section{SECTION ONE - Biotechnology in Europe}

1.0. Overview of European Activities in Biotechnology Karl Simpson

1.1. Belgium Adapted from speech made by $\mathrm{Mr} C$. de Wispelaere

1.2. Denmark Bruno Hansen

1.3. France .46 Daniel Thomas

1.4. The Federal Republic of Germany Helmut Zeittrager

1.5. Greece Presentations by Drs Tzotzos and Dourtouglou

1.6. The Republic of Ireland

1.7. Italy Carmello Iacobello

1.8. The Netherlands Henk C. van der Plas

1.9. Portugal Julio Novais
1.10. Spain

Armando Albert

1.11. The United Kingdom

Roy Smither

\section{SECTION TWO - Biotechnology in Latin America}

Comments Luis Ramiro Alfonsin

2.0. Overview of Latin American Activities in Biotechnology..... Karl Simpson

2.1. Argentina

José La Torre and Sara B. de Rietti

2.2. Brazil Antonio Paes de Carvalho

2.3. Mexico Rodolfo Quintero Ramirez and Rosa Luz Gonzalez Aguirre

2.4. The Andean Countries

B. Carlos Aguirre

Health in the Third World: The Role of International Co-operation.... 205 Luiz Pereira da Silva

Conclusions and Analysis 211 


\section{PREFACE}

The accession of Spain and Portugal to membership of the European Community in January 1985 not only brought new vitality to the European initiative, but served as a powerful reminder of the broader dimensions of the Spanish - and Portuguese-speaking worlds. A reinforcement of Europe's natural and historical internationalism of outlook was particularly relevant in the context of biotechnology; for the sophisticated multi-disciplinary scientific base, and the several broad application areas, force on biotechnology an internationalism both for access to scientific capability, and for access to worldwide markets.

Such was the rationale for SOBELA': a Seminar on Biotechnology in Europe and Latin America', which in April 1987 brought some 50 Latin American entrepreneurs, policy-makers and academic leaders to Europe and to Brussels. At the Commission's Borschette Conference Centre, they heard presentations from eleven of the Community Member States, each emphasising its strengths in biotechnology and its interest in promoting industrial collaboration with firms in Latin America.

The seminar was opened by speeches from Vice-President KarlHeinz Narjes on behalf of the Commission, and by His Excellency Luis Ramiro Alfonsin of Argentina, senior Latin American diplomat in Brussels. In the closing session, Directors-General Paolo Fasella (Science, Research and Development, DG XII) and Jean Durieux (External Relations, DG I) welcomed Their Excellencies the ambassadors from Argentina, Mexico, Brazil, Uruguay and Colombia.

The conference itself was preceded and followed by visits to the leading centers in the various Member States. The fruits of these exchanges were shown through more than a hundred proposals for industrial collaboration which resulted, many of them now converted into ongoing relationships. The Commission through its Directorate-General for External Relations is continuing to promote such collaboration, helping firms in each continent to find useful partners for trade, investment, technical collaboration or marketing.

The materials presented at the conference have been updated and edited, to give in this book an up-to-date picture of capabilities and common interests. Although inevitably any book on biotechnology is obsolete by the time it appears, there is nothing obsolescent about the dynamism now being displayed in the development of the bioindustries in both continents. We hope that the presentations assembled in this volume will testify to this dynamic development, and stimulate its further promotion.

The Editors,

Bernardo Sorj Mark Cantley

Karl Simpson 


\section{WELCOMING SPEECH}

Karl-Heinz Narjes

Draft text of a speech by Vice-President Karl-Heinz Narjes, on 27 April 1987, at the opening session of the 'Seminar on Biotechnology in Europe and Latin America', Conference Centre Albert Borschette, Brussels.

Your Excellency, Mr. Chairman, Ladies and Gentlemen,

It gives me great pleasure to welcome, on behalf of the Commission, the many distinguished visitors who have kindly accepted our invitation to this international gathering. There are present, representatives of some twenty different nations; but let me emphasise not our diversity, but our common interests. The European Community and its Member States have worked together to organise this seminar, and to offer to our guests from Latin America our hospitality; our friendship; our ideas; and our hopes for continuing and mutually beneficial collaboration.

The subject on which our common interests will be focussed during this three-day seminar is biotechnology. Much can be said, much will be said, during these three busy days; but even if we talk all day, we shall not exhaust the range of topics covered by this broad subject. I speak with some confidence on this; the Commission has been talking about biotechnology, and developing its policies, for over ten years; some of our Member States for much longer. Whether we adopt a narrow or a broad definition, we have to recognise that ultimately the biological revolutions in progress will influence or transform every field of application of the life sciences - including agriculture and forestry, health care and pharmaceuticals, organic waste and water recycling, and the care of the environment.

Initially, we saw biotechnology mainly as a research matter. Our first programme, the biomolecular engineering programme, ran from nineteen eighty-two to nineteen eighty-six, and was limited to the agriculture and agrofood fields. It sought to remove obstacles to the transfer into practice of the advances in biological research. It was successful not only in scientific terms, but in catalysing trans-frontier collaboration within our community, through transnational cooperation in research, and through training grants for researchers moving to laboratories outside their home country.

Our current biotechnology research action programme runs until nineteen eighty-nine. It covers a wider range of subjects, including topics of importance to all the bioindustries, both in research, and in improving the infrastructure for research. We expect to expand the programme further in the near future. You will probably hear more about these activities during the course of the seminar.

I should mention also that the breadth of biotechnology inevitably involves several other research areas, such as our agricultural research, our medical research, and (of particular relevance to this seminar), our programmes of science and technology for development. The first of these programmes concerned tropical agriculture, health and nutrition. It ended in December 1986; and we hope shortly to finalise a substantially larger effort in the same areas, including a greater involvement of laboratories in developing countries.

We also plan a major new biotechnology-based initiative to stimulate innovative developments at the interfaces between industry and agriculture. The industrialist, the farmer and the scientist must work together to demonstrate and develop these innovations. This programme will seek to develop:

- New crops, better adapted to market needs in both food and nonfood applications;

- New processes for cultivating and harvesting crops, for splitting them into their constituent elements, and for transforming these into higher value products;

- New approaches to the control of pests and diseases, and to the control of nutrition and metabolism in plants and animals. In this or in other programmes, we shall be continuing research on the assessment and management of any related risks.

But our policies for biotechnology in Europe go beyond research. They interact with our plans for agricultural and industrial development, for safeguarding the environment, and for developing harmonised regulatory regimes in the Common Market. They include matters 
ranging from price regimes for raw materials, to refinements of the laws on patents and on plant variety protection.

In the context of this seminar, I want to emphasise the international, indeed the global, dimensions of biotechnology. The techniques, products and services of biotechnology are of central importance to countries rich or poor, at every stage or their economic development. Here in Europe, we believe we have major strengths and capabilities in biotechnology, and we want to talk about these with you during the coming days. We are also sure that we can learn from your experiences in your various countries. I recognise that we shall have some differences of opinion - that makes it all the more necessary to continue our dialogue, on occasions such as this, and to understand the basis for our differences. But above all, we believe that we have a common interest in learning together how to develop and use biotechnology for your needs and ours, whether we speak of social needs for health care and basic nutrition, or needs for commercial and competitive developments.

Let me cite some practical examples. There is much fashionable talk about the hypothetical risks of biotechnology. When we talk about the needs for better vaccines, diagnostics and therapies, we are not talking hypothetically, but about real, current and continuing disasters; about hundreds of thousands of people round the world dying daily, to-day and every day, from avoidable causes, from starvation and preventable disease. We have the technology to produce the food; we have vaccines and therapies for many of the diseases that are still killing people. Through the methods of biotechnology, we have good prospects for developing vaccines against major diseases not yet curable, for example through our new ability to study the constituent parts of viruses, and to manufacture in large quantities and high purity their antigenic proteins. The development of monoclonal antibodies is providing precise and effective diagnostic tools, and the basis for delivering drugs to precisely targetted cells in the body. Such technologies are essential in the continuing battle against parasitic diseases such as Chagas' or to combat the continuing and ever-changing challenges of malaria. They are equally needed to confront novel challenges such as the AIDS virus. The major risk to be avoided is the risk of unnecessary delay.
Concern is sometimes expressed about the impact of biotechnology on the environment. Around the world, some two hundred million people are engaged in 'slash and burn' agriculture. Of course, they are driven by their local necessities; but by their actions, they are destroying the remaining areas of tropical forest, with a loss of species estimated at several hundred per day. We are likely to lose half of all current species within twenty years; it is an environmental catastrophe, a species extinction of a magnitude unparalleled since the death of the dinosaurs. It is not hypothetical; it is happening now. Yet biotechnology can offer the means to feed the world's whole population more than adequately, using far less land than we cultivate today. Further major gains in agricultural productivity are now seen to be possible. By pursuing these, we should be able to take the pressure off the environmentally sensitive areas, such as the uplands and the wetlands, the unique ecological habitats. We should be able to defend our forest, be it in temperate or in tropical zones, and restore our environment, replanting appropriate species in degraded areas such as, here in Europe, parts of our Mediterranean littoral.

I do not want to be simplistic about the practical difficulties which inhibit the application of the new technologies to the problems of health care, agriculture and environment. The political and economic difficulties are often greater than those of science and technology. And above all, the application of new science demands adaptation to local conditions, and integration with local knowledge. Therefore collaboration and dialogue are essential, and our joint learning will inevitably have to proceed through trial and error.

To put biotechnology to work requires men of action, bringing together managerial abilities, local knowledge, capital and science, and there must be a functioning system of trade. The successful application of biotechnology depends on appropriate exchanges, not only of the ideas and results of $R \& D$, but also of the capital investment and trade in goods and services which follow from the success of such research. There is no alternative to progress in the liberalisation of world trade. The policy of the European Community, which is the largest trading bloc in the world, is to work seriously for the improvement of the current conditions of world trade, through the GATT framework. For we know, not least from our own experience within Europe, from Germany's Zoll Verein in the nineteenth century to our community of to-day, that trade is a 'non-zero-sum' game, in 
which all players can win. But this policy has to be accompanied by adequate measures in the same direction by the other important trading countries. We are happy to see the corresponding bilateral and multi-lateral agreements developing between countries within Latin America, and between Latin America and Europe. These developments provide the context within which biotechnology can thrive, encouraged by the prospect of global market opportunities, and driven by the social and economic needs to which biotechnology is relevant.

A subject which must raise, in connection with world trading conditions, is that of intellectual property. As our world economy evolves more and more towards knowledge-based industries, an effective international system of respect for intellectual property is increasingly essential. It is a mistake to see patents or plant variety rights as systems defending the rich against the poor. Many biotechnology innovations may be realised by small enterprises. In order to encourage innovation, it is essential to provide adequate protection; and such protection facilitates technology transfer, where secrecy would inhibit it. As our biological science advances, the principles of protection for innovation are just as applicable to plants, foods and medicines as they have been to electrical or mechanical devices.

We understand the strong desire of developing countries - indeed, of all countries - to have effective control of science and technology. But if we wish to enjoy the full benefits of science and technology, activities which are as international in their sources as in their applications, then we have to accept the fact of growing international exchanges. Recent historical experiences show that escape from economic and technological dependence is not through isolationism, but by increasing participation through new creative models of involvement of worldwide developments and consequent interdependence. The need again is to work together to define fair conditions for such interdependence.

The scientists have delivered the goods, in terms of basic advances in understanding and techniques. In Europe, we have recognised their importance in the amendments to the treaty which are coming into effect: the Single Europe Act gives an explicit legal base for our science, technology and development activities. We have been debating with our
Member States the final details of our overall R\&D programme, in which biotechnology is a major element.

So if science and politics are playing their part well, they provide to the businessmen, the entrepreneurs, the means and the possibilities for innovation, investment and hence economic development. I hope that many contacts will be made at this seminar, and that seeds of awareness will be sown in these three days and in your visits to our Member States. We must develop greater awareness of one another's needs and capabilities, and hence build co-operative and continuing relationships, which will help us to develop and to share our advances in biotechnology and to apply them to the achievement of our social and economic objectives. 


\section{REMARKS}

Phili Viehoff

Remarks by Ms. Phili Viehoff, Member of the European Parliament and Rapporteur on Biotechnology for the Committee on Energy, Research and Technology, at the opening of the second day's proceedings, Tuesday 28 April 1987.

Ladies and Gentlemen,

Developments in biotechnology have been looked at on a number of occasions in recent years by the European Parliament. In the past, it was mainly the Committee on Energy, Research and Technology which was responsible for drawing up reports, but for my last report, entitled 'Biotechnology in Europe and the need for an integrated policy', adopted in February by the European Parliament, a number of parliamentary committees were asked to deliver opinions; making specific policy recommendations for the medium and long term.

I found it of utmost importance that this multidisciplinary technology, with such a wide range of applications was discussed not only in the Committee for Energy, Research and Technology. Now that the results of biotechnology research are rapidly finding their way into commercial applications in many sectors of industry, agriculture and health care, with far-reaching consequences, it is important to consider the various policy aspects more closely.

I want to underline the fact that in a representative democracy, Parliaments, before users of future-oriented research work, are amongst the makers of the future. This is important to mention, because there is an increasing tendency in several European countries to forget or minimize the role of Parliament in advanced societies. The real decisions are too often taken by powerful interest groups.

It is true that Parliaments are facing increasing difficulties to play their role to its full and legitimate scope in a more and more complex and fast changing society.
It is not easy to enact laws on fundamental issues of complex nature like, for instance, biotechnology. In many instances it implies a high degree of confidence in the assessment and monitoring of the long-term implications and consequences of the decisions taken today.

This is not yet the case! The decisions taken today do have more than ever in the past far-reaching consequences for millions of people, whose daily life will be deeply affected in the future. In a modern representative democracy, it is a must that Parliament has the capability to legislate on the basis of honest attempts to forecast and assess the long-term implications and consequences of a given development; so that it is possible to monitor and direct the processes in such a way that the impact is for the benefit of mankind, not to its detriment. Since it has become clear that developments in biotechnology have an international-character, international cooperation, regulations and legislation are of great importance. Especially regulations in the field of deliberate release of manipulated micro-organisms, because they are not at all controlled by national borders.

Important is also the democratization of the decision-making process. This means that more attention should be paid to the provision of balanced information to the public at large in order to increase public awareness. 


\section{INTRODUCTION}

Karl Simpson

The Seminar on Biotechnology in Europe and Latin America (SOBELA) took place in Brussels, 27-29 April 1987. Unlike many recent meetings in biotechnology this was not an opportunity to display the latest developments, but more importantly a chance to exchange information and prepare commercial agreements based on the transfer of skills and technology in the biosciences.

The meeting opened with important statements of interest and goodwill by key scientific and political figures from Europe and Latin America. Later, businessmen and scientists from the two sides of the Atlantic described the infrastructures that support biotechnology activities in their respective regions. It emerged that there was real scope for two way exchange of skills, materials and equipment.

The Commission of the European Communities, CEC, and various multinational groupings in Latin America were able to compare and contrast the effectiveness of their enabling programmes. In both areas regulation and legislation raise barriers to the free exchange of skills and commodities resulting from biotechnology. In both areas collaborative ventures are breaking down such barriers, albeit too slowly. Both areas perceive the greatest competitive challenges to their biotechnology industries to come from the USA and Japan.

Since April 1987 the stock market has become a less than safe investment and the US dollar is no longer a safe alternative to gold. These developments will have long lasting effects on the ease of raising capital and the success of exported products from Latin America. More pressure will be applied to Latin American governments to provide the means to enable the development of an internationally competitive industry. European biotechnology has moved rapidly from the position described in 'Industrial Biotechnology in Europe', edited by Duncan Davies, (CEPS, CEE, 1986) in which Europe was perceived to be failing to compete. In the past year there has been a flurry of supportive and concertation measures at both national and Community levels.

\section{Why SOBELA?}

Europe and Latin America have social, cultural and linguistic ties, which for many years have supported significant commercial exchanges. The European Community is Latin America's second biggest trading partner (after the USA) and the biggest supplier of development aid.

The present problems of the Latin American economies lead many Europeans to ignore the wealth of natural resources and the size of potential markets. The good educational infrastructure and the presence of modern technology and science-based industry offer considerable scope for mutually profitable exchanges in the area of biotechnology. Despite sometimes being included amongst the nations of the 'Third World', Latin America has made significant contributions to developments in biotechnology and may have acted as a stimulus to action in European biotechnology.

Existing training schemes funded by the European Community and its Member States do much to enable skilled management and senior scientific personnel to keep ahead of the latest technological developments. Biotechnology also depends on the availability of highly skilled technicians for whom fewer international training programmes are accessible. The absence of such personnel is a serious hindrance to the development of the biotechnology industry in Latin America. SOBELA participants meeting at informal events had the opportunity to discuss, without commitment, the nature of potential collaborations in this and other areas of interest to the biotechnology industry.

In the absence of a formal biotechnology link between the European Community and Latin America, SOBELA provided a forum for dialogue. The presentations, summarised in the following pages, presented existing national initiatives in industry and in the public sector. It will be immediately noticeable that this was not a scientific seminar, but more importantly perhaps, an overture for collaboration in industry and the underlying science, mediated by diplomatic goodwill and influence. How can European/Latin American collaboration in biotechnology serve national priorities?

The example of Brazil's ambitious Gasohol programme so impressed France's President Giscard d'Estaing during his 1977 visit, that he commissioned a report on French options in biotechnology. The report, Sciences de la Vie et Societé' by Gros, Jacob and Royer (1979) initiated the 
chain of events that lead to the first 'Programme Mobilisateur', designed to establish France as a leading contributor to the new technology, and participant in the markets of the emerging 'bioindustries'.

The United Kingdom and other European states in turn began the implementation of hastily contrived programmes, designed to salvage national position or pride in an emergent industry that seemed once again destined to be dominated by the USA and Japan.

The example cited may in one case have acted as a spur to development in Europe, but in general the direction of technology transfer is predominantly in the opposite sense. What can Europe and Latin America do for each other? What are the perceived needs of these two widely different groups of nations? Firstly we shall examine what we mean by biotechnology.

\section{The Scope of Biotechnology}

Very broadly, biotechnology may be defined as the purposeful application of biological science, thus encapsulating most aspects of current and traditional agriculture, food production and health care, narrower definitions of phrases such as 'new biotechnology', forms specifically upon the more prominent modern techniques of genetic engineering, monoclonal antibodies, and their applications.

Biotechnology has a prehistory, which predates the keeping of records or experimental details. Into this area must fall the first examples of cheesemaking, beer and wine manufacture and some aspects of traditional medicine. The transition from tradition to science took place around the end of the 18th century. At about that time the scientific method was becoming respected, the microscope was becoming a serious research instrument and the value of careful measurement was becoming realised. The quantitative approach saw fruits in the researches of Mendel and the flowering of organic chemistry, although a century was to pass before those disparate strands could be drawn together in the new biology.

Until the second world war many basic organic chemicals were made by fermentation and subsequent purification. Glycerol, acetic acid, citric acid and many other solvents and acids were extracted from stirred tank fermenters using molasses as a raw material. In Japan monosodium glutamate production from strains of aspergillus was the first pure product of the fermentation industry, other than alcohol.

Microbiological development in the same period had been rapid as had the growth of medical genetics, but perhaps the most critical discovery for modern biotechnology was the discovery of penicillin action by Fleming in 1928. The stimulus of the second world war created a need for the large scale production of antibiotics. Because of the development of several different strands of appropriate technology it became possible to achieve the growth of moulds and filamentous bacteria in highly defined and controlled conditions. In 1940 Florey and Chain succeeded in isolating and purifying penicillin in a manner which allowed mass production. The development of downstream processing can be traced to this period.

The perfection of the hybridoma technique for the production of monoclonal antibodies resulted from the work of an Argentine scientist carried out in a British laboratory. César Milstein with Georges Köhler went on to share the Nobel prize.

In Latin America it is possible to say that much large scale use of biotechnology remains at roughly the stage reached in Europe by 1945. There are relatively sophisticated brewing and food technologies and increasingly a degree of competence in medical technologies such as vaccine manufacture. The inclusion of state of the art skills will hopefully be one of the results of some of the ambitious programmes described in this presentation.

There is a real danger that biotechnology is being presented as a new industry. This is quite clearly not the case. Biotechnology is a set of enabling technologies which will find application in the existing bioindustries, i.e. the several sectors of activity based upon the applications of life sciences and/or the use of materials of organic origin. It is quite fair to say that some aspects of biotechnology have allowed the launch of new companies such as Genentech or Celltech, which rely exclusively on the new technology for their sales. The outlets for their products quite clearly label those companies as newcomers in the pharmaceutical industry, rather than harbingers of a completely new industrial sector.

Modern biotechnology has the potential to change profoundly the nature of several major industrial sectors. This potential has as its foundations two very different sets of skills. Firstly, there exists an 
assemblage of biological and engineering skills built up over centuries of experience in the fermentation industry. Secondly, and in the public eye, more prominently, modern molecular biology has allowed the tailoring of genomic material and cells to serve specific goals. The first biotechnology revolution occurred, not in the 1970s, but in the 1940s when the industrial scale production of antibiotics necessitated radically new developments in fermentation technology and downstream processing.

In the course of the Seminar Professor Da Silva, working in Paris at the Pasteur Institute, used the example of vaccine production to identify four generations of biotechnology.

\begin{tabular}{|lcc|}
\hline Generation & Vaccine Type & Technology used \\
\hline Fist & Traditional & Eggs/in vivo extract \\
Second & Polio, Mumps, Rabies & Cell culture isolation of virus \\
Third & Hepatitis & Genetic manipulation \\
Fourth & AIDS? & DNA/Peptide synthesis \\
\hline
\end{tabular}

Europe is currently experimenting with Fourth Generation vaccine production, while Latin America is locked into the Second Generation. Can it become economically justifiable for Latin America to acquire its own Third and Fourth Generation capacity?

From the viewpoint of a commercial entrepreneur, biotechnology serves to make money from biology. Growing public concern for the environment and public health risks, has in some cases limited the application of biotechnology. Such issues as the erosion of the earth's ozone layer and $\mathrm{CO}_{2}$ build up in the atmosphere have sensitized the public to possible harmful effects of scientific and technological innovation. It is to the credit of the biotechnology industry in Europe and North America that their own policing standards have disarmed most critics. Biotechnology has succeeded in building up an environmentally responsible image, although as Mrs Viehoff emphasised, there is no room for complacency. The environmental record of the Latin American bioindustry will come under dose scrutiny if its products are to be launched on the European market.

Like any innovative industrial activity, biotechnology is underpinned by an investment in Research and Development, R\&D. The R\&D financing comes either from the private sector, the public sector or a mixture of both. In the following chapters specific examples of European and Latin
American experiences will be presented, however certain general principles can be outlined here. Industry is concerned with making money in the medium or short term. R\&D in biotechnology is very expensive and in industrial laboratories must be aimed at process improvement or product development, linked to astute market analysis if profits and long term success are to be achieved. In the case of modern genetics, applied industrial research is supported by the results of public sector research, published in open sources.

To take a very obvious example. The structure of DNA, resolved by Watson and Crick in 1953, underpins the whole of modern molecular biology, which is one of the foundation stones of biotechnology. The discovery of DNA structure was made possible by public sector funding. The synthesis of human insulin by a yeast or bacteria would be unthinkable without knowledge of DNA structure. Human insulin is sold by many reputable companies, who could not dream of financing a research programme that might give commercial results only after 25 years. Yet it was only in 1988 that the first genetically engineered insulins appeared on the market.

The European Commission has been deeply involved in discussions about the nature of fundamental research, precompetitive applied research and competitive industrial research, as applied to the biotechnology area. Fundamental research in Europe has historically been a matter for national funding programmes, while competitive research is quite properly the domain of industry. The middle ground is a difficult area in which all available goodwill must be coordinated so as to realise public sector/private sector collaboration. In Latin America collaboration in the Andean Pact states and between Argentina and Brazil is tackling specific goals perceived to be of regional benefit. The European Commission has attempted to tackle this middle ground through the Biotechnology Action Programme, BAP, which will be described later. Future European Community programmes will concentrate on providing enabling technology for the European bioindustry in order to enhance international competitiveness. The nature of European/Latin American collaborations may depend to some extent on the willingness to compromise such competitiveness in relations with the Latin American states.

Ten years ago very few firms could think of a commercially justifiable reason for having molecular geneticists on their staffs. It would now be considered foolhardy for a European pharmaceutical company not 
to employ such people. Later on, contributors to this volume will show why this is not always the case in Latin America.

At present the agricultural industry is waking up to the promise of biotechnology. In ten years it will be unthinkable for a major seed supplier not to have a molecular genetics team. Dr Sargeant, working in the European Commission, showed that it is likely that the very nature of agriculture and land use may be changed by developments made possible by biotechnological research. Such consequences might be of more immediate relevance to agriculture in the developing world, including Latin America.

In Western Europe, the United States and Japan, the main thrust of recent industrial activity in biotechnology has been orientated to the production of therapeutic products and diagnostics, both in the health sector. The public perception of biotechnology has been strongly influenced by issues as diverse as AIDS, the recent availability of highly publicised new wonder drugs, thrombolytic agents for heart attack victims and the dramatic application through forensic science of 'genetic fingerprinting'.

\section{What can Biotechnology Offer?}

The first impact of biotechnology has been in the area of human health. The public has seen remarkable progress made in the treatment of viral diseases and cancer, using the twin technologies of molecular genetics and cell fusion. Molecular genetics gave rise to genetic manipulation and cell fusion gave rise to the 'magic bullets' of monoclonal antibodies.

Products resulting from DNA cloning and expression in microorganisms include: insulin, lymphokines, clotting factors and thrombolytic agents. Monoclonal antibodies have been the basis for simplified diagnostic tests and the hope of a cure for several cancers. Monoclonal antibodies can be used as guided missiles, carrying a 'warhead' of toxin or radioactive element to a specific target, such as the cells of a malignant tumour.

There is a great deal more to biotechnology than the health care sector. As a set of technologies it is poised to offer benefits to a number of industrial sectors including: Food, Environment, Agriculture and Animal Health, Chemicals, Mining, Energy and, of course, Human Health.

Despite the conspicuous successes of some health care applications, some goals have proved unexpectedly difficult to realise. Plant biotechnology, for long the Cinderella of the biosciences is hastily constructing a carriage to get to the ball! Despite the early delays, the pace of discovery in this area is now remarkable.

The prospects of controlled nitrogen fixation by incorporating the genes of bacteria into flowering plants have proved difficult to realise. The complexity of the problem was underestimated by the naively phrased publicity which portrayed molecular biology as a universal solution in search of problems to attack. The hopes for alcohol from wood have also evaporated as enzymatic means of lignocellulose degradation have proved impracticable as a commercial process. Responsible scientists had always pointed out the difficulties involved, but the media, conditioned to a science which realised the impossible, would not accept such stark realism.

Political pressures are also significant. Debate has raged on the introduction of an EEC sponsored bio-alcohol programme, portrayed as an alternative to adding lead to petrol. Backed by several agricultural and fermentation companies, but strongly opposed by producers of industrial alcohol and more cost-effective lead substitutes, the ultimate decision looks set to be made as much on political grounds as on economic: finally, the argument was resolved by the decline in the price of oil and the strengthened Community commitment to budget discipline.

The Latin American countries with their vast genetic resources could well harbour microbiological resources that might offer solutions to some industrial process problems. Screening and identification of natural resources is an aspect of biotechnology that is often overlooked in Europe and North America. The potential reward in terms of useful biological activities is immense. Microbial screening using fairly traditional technologies is a key area in which Latin America can make a contribution to European biotechnology. A recent expedition to Brazil by staff of the Cranfield Institute of Technology, UK, underlined the importance of resources held in developing countries. The expedition hoped to collect samples from the Amazonian forest, with a view to understanding the rapid turnover of vegetable life on a very thin topsoil. Genes locked in Amazonian organisms could play an important role in the energy and environmental industries in years to come. Obvious applications in the environment sector include sewage treatment. The growing problem of urban sprawl in the developing world, makes sewage control a major issue in environment and public health. 
Mining has received comparatively little attention from the public, but micro-organisms have been developed that are capable of concentrating minerals of commercial value from normally unworkable deposits. The same techniques could scavenge environmentally dangerous elements such as Cadmium or Mercury.

Biotechnology can do more than exploit existing markets. As old markets are eroded biotechnology has the potential to create new markets and revenues. In the context of SOBELA we must address the question of how biotechnology can serve the common interests of Latin America and Europe. Cynics will find it easy to say that major European companies will exploit Latin America. Collaboration should be approached with caution so as to distribute the benefits equitably between partners. The contributions of the following chapters show that indeed we do have something to learn from each other in terms both of science and models of cooperation.

\section{European Biotechnology}

Most European states have taken action at government level to improve competitiveness in the area of biotechnology. National programmes and coordinating bodies have until recently had little interchange of views. Even the European Commission has had comparatively little success in coordinating national strategies in biotechnology. Despite thirty years of community it is not generally appreciated among European governments, to what extent the European Commission works on their behalf in the harmonisation of regulations and the elimination of barriers to trade and free movement of personnel and skills. The probable impact of the 1992 target date for the removal of internal barriers to trade is gradually being appreciated by European industrialists, thanks to an information campaign orchestrated at national levels.

Total public sector biotechnology spending in the EEC member states may not be far short of that spent in the USA - estimated at \$2.7 billion in 1987 by a report from the Congressional Office of Technology Assessment. Partly because of duplication and fragmentation of effort and largely because of differences of commercial opportunism and the absence of a real Common Market, Europe nonetheless lags behind both the USA and Japan in the commercial exploitation of biotechnology.
The funding of new ventures has been easier in the USA than in Europe. Seedcorn capital, venture capital, tax concessions and the entrepreneurial tradition are particularly North American attributes. Europe however has less often had to write off investments in failed ventures. The most conspicuous examples of failure in Europe have involved US companies operating without a tightly defined business plan. In the past two years European entrepreneurs have established a substantial pool of venture capital, with several specialist funds able to evaluate ventures in biotechnology. The United Kingdom has Europe's most sophisticated venture capital market, modelled on the USA, but characterised also by European conservatism. Some analysts now say that there are more new funds in Europe than the USA, although the pool of American funds, especially in the area of seedcorn capital will continue to be larger for the foreseeable future.

Europe probably has much to offer Latin America by way of advice on business start up schemes. If this can be integrated with some of the existing programmes and experience, it may be possible to fund suitably targeted biotechnology start-ups in Latin America.

In Europe two very different types of company have played a role in the new biotechnology. In the first instance medium to large companies, with diverse products and a long established tradition in product sectors ranging from engineering and chemicals to ethical products, have adopted the new technologies as a logical extension to their portfolios. More recently a second kind of company has emerged, backed by risk capital, small to medium sized, with a very few but very high technology products. Whereas in the USA such small companies dominate the biotechnology sector, in Europe it is the old, traditional, medium to large companies that dominate.

The larger companies in Europe, such as Elf-Aquitaine, Hoechst, ICI, Unilever etc. have added rDNA technology to their research programmes in health care and agriculture. In the UK and Netherlands university/industry partnership has played a major role in transferring appropriate technologies. Many of the resulting small firms, which succeed by attracting investment, become in turn targets for acquisition by the larger companies with a more conservative approach to new technology. Large companies are often unwilling to gamble on untested technology, but happy to pay the going price for proven products. 
Even for the largest companies the regulatory and legislative barriers that exist in Europe are a major headache. A large company will have a regulatory affairs department far larger and more expensive than a USA company of the same size that focuses only on the internal USA market.

\section{Latin American Biotechnology}

In Latin America as in Europe, manufacturers of ethical products have had to face a number of different regulatory regimes. The cost of overcoming different national requirements has proved prohibitive for many smaller companies. In Europe as in Latin America, multi-national negotiations are moving ahead with the desire to provide a unified regulatory system. SOBELA might prove a launch point for European/Latin American negotiations in this area.

The SOBELA meeting demonstrated the steps taken by Latin American countries to rationalise, regroup and pool skills in this important area of high technology. Biotechnology has been the focus of an almost unprecedented dialogue between the Latin American states. Typical results of this dialogue include Argentinean/ Brazil collaborations, Andean Pact collaborations and an increasing Mexican involvement in South American biotechnology.

Whereas there are a number of interesting biotechnology start-ups funded by private or state organisations, it is notable that the local market is already being assaulted by the established multinationals. Many middle sized European, Japanese and N American firms are establishing marketing structures in Latin America. Several are contemplating the establishment of manufacturing and R\&D facilities. These companies in particular must be encouraged to enter into a constructive dialogue with the nascent domestic biotechnology companies. This route might also be the most appropriate if European companies are to avoid the pitfalls of inadequate patent protection. It is difficult for companies to defend their intellectual property rights if they are far away from the market or competition concerned - even where such protection is legally guaranteed. Several small European companies have lacked the financial resources to defend infringements of their intellectual property rights in the USA.

\section{The SOBELA Meeting}

Introductions by several distinguished speakers confirmed the extent of goodwill among the participating states. The subsequent presentations gave an overview of the status of biotechnology in Europe and Latin America. Speakers from both sides of the Atlantic affirmed their governments' commitments to collaboration and several presenters were able to speak of specific examples.

Dr Pereira da Silva explained that biotechnology cannot be regarded as a panacea for the problems of a developing economy, although its application to well defined problems could yield very significant benefits. Many of his recommendations could be summarised by saying that what Latin America, and other developing countries, need is the establishment of bilateral accords with developed nations which permit training and the creation of a domestic infrastructure capable of supporting the benefits to be wrought by biotechnology.

The following chapters consider the state of biotechnology in Europe and Latin America. To what extent are the goals of collaboration likely to bring tangible benefits to participants? 
European administrations and industrial organisations have realised that they cannot afford to miss out on the exploitation of biotechnology. European scientists working in industrial and university laboratories have made decisive contributions to the methodology of this 'New Biotechnology'. The first University Chair in biotechnology was established in Lyngby, Denmark in 1905 and the world enzymes market is dominated by two European companies; Novo, Denmark and GistBrocades, Netherlands.

Although total European industrial spending on biotechnology is approaching that of the USA, it is in the USA and increasingly Japan, that new commercial opportunities are being exploited. The funding of new ventures has been far more difficult in Europe. The USA offers important tax concessions for new ventures and there is ready availability of seedcorn and venture capital. Perhaps most importantly the USA has an entrepreneurial tradition that respects the risk taker.

The most important disadvantages facing Europe are those of internal language and trade barriers. Despite the activities of the European Commission there are still separate markets in the European Community, with different regulatory practices, legislatures and languages. rDNA regulations vary widely in the community. In Denmark draconian legislation is driving R\&D out of the country to more hospitable locations. The same may soon happen in Germany where a strong, but uninformed Green movement has considerable influence. Surveys have revealed that opposition to rDNA is most deeply rooted where the public perceives itself to be uninformed.

The harmonisation of Community regulations, aimed at creating a single market ready for January 1st 1993, is expected to improve this state of affairs, although much work will have to be done. The European Community has adopted a number of research and training programmes to stimulate and strengthen biotechnology in Europe. Proposals from the Commission from the mid-1970s were finally adopted by the Member States in 1981, launching the Biomolecular Engineering Programme, SEP': 15 MECU, 1982-86. This addressed specific bottlenecks, applying the results of 
modern genetics and enzymology in the agro-food sector. The larger Biotechnology Action Programme, 'BAP': 75 MECU, 1985-89, embraced a wider range of biotechnology topics, including topics of interest to a wider range of industries, an expanded safety programme, and projects on 'infrastructure' to strengthen cell- and micro-organism collections and databanks. At the time of going to press, a 100 MECU programme, Biotechnology Research and Innovation for Development and Growth in Europe, 'BRIDGE', 1990-94 is before Council and Parliament.

In addition to the research and training programmes, the Commission has recognised since 1983 the value of a coherent strategy for biotechnology, embracing not only the programmes mentioned above, but five other action priorities:

- new regimes for sugar and starch, to make these raw materials available at a competitive price to Community industry;

- new regulations, to provide in the context of the developing Common Market a common regulatory framework for biotechnology and its products;

- new regulations for the protection of intellectual property (patents and plant varieties), to ensure in the field of biotechnology clarity of legislation and adequate protection to maintain the incentive for research and innovation;

- demonstration projects, to stimulate the transfer of new technology towards commercialisation, in particular across the intersectoral and inter-disciplinary boundaries between science, industry and agriculture. The $80 \mathrm{MECU}$ European Collaborative Linkage of Agriculture and Industry through Research, 'ECLAIR', was a result launched in 1989;

- a 'concertation' action, for monitoring and awareness of emerging opportunities and challenges, and in order to improve co-ordination in biotechnology relevant policies between the several Commission services involved, and between Community and Member States. With the strong support of the European Parliament, this multidimensional response enabled the Commission to develop an integrated response to the challenges of biotechnology.
One of the most desirable consequences of Community and National activities in biotechnology has been the move to enhance communication between nations, industry, universities and ministries. Inter-national consultation has been a feature of newly established biotechnology programmes such as those of Greece and Spain.

\section{The European Biotechnology Industry}

In the USA the biotechnology industry is dominated by small high tech companies with few products, brought into existence with venture funding. In Europe medium to large companies with a long established pedigree and a diverse range of products from fertilisers to DNA probes are dominant. Until very recently only in the UK, and to a much lesser extent the Netherlands, has venture capital allowed the emergence of significant numbers of small to medium US style ventures. In 1988 and 1989 new venture capital companies are seeking business in all parts of the community. Significantly there is some real seed corn capital available.

All of Europe's traditional chemical and pharmaceutical giants have now invested heavily in rDNA technology, adding it to their mainstream programmes in the health care and agriculture sectors. University/Industry partnerships have played a major rle in transfer-ring the appropriate technologies. In the UK this is typified by the ICI/University of Leicester relationship. Leicester, where Alec Jeffreys invented DNA fingerprinting, is one of Europe's leading centres of rDNA research. In W Germany Hoechst (still in disfavour with the government after its decision to invest in Massachusetts General Hospital) has a number of collaborative ventures with university laboratories.

\section{What Are Europe's Strengths?}

The fragmentation of Europe has paradoxically provided a major asset. Firms have grown up in an environment that requires export earnings. Knowledge of export regulations and a lack of dependence upon internal markets are in sharp contrast to many US firms who have the world's largest single market at their doorstep. The old colonial powers of Europe have left their languages as a permanent monument to occupation. Language thus provides privileged access to markets such as Latin America and Africa. 
Several areas of biotechnology are dominated by European science or companies including: enzyme production, agro-biotechnology, biosensors, waste treatment and speciality chemicals.

European firms are generally willing to contemplate participation in joint ventures, both within and outside the Community. There is some apprehension about the loss of European proprietary knowledge to the USA and Japan through mismanagement of joint venture activity.

\section{A Summary of National Activities in the EEC}

BELGIUM

The governments of the Flemish and French speaking areas have both implemented support programmes for biotechnology. Large companies Solvay and Smith Kline Rit have moved firmly into biotech. Small companies including Plant Genetic Systems and Phytotec, with good university contacts are making rapid progress to success internationally.

\section{DENMARK}

Despite a tough attitude to biotech legislation, the government has committed another US\$60 million in the next four years. A small country, but strong in enzymes and gene technology. Novo has been active in protein engineering and European collaboration. Rationalisation in the domestic biotechnology industry is exemplified by the merger of Novo and Nordisk, both major insulin producers with rDNA technology.

FRANCE

In 1987 the conservative government overturned spending committed by the departed socialists, but the biotechnology Mobilisation Programme continued in weakened form. May 1988 saw the Socialists return under Rocard, and Minister Curien almost immediately instituted massive new investment in biotechnology. France has major strengths in bioreactors centred on Daniel Thomas in the University of Compiègne. Agro biotechnology is another strong field, Limagrain has developed artificial seeds and Moet-Hennessy is looking at the micropropagation of woody plants. Club Agri has a 4 year, US\$3 million programme of club sponsored research.

Sanofi, an Elf Aquitaine subsidiary with major health-care biotech commitments had turnover of more than US\$600 million last year.
Transgène, the rDNA and cell biology firm works in collaboration with several major French companies and is starting to be a candidate for entry into the international league.

\section{FEDERAL REPUBLIC OF GERMANY}

One of Europe's biggest biotech spenders. Major public expenditure by both central (US\$700 million over 5 years in latest programme) and regional governments. Central government is being forced by Green movement to enact restrictive legislation. Some companies may look elsewhere for new R\&D activity. Biotechnology Centre in Braunschweig is world class for fermentation development and general biotech activity. Companies such as Hoechst, Bayer, BASF have bought in all the new skills, but are very secretive about R\&D. Hoechst is far advanced in yeast expression systems, but information about future products is mostly rumour. BASF is the latest giant to earn government disapproval as it sites its major molecular biology facility in the USA. The Bissendorf Biotechnology Group have come from nowhere to being an exciting group of companies with international connections and major investments. Venture capital is opening up and a number of new firms are taking off. Middle sized companies such as Biotest have gone public to fund new biotech activities.

GREECE

Not really a biotech power, but the Institute for Molecular Biology and Biotechnology, Heraklion, is a major new institute devoted to keeping Greece in the picture. Vioryl is important in flavours, pheromones and plant tissue culture. Biohellas is first biotech company to exploit new legislation to create high tech enterprises. Old pharmaceutical companies such as PN Gerolymatos are entering the area of biotechnology.

\section{REPUBLIC OF IRELAND}

Weak economy undermines the very strong university system which offers top class skills. Small biotech companies have arisen to exploit Ireland's Import Substitution Programme. Guinness has major bio-tech investment with top class rDNA facilities and skills in yeast biotech. The Agricultural Institute in Dublin funds animal and plant biotech studies. Several companies such as Biocon, Nochtec, are having success in exports. 
ITALY

Has come rather late into the arena, but is putting money into a major national initiative to support industry in a range of mission-orientated projects. The government has talked of an Italian Human Genome project. Major companies are in acquisition moods and have got hold of biotech skills. Farmitalia, Ferruzzi and the ENI group (including Sclavo) are leading firms. Major academic industrial collaboration is being encouraged.

\section{THE NETHERLANDS}

Small country, but host to several multinationals. Biotechnology is of great importance with $7 \%$ of world turnover. The government restructured biology six years ago and most university research is now partly industry sponsored. After uncomfortable start, applied research is stronger in Netherlands than anywhere else in Europe. National skills include enzymes, yeast, dairy biotech, protein engineering. Major companies include: Unilever, Philips, Shell, Akzo, Gist-Brocades. Many small companies are university or institute based and enjoy good relations with big brothers. Government encourages foreign biotech investment.

\section{PORTUGAL}

Newly arrived in the EEC, Portugal has little biotech. A national Biotechnology Centre is now proposed. Companies include: Cipan (antibiotics) and Franco-Farmaceutica (immunology, vaccines). The 21 renowned Gulbenkian foundation is not interested in commercial spin off operations.

\section{SPAIN}

Spain until recently had no significant biotechnology industry, although it has first class university facilities. A major Mobilisation Programme is intended to put Spain on the biotech map. Built at a cost of US\$3 million the new Biotechnology Centre with a British head, Dr Michael Parkhouse, will house more than 100 scientists. Biotechnology active companies include: Atom, Laboratoris Girfols, Laboratoris Knickerbocker and Processos Enzimaticos. University/ industry collaboration is in its infancy.

\section{UNITED KINGDOM}

Government spending in biotech is lower than that of Germany, but UK has arguably the most healthy biotech industry in Europe. UK firms pioneered access to venture capital, about half European venture funding in biotech is British (although as much as $70 \%$ is invested in USA). Despite cut-backs in fundamental research, applied research is receiving support from the biotech programmes of several ministries. Giants like ICI, Unilever, as well as smaller firms work with university departments.

Celltech is now in profit situation as world's largest monoclonals producer. It will be the first British start up to make the transition from small high tech to tomorrow's new style middle size pharmaceutical firm. Although overall spending is limited the UK actually has competence in a wider range of biotech activities than the USA. Strong points include biosensors and protein engineering, PE. The Inmos transputers are being assembled in parallel to give enormous real time power for PE applications in the hands of companies like British Biotechnology, which in addition is perhaps the only firm to offer routine gene synthesis. The UK has pioneered the application of the 'club' concept for industry-university collaboration. 


\subsection{BELGIUM}

Adapted from speech made by $\mathrm{Mr}$ C. de Wispelaere

In 1980 the state of Belgium agreed to a substantial devolution of power to the two regions of French and Dutch speaking peoples. This move was to have profound consequences on all aspects of Belgian administration, including science and industrial policy.

National and Regional funds are administered separately, but despite the potential for conflict, pragmatic administrators make the system work.

Biotechnology has long been regarded as a strategic technology, and as such has received strong support from both state and regions. In practical terms the regions have placed greater emphasis on industrial biotechnology, while the state has emphasised fundamental or precompetitive research and international collaboration programmes of both academic and industrial nature.

\section{The Role of the State}

Belgium has a highly developed university system and a distinguished record of achievement in the life sciences. In 1984 the state made available funds of US $\$ 125$ million for life science research of which US\$50 million was designated for biology and biotechnology.

Funds are administered by a number of bodies:

- The Ministry of Education which funds the day to day running of the universities.

- The Belgian Science Policy Office which carries out three different initiatives

- concerted actions Centres of excellence are identified and supported with grants over a six year period.

- impulse programmes fund applied research tools such as microbial culture collections and strategic studies aimed to optimise the performance of Belgian biotechnology.
- interuniversity attraction poles for high technology aim to further increase the efficiency of university biotechnology by 'networking'.

- The National Fund for Scientific Research (NFWO IFURS) financed by the Ministry of Education provides grants for research.

- The Institute for the Encouragement of Scientific Research in Industry and Agriculture (IWONL IIRSIA) is funded by the Ministries of Economic Affairs and Agriculture. It provides grants for applied research.

- The Regional Authorities also allocate funds to university research in biotechnology.

\section{Some Prominent Research Groups in the Areas of Agriculture and Medicine}

AGRICULTURE

Professors Van Montagu and Schell from Rijksuniversiteit Gent are active in plant molecular genetics and Agrobacterium.

Professor Briquet at the Université Catholique de Louvain is renowned for his work on cytoplasmic male sterility.

Professors Bernier, Université de l'Etat à Liège, and Jacobs, Vrije Universiteit Brussel, work in the area of molecular physiology of plants.

Professors Boxus and Semal, Faculté des Sciences Agronomiques de Gembloux, are known for excellence in micropropagation.

\section{MEDICINE AND HEALTH}

Excellence is found in many centres. Those with broad based competence include:

The Institute of Molecular and Cellular Pathology (ICP), associated with the Catholic University of Louvain, was founded in 1975 by Nobel laureate Christian de Duve. 


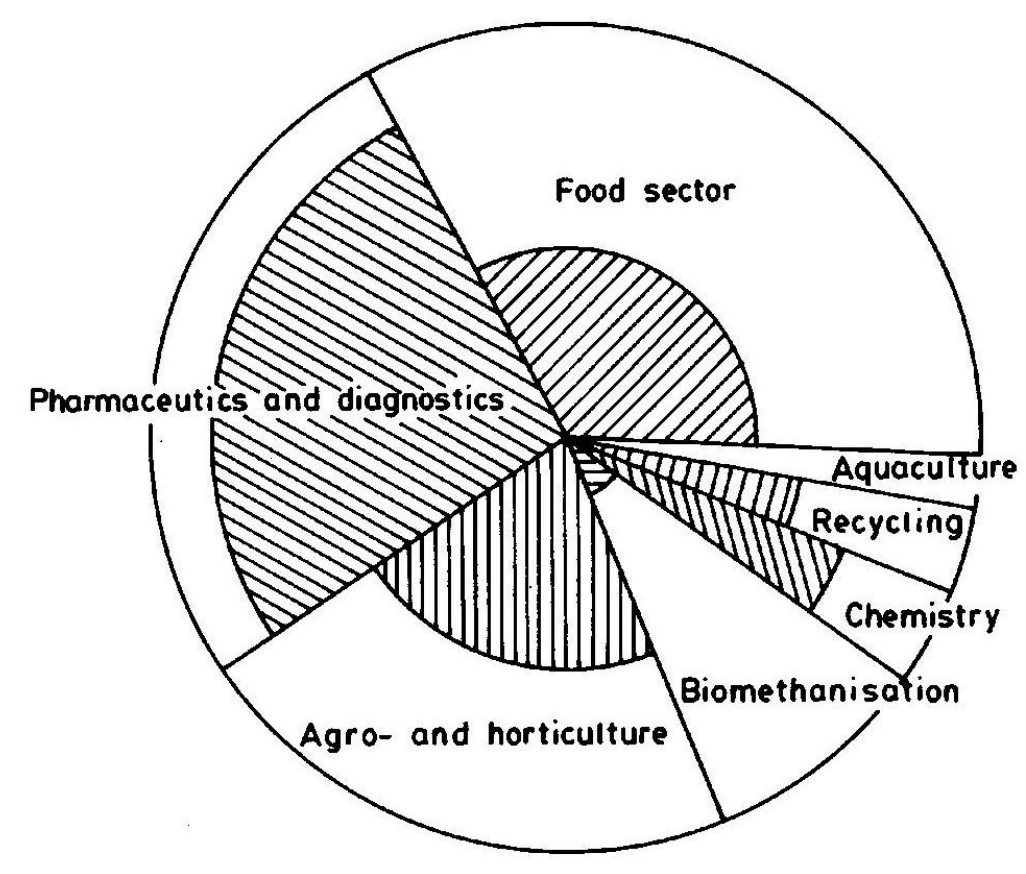

companies using traditional techniques

Q7ד companies using new biotechnological applications e.g. recombinant DNA, cell fusion, new bioprocessing techniques, advanced propagation techniques

\section{Fig. 1. Sectorial distribution of Belgian companies}

The Institute of Molecular Biology, at the Free University of Brussels (VUB/ULB) carries out basic research in prokaryote and eukaryote genetic manipulation, developmental biology and immunology.

The REGA institute of the Catholic University of Louvain, founded by Professor de Somer is a centre for applied research in medical microbiology and immunology. Excellent work in lymphokines, cytokines and interferons has been carried out.

Smaller centres of excellence include:
Professor Ghuysen's group at the State University of Liège, which studies the molecular basis of enzyme activity.

Professor Fiers at the University of Ghent elucidated the complete primary structure of a gene in 1972. He is now active in the cloning and expression of interferons and lymphokines.

Professor Collen of the Catholic University, Louvain isolated Tissue Plasminogen Activator, TPA, currently at the focus of attention as a treatment for heart attack and thrombosis.

Professor Martial's group at Liège has studied the expression of genes for prolactin, growth hormone and placental lactogen.

Many other excellent teams exist, suffice it to say that the quality of precompetitive research in Belgium is high. Twenty six Belgian research teams participate in the European Commission's Biotechnology Action Programme, BAP.

In the industrial sector, involvement in biotechnology is keen, although Belgian firms are active predominantly in traditional biotechnologies in the food, pharmaceutical and agricultural areas. Involvement in the new biotechnologies of gene manipulation and advanced bioprocessing is concentrated in the pharmaceutical industry, although exceptions such as Plant Genetic Systems have achieved world renown.

\section{Biotechnology in Flanders}

Flanders is the Flemish (or Dutch) speaking part of Belgium. Flemish policy concentrates on the stimulation of contact between industrial and institutional laboratories with a view to augmenting regional competitiveness. Co-operation models such as Limited Research Partnerships are implemented when appropriate.

Third Industrial Revolution in Flanders, DIRV, is the title of the regional action plan for high technology, designed to stimulate businessmen looking for new technologies and markets and foreign investors looking for high tech locations for production sites. Biotechnology is identified as one of the strategic technologies. 
Nearly 60 companies in Flanders are in some way exploiting biotechnology. The whole spectrum of biotechnological applications is covered, but there is an emphasis on food and agricultural activities (2/3 of Belgian agro-food companies are in Flanders).

\begin{tabular}{|lcc|}
\hline \multicolumn{4}{|c|}{ Table 1. Companies in Flanders involved in applications of biotechnology. } \\
\hline Food industry & Flanders & Belgium \\
Diagnostics and therapeutics & 19 & 26 \\
Agriculture and horticulture & 7 & 31 \\
Environment & 13 & 21 \\
Chemistry & 10 & 18 \\
Aquaculture & 2 & 10 \\
Engineering & 1 & 2 \\
Total & 9 & 12 \\
& 60 & 120 \\
\hline
\end{tabular}

Agro-food applications include refinements of traditional fermentations of milk products, beer, bread, meat products and sugar.

CEBOBA is a research centre founded by the agriculturalists association, AVEVE and the Artois brewery. Adding value to starch and lignocellulose substrates is the focus of activity.

Amylurn in Aalst is studying the fermentation of starch and sugars, and with Plant Genetic Systems, PGS, participates in a Limited Research Partnership on protein engineering of saccharide enzymes.

Plant Genetic Systems merits further attention as the 'Jewel in the Crown' of Belgian biotechnology. Founded in 1982 as a joint venture funded by: Tienen Sugar Refinery, Radar, Hilleshög (a Volvo subsidiary) and the Regional Investment Company of Flanders. PGS has attracted attention in the international press for its achievements in developing herbicide resistant plants by gene manipulation. Further work includes new developments in Plant Engineering, Microbial Engineering and Protein Engineering. Close links with Professor Marc van Montagu in the university of Gent and Professor Shoshana Wodak in the University of Brussels assure excellence in genetics and computer aided protein design.

Medical Sector developments are underrepresented in Flanders with only $25 \%$ of the Belgian biomedical companies. Those companies have however been active in exploiting the advances of the regional universities.
Special emphasis has been placed on the development of diagnostics and the production of biological substances. Two companies illustrate the situation in Flanders:

Innogenetics was established in 1985 to develop and market diagnostic and therapeutic products for the human and animal health care market using recombinant DNA, cell culture, monoclonal antibodies and other advanced biotechnologies. The company has its own R\&D competence and a number of collaborative ventures both in Belgium and abroad.

Biogent was established in 1982 as a division of Biogen US. It operates in dose association with Professor Fiers at the Laboratory of Molecular Biology. rDNA technology is used to develop products for cancer treatment, immunological anomalies, viral infections, cardiovascular and other diseases.

\section{Biotechnology in Wallonia}

The Walloon region (French speaking) has aimed to establish itself as a pole of excellence, essentially orientated towards the outside world. Several measures have been taken to expedite this aim:

Direct support to universities for applied industrially orientated research. Examples include development of a vaccine against swine plague, development of antibiotics by protein engineering and the improvement of plant species by in vitro culture.

Support to and co-operation with industry. Essentially to support innovation for example by making available 'Technology Innovation Consultants' (in French - Responsable d'Innovation Technologique) and by funding sectorial analyses so as to tailor a competitive strategy. In 1982 the Walloon Regional Investment Company launched a holding company, Companie de Dévelopment de l'Agro-industrie et des Biotechnologies.

Intra and extraregional actions. Operation Athena is designed to alert companies to the possibilities of new technology. It aims to: inform, incite, support, fund and communicate. Launched in 1982 this venture is increasingly successful and has produced a journal; 'Athena' a meeting programme; 'Journées Athena' and a annual award for innovation, the 'Golden Owl'. 
Co-operation is strongly directed to foreign partners, including companies in the USA, Japan, Europe, Latin America and elsewhere.

Number of University Labs

Number of Enterprises

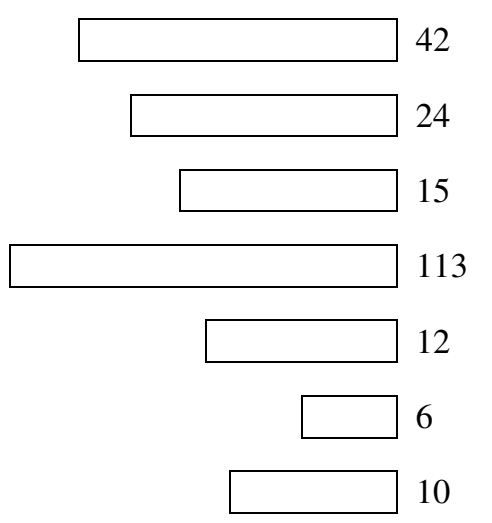

6

8

5

19

\section{Health Care}

Environment/Energy

Equipment

Others
4

2

9

Fig. 2. Biotechnology in Wallonia

\section{The Biotechnology Scene in Wallonia}

Fifty companies and more than 250 French speaking university laboratories are active in biotechnology. The large university contribution emphasise that prospects for industrial/university collaboration are by no means exhausted. More than half of the active companies were satisfied with their university partners. Universities have gone to great lengths to present a hospitable infrastructure by creating science parks, pilot laboratories and R\&D interfaces.

Particular regional strengths include: in vitro plant multiplication $(6$ companies), vaccines, therapeutics and diagnostics (9 companies), environmental applications (6 companies) and extraction and purification of natural products (5 companies). Notable new companies include:

- Phytotec, a joint venture of Native Plant Institute, USA, and the Belgian company, Société Européenne de Sémences, devoted to plant development.

- IRE-Celltarg, is involved in the use of monoclonal antibodies as targeting agents for cytotoxic agents, such as radio-isotopes.

Partners in this project include, the Liposome Company, USA, and the Institut des Radioéléments (IRE) of the Catholic University of Louvain.

- IRE-Medgenix, manufactures in vitro diagnostic agents and involves partners, IRE and Bioassay Ltd.

In addition Wallonia is host to many Belgian and foreign multinational companies including: Monsanto, Smith Kline Rit, Hybritech, NPI, Sanofi, Noorden, Lederle-Cyanamid etc. The Walloon authorities have stated that per capita investment in biotechnology is the highest in the world. 


\subsection{DENMARK}

Bruno Hansen

\section{Introduction}

Biotechnology has a long tradition in Denmark. Substantial funds have been devoted to research in both private and public sectors. Modern biotechnology is used in many different areas of industry and in the public sector.

The following review emphasises applications of the latest developments in biotechnology in the following sectors.

1. Manpower in molecular biology and biotechnology;

2. Public institutions including universities performing research in molecular biology and biotechnology;

3. Biotechnological industries and their research;

4. Government funded research programmes in molecular biology and biotechnology;

5. International collaboration;

6. Legislation concerning control of research and production.

\section{Manpower in Molecular Biology and Biotechnology}

Graduates in molecular biology are produced at the universities of Copenhagen, Aarhus and Odense, but most workers in the field are graduates from other institutions which have a molecular biological component in their curriculum as summarised in the table below.

\begin{tabular}{|lc|}
\hline Table 1. Output of potential workers in biotechnology & \\
\hline Institution (s) & $\begin{array}{c}1987 \\
\text { Number of } \\
\text { Graduates }\end{array}$ \\
\hline $\begin{array}{l}\text { Universities of Copenhagen, Aarhus, Odense: } \\
\text { graduating in molecular biology, biochemistry, biology and } \\
\quad \text { chemistry }\end{array}$ & 215 \\
$\quad$ graduating in medicine & 560 \\
$\begin{array}{l}\text { Danish Technical University: } \\
\text { graduates in chemical engineering }\end{array}$ & 70 \\
$\begin{array}{l}\text { Royal Danish School of Pharmacy } \\
\text { graduates in pharmacology }\end{array}$ & 70 \\
$\begin{array}{l}\text { Royal Danish Veterinary and Agricultural University } \\
\text { graduates I veterinary science, agronomy, food technology, }\end{array}$ & 275 \\
$\quad$ horticulture, dairy science & 1190 \\
\hline
\end{tabular}

Clearly the total is large enough to support a considerable expansion of Denmark's biotechnology activity. All of the above institutes also offer advanced training and degrees, but a lack of training grants and facilities has limited intake.

The bottlenecks have been identified as limited facilities and staff at senior level, but the enthusiastic response of Denmark's scientific community to the new biotechnology indicates considerable scope for expansion.

The new biotechnology programme aims to substantially increase research training in biotechnology. The scientific manpower available to support the programme has a broad base of appropriate competence. The tendency of Danish scientists to have spent time in foreign laboratories adds further to the experience base of Danish biotechnology.

\section{Public Institutions Including Universities Performing Research in Molecular Biology and Biotechnology}

\section{UNIVERSITIES}

As mentioned above all of the institutions shown in Table 1 carry out research and award higher degrees. Some of the laboratories have achieved international distinction. 
Basic operating funding for university linked institutes and laboratories comes from the university research budget, which is almost entirely provided by the government. To supplement the government funds there is competition for funds from agencies which include research councils, private foundations, government research initiatives and international initiatives such as the European Commission's Biotechnology Action Programme.

Almost all of the universities are involved in active collaboration, either with other universities and institutes at home and abroad or with industry both at home and abroad.

GOVERNMENT RESEARCH INSTITUTES ETC.

Ministry of Interior Affairs: At the Government Serum Institute, high level research is dedicated to the production of diagnostics, sera and vaccines. The University Hospital in Copenhagen works in close cooperation with the medical faculty at the University and with other hospitals especially those in university cities.

Ministry of Agriculture: Gives support to several institutes active in biotechnology, notably the Veterinary Serum Laboratory in Copenhagen, The Institute for Veterinary Virus Research at Lindholm and the Research Institute for Animal Husbandry at Foulum.

Ministry of Fisheries: The Institute for Fish Research at Lyngby and Hirtshals and the Fishery and Sea Investigations at Hirtshals are both active in aspects of aquatic biotechnology.

Ministry of Energy: At the Research Establishment in Riso plant biotechnology and especially protoplast technology is the focus of effort.

Ministry of Environmental Affairs: Has a largely supervisory role. Research funding is not a primary objective.

Ministry of Labour: At the National Institute of Occupational Health, steps have been taken to initiate a programme in gene technology and health care problems in related to modern biotechnological procedures.

Ministry of Industry: Several programmes support R\&D in biotechnology. Support is given to Technological Service Institutes, independent, non-profit institutes working in co-operation with industry and in some fields with the public sector. Several such institutes are active in biotechnology, especially those sponsored by the Academy for Technical Services, ATV. Notable are, the Gene Technology Laboratory, Lyngby, the Danish Aquaculture Institute, Horsholm and the Institute for Biotechnology, Kolding.

\section{Biotechnological Industries and Their Research}

Alfred Benzon A/S

A small highly specialised company operating in the molecular biology and active peptide sector. Major R\&D commitment.

Danisco A/S

Investing heavily in biotechnology, Danisco and its subsidiaries are involved in the production of enzymes, emulsifiers food additives and sewage treatment.

De Danske Sukkerfabrikker A/S

Active in plant genetics and membrane technology. Passage of new rDNA regulations has prevented field trials (in Denmark) of genetically modified sugar beet.

\section{Chr Hansens Laboratorium A/S}

Involved in production of chymosin and lactic acid bacteria cultures.

Novo Industry $A / S$

Novo is a major producer of insulin and industrial enzymes. With about 4.000 employees in Denmark, Novo is by Danish standards a big company. Almost all biotechnological activities are undertaken by Novo, and R\&D represents a very large proportion of total turnover.

\section{Nordisk Gentofte}

Is also involved in Insulin production. Other products include peptide and protein pharmaceuticals including human growth hormone, serum albumin and factor VIII.

\section{United Breweries}

Include the Carlsberg Research Centre and Carlbiotech. This company has a long tradition of innovation and investment in biotechnology. Products and interests include: enzymes, hormones, plant molecular genetics, fermentation and protein engineering. 
Other companies

Include; Aarhus Oliefabrik, Convex Biotechnology, Dansk Sojaakagefabrik, L Dxhnfeldt, Ferrosan, Fredericia Cellulosefabrik, Kobenhavns Pektinfabrik, Lundbeck.

Almost all Danish biotechnology companies are involved in formal or informal relationships with universities and government research institutes. Personal contact plays an important role in establishing these important networks. Expensive instrumentation is often shared.

\section{Government Funded Research Programmes in Molecular Biology and Technology}

In a well established pattern, the research councils have provided funds for scientific research in many areas including molecular biology and biotechnology. Applications for such funds are competitive.

The Ministry of Industry through its Agency of Technology has supported biotechnology through a number of programmes. Two in particular were specifically designed to support biotechnology.

THE RESEARCH PROGRAMME FOR BIOMOLECULAR TECHNIQUE

Approved in June 1984 Parliament voted DKr33.6 million for a five year programme of research administered by the research councils.

\begin{tabular}{|lccccc|}
\hline Table 2. The following appropriations have been made so far. \\
\hline \multicolumn{7}{|c|}{ DKr 1000 } \\
Biorganic chemistry & 1984 & 1985 & 1986 & 1987 & 1988 \\
Biostructural chemistry & 880 & 741 & 770 & 870 & 870 \\
Genetic stability & 400 & 818 & 850 & 850 & 850 \\
Purification & 775 & 767 & 860 & 1010 & 1010 \\
Plant cells & 150 & 460 & 690 & 840 & 840 \\
Plant genes & 400 & 511 & 679 & 680 & 680 \\
Reproductive biology & 0 & 1022 & 1158 & 1160 & 1160 \\
Reagents and vaccines & 300 & 734 & 884 & 1035 & 1035 \\
Total & 0 & 460 & 901 & 1150 & 1150 \\
\hline
\end{tabular}

RESEARCH AS A BASIS FOR TECHNOLOGICAL DEVELOPMENT

Approved by parliament in 1985, this five year programme totals DKr300 million, with biotechnology getting DKr 60 million. The research councils administer the funds.

THE NEW BIOTECHNOLOGY PROGRAMME

Proposed by the government in 1986, funds were approved in principle in 1987, but at the time of writing final programme approval has not been given, and the following outline is necessarily provisional.

THE DANISH PROGRAMME FOR BIOTECHNOLOGY 1987-1990

\section{Introduction}

The recent advances in biological sciences have profound implications for applied biology and for Danish production and export, as well as for the environment, health care and nutrition.

Denmark must secure an independent competence in biotechnology, characterised by an intensified national effort. The proposed national programme has three main elements:

- Biotechnology Research Centres

- Education

- Information and technology assessment 
The programme will have a broad based steering committee with representatives from the ministries, universities and industry.

Biotechnology Research Centres will form the core of the programme. The establishment of 6-10 centres is visualised. A centre would not be a physical structure, but the formalised association of research groups in institutes and industry. For a country which until recently had a clear rift between universities and industry this is a major step. The achievement of an intellectual critical mass is one of the objectives of such centres.

Technology transfer from university to industry would be facilitated by the centres leading to rapid commercialisation of research work.

A call for applications for grants was distributed. Applications contain information on the qualifications of participating scientists, the nature of the projects and proposed budgets. The biotechnology programme is intended to supply only part of the costs, essential infrastructure being provided by the participants. Grants would be given for the whole funding period, and holders would have considerable flexibility to target fund according to changing project requirements. This requires a radical change away from closely monitored research funds.

The centres will concentrate on disciplines such as: biochemistry, molecular genetics, immunology, growth physiology, microbiology, bioindustrial processing technology and research must be directed to optimisation of microorganism, cell cultures and molecular biology applications.

Each centre will focus upon a large area and funding will depend upon the quality and distribution of the applicants. It is intended that the following areas be covered:

- Molecular biology, biotechnological methods and processes

- Fermentation and down stream processing

- Plant production

- Animal production

- Marine biology, fish farming, use of aquatic resources

- Food production

- Environmental protection, ecology, use of waste products

- Health care
At the time of writing more than 50 applications had been received, covering the whole target area.

\section{Education}

There must be an increase in the supply of biotechnologists. Part of the programme appropriation is aimed at increasing the output of MS level graduates in relevant subjects.

DKr60 million has been budgeted for education in the programme to be used in the following way:

\begin{tabular}{|lcccc|}
\hline & \multicolumn{4}{c|}{ DKr million } \\
\cline { 2 - 5 } & 1987 & 1988 & 1989 & 1990 \\
\hline Final year undergraduate stipends & 6.0 & 8.0 & 8.0 & 8.0 \\
Bottleneck courses & 2.0 & 2.0 & 2.0 & 2.0 \\
Curriculum development & 3.5 & 2.5 & 1.0 & 1.0 \\
Retraining & 4.5 & 4.5 & 2.0 & 2.0 \\
Instrumentation for education & 4.0 & 3.0 & 2.0 & 2.0 \\
Total & 20.0 & 20.0 & 15.0 & 15.0 \\
\hline
\end{tabular}

The aim of the funding described above is to increase the production of relevant graduates to a level of 150-200 per year, increasing to 300 by 1990 .

Ph.D. level research will take place in research centres, which will be obliged to have a number of graduate students on their staffs. The centres will also have to arrange courses, workshops etc for other scientists.

\section{Information and Technology Assessment}

There has been much concern in Denmark over the risks and ethical concerns involved in biotechnology. Public information is a key need. Research must also be undertaken to evaluate the implications of biotechnology for the economy, the environment, public health and nutrition.

The information programme will focus on providing the public with more and better material on molecular biology and biotechnology. This should not take the form of 'official information'. Translation of key literature into Danish could play a part of the programme. Existing information channels, including schools, public libraries etc. will be used for distribution. Access to international studies on technology assessment will be facilitated. The objective is to provide a coherent background for the ongoing debate. 
Overall Programme Budget

The following appropriation has been made for the National Biotechnology Programme:

\begin{tabular}{|lccccc|}
\hline & \multicolumn{5}{c|}{ DKr million } \\
\cline { 2 - 6 } & 1987 & 1988 & 1989 & 1990 & Total \\
\hline Research centres & 50 & 100 & 130 & 130 & 410 \\
Education & 20 & 20 & 15 & 15 & 70 \\
Information and & 5 & 5 & 5 & 5 & 20 \\
technology assessment & 75 & 125 & 150 & 150 & 500 \\
Totals & & & &
\end{tabular}

\section{International Collaboration}

Several Danish institutions and companies participate in the EEC Biotechnology Action Programme 1985-1989. Denmark is also a member of the European Molecular Biology Laboratory, EMBL, and is playing an active role in the EUREKA programme. A Nordic collaborative programme in biotechnology is being considered, and is seeing first fruits in agreements on protein engineering. Co-ordination of international co-operation and national programmes is a high priority.

\section{Legislation Concerning the Control of Research and Production}

In 1986 Denmark was the first country to enact legislation to regulate genetic manipulation (an official English translation is available). The law is wide reaching and precise details of interpretation will depend upon existing regulatory procedures. The law is administered by the Ministry of Environmental Affairs.

\subsection{France}

Daniel Thomas

\section{Introduction}

France has a long and distinguished history in the domain of biotechnology. The lasting legacy of Pasteur continues to be a world class centre of excellence in many areas of biotechnological relevance.

While the early history of biotechnology was distinguished the recent past has been less so. The Pasteur Institute represented the only focus of modern biotechnology in France. Many universities and industrial laboratories were working in relevant areas, but no overall aims or objectives integrated the obvious potential for excellence (Institut Pasteur excepted). Moved by the growing impact of the 'new biotechnology' of gene manipulation and monoclonal antibody production, France decided to assert its competence on the world stage. To a large extent this initiative was the result of President Mitterand's personal will to achieve French preeminence.

\section{The 'Programme Mobilisateur'}

Accordingly in 1982 the 'Programme Mobilisateur' was launched under the aegis of the Ministry of Technology, to cover a mobilisation in seven strategic areas of technology, including biotechnology. The original aim of the programme was to give France's biotechnology industry $10 \%$ of the world market by 1995 . Spending in biotechnology by industry and government was quadrupled from about FF250 million in 1981 to FF1 billion in 1982.

Professor Daniel Thomas of the university of Compiègne was put in overall charge of the biotechnology programme. Provided with considerable means, both financial and political, the programme had an immediate rejuvenating and integrating effect on France's biotechnology endeavour. Special importance was given to the agriculture and agro-food sectors, vital for long term global strategies. Of great and lasting value has been the building of bridges between the industrial and academic research sectors. This process is gaining momentum. 
France has not failed to see the importance of international cooperation and the programme is specifically orientated to maximising the benefits obtainable from such collaboration. No fewer than 60 countries have sought French help in relevant areas of application and France has much to learn from EEC partners and the USA.

\section{PRIORITIES OF THE PROGRAMME MOBILISATEUR}

1. to assure logistical support for biotechnology

2. by consultation with the research administrations, CEA, CNRS, INSERM and INRA, involve the scientific community in determination of themes and priorities

3. intervene directly to initiate applied research projects that involve industrial/academic collaboration.

4. the provision of a training programme so as to meet the needs of a growing biotechnology industry

5. break down France's traditional isolation by forging international collaborations.

I. ELEMENTS OF LOGISTICAL SUPPORT

France is moving rapidly to establish the infrastructure necessary for a dynamic national biotechnology enterprise. Aspects of the infrastructure requirement include:

Establishment of competence in bioinformatics, to include nucleic acid sequence data banks, crystallographic data banks, Microbial data banks etc. There is a real need to develop a French competence in molecular graphics. In many cases existing European resources (EMBL for example) imply the formation of regional nodes and will offer valuable opportunities for French participation.

\section{THEMES AND PRIORITIES}

Five theme areas have been defined, including molecular biology, microbiology, enzymology/protein structure, plants and immunology.

Gene manipulation is but a means to an end and it should be made routinely available to all those with a requirement.
Microbial diversity presents a range of untapped potential. Classification and studies in microbial physiology and genetics hold out the prospect of valuable new products and processes. Anaerobes in particular have been largely ignored.

Enzymes/Protein structure. With the increased capability for tailoring genes, it is necessary to develop those tools which make protein engineering a possibility. X-Ray diffraction, molecular graphics, NMR determinations and the tools of molecular genetics form an integrated package for protein design and modification.

Plant molecular biology has been recognised as a weak link in the economic growth of biotechnology. France defined this priority area even before the EEC. Government institutes, especially INRA (Institut National pour la Recherche Agronomique) have international standing. The main requirement is increased manpower.

Immunology has been the key to dramatic changes in diagnosis. Monoclonal antibodies resulting from hybridoma technology have created a new industry in rapid diagnosis, from pregnancy to swine fever. French industry has moved fast to remain competitive, but investment in basic research and training is essential.

III. INITIATION OF PROJECTS

The first area for action is the agro-food sector and the six following projects have been designated as being of industrial priority. Research in these areas will have direct economic benefits to French competitiveness.

Identification and classification of micro-organisms, development of fast diagnostic tools.

Development of competence in mixed or sequential culture methodology in the dairy and brewing industries.

The optimisation of enzymes in media of economic importance: complex media, heterogeneous media, non-aqueous media.

Special emphasis on R\&D of milk related bacteria in all sectors of the French food industry.

Optimisation of fermentation processes, both traditional and modern. 
Improvements in the understanding and control of the vinification process. areas.

At the end of 1985 FF35 million had been set aside for these priority

The second area for action is health, where France has a number of internationally competitive companies. Priority is to be given to the early recognition of disease states. Biotechnology has enormous scope for applications in preventative medicine: vaccines, diagnostics etc. for both human and veterinary applications. The fate of proteins from expression, through extraction and purification in commercial cultures is a priority. This will be linked to structural studies.

\section{TRAINING}

Centres of excellence, 'Poles' in the French nomenclature will meet the training requirements of the scientists and engineers needed to steer France's biotechnology industry towards the future. Centres at Compiègne and Toulouse are being followed by several others.

\section{INTERNATIONAL COLLABORATION}

The 'Programme Mobilisateur' is committed to close collaboration with European initiatives such as the BAP and BRIDGE programmes of the EEC and the EUREKA programme. The contribution of industry to these collaborative ventures will be critical. The Versailles Summit in 1986 defined the need for an international biotechnology network. France already contributes to model structures such as EMBL (France contributes 22\% of operating funds).

France has recognised the potential of collaboration with Latin America. A French delegation visited Argentina in 1986 and Brazil in 1987. Mexico has an established collaboration with France in the field of fermentation in the solid phase. ORSTOM, concerned with French overseas relations with the 3rd world is concerned with the potential of biotechnology to add value to marginal agriculture.

\section{Public Institutions in Biotechnology}

France has an established tradition of excellence in many fields of fundamental and applied research. The 'Programme Mobilisateur' referred to above rectifies an omission in the case of biotechnology. The research organisations active in biotechnology include the following: Centre des Etudes Nucleaire, CEA; Centre National de la Recherche Scientifique, CNRS; Institute National de la Recherche Agronomique, INRA; Institut National de la Santé et de la Recherche Medicale, INSERM; Institut Pasteur and the universities.

All of these organisations now have a structure which permits academic-industrial technology transfer. The Pasteur Institute is now a hybrid organisation with commercial and basic research activities.

The CEA, rather like equivalent institutions in W Germany and the United Kingdom has peripheral, but significant interests in biotechnology. These range from the obvious association of radiolabelling and diagnostics, through to the development of an independent competence in much of the relevant molecular biology and immunology.

The CNRS is France's leading agency for the funding of fundamental research. It has many institutes and employs a large number of France's fundamental research workers. Increasingly the CNRS is responding to the call for more applied research trends. The CNRS has played a major role in developing molecular biology and immunology in France.

INRA has always had a strong commitment to applied agricultural research. In recent years it has made determined moves to be at the forefront of biotechnology. Research on animal vaccines and immunogenicity is world class. INRA has several exclusive licencing deals with French companies, particularly in the area of diagnostics development.

INSERM, with its responsibility for medical research has always had applied research as a major part of its portfolio of work. Immunology research is one of INSERM's foci of excellence. INSERM is moving towards a clearer interpretation of its role in a scientific climate that increasingly heeds the call of economic necessity. 
INSERM has close relations with the newly founded company Immunotech, which commercialises the results of research. This involves a far greater degree of communication with other institutions and industry. Other areas of activity include the development of new bioactive agents, lymphokines and artificial vaccines.

The Institut Pasteur has a purely commercial division, Pasteur Production, a classic example of government privatisation. It is responsible for vaccine production and therapeutics. Its cell culture facilities are outstanding as are the basic biology support services. Research in the government sponsored Institute proper is supported by a number of funding agencies and covers areas as diverse as chromosome structure, microbial physiology and AIDS. Government funds of FF100 million are targeted at the disease, much of the spending is on the Pasteur facilities, which have developed sensitive tests.

The universities also make a contribution to biotechnological research. The university of Compiègne and certain other facilities are developing strong industrial and institutional links.

\section{The Biotechnology Industry}

The French biotechnology industry is dominated by three large pharmaceutical companies, Rhône-Poulenc, Roussel-Uclaf and Sanofi with in addition a much less significant 'second division' including both agrofood and pharmaceutical companies such as Bertin, Mérieux, LafargeCoppée, Limagrain, Moet-Hennessey, Serono.

Unlike the USA France has not seen a wave of opportunistic start ups in biotechnology. There have however been a number of company launches from the public sector and from big industry. Companies such as Immunotech, Transia and Transgène would fall into this category. Transgéne is a start up funded by predominantly government originated funds. An increasing proportion of the ownership has been acquired by private investors. Transia is a genetic engineering company set up by a consortium of agro-food industry. Biosys is a university of Compiègne spin off in the immunoogicals area. Venture capital funded launches are few and include Clonatec.
A fourth category of biotechnology companies would be the large agro-food companies with a small activity in the field. Such companies are typified by Fromageries Bel, Moet Hennessey, Gervais-Danone.

The interest level and commitment to biotechnology varies from Sanofi's state of the art competence in rDNA and expression systems, to a straightforward requirement for better process control in the cheese industry. 


\subsection{THE FEDERAL REPUbLiC OF GERMANY}

Helmut Zeittrager

\section{Introduction}

The government of the FRG was one of the first to recognise the strategic significance of biotechnology. By 1974 the BMFT (Bundesministerium für Forschung und Technologie) had already begun the promotion of biotechnology. Dechema (Deutsche Gesellschaft für Chemisches Apparatwesen), an industrial representative body for the chemical industry played a role in dissemination of information and in 1978 was instrumental in founding EFB, European Federation of Biotechnology.

The German Biotechnology Co-ordinating Committee, Arbeitsgemeinschaft Biotechnologie, was founded in 1978 and acts to integrate biotechnology activities in both industry and academie sectors. The first German biotechnology programme, the 'Leistungsplan' (Performance Plan) was launched in 1979. It incorporated many of the key proposals made by Dechema in collaboration with the BMFT. In the period 1979-84 a total of US\$350 million was allocated to biotechnology. include:

Other government departments supporting research in biotechnology

- Deutsche Forschungsgemeinschaft, DFG, who focus on basic research. In 1984 bioscience funding accounted for US\$107 million, one third of the total funding. DFG is an association of universities funded by local and federal government.

- BMWi, Federal Ministry for the Economy.

- BML, Federal Ministry for Agriculture.

The BMFT is keenly aware of both the opportunities and risks presented by biotechnology. Their position is summarised in a booklet obtainable from the BMFT in Bonn, FRG.

In a major policy speech in May 1983, the Chancellor defined the government position with regard to biotechnology:
Our society needs technical progress. Globally, developments are taking place at a furious pace, in the information and communications technologies, in new production techniques, in biotechnology and in the development of new materials. These offer opportunities, but also carry with them dangers. We know that not everything that is humanly possible is suitable for mankind. This is the challenge which we have to face. We must seek to remain master of the technology.

The Federal government subsequently drew up a programme for applied biological and biotechnological research for the period 1985-88. Biotechnology was given a central innovative role among the applied sciences. The following research objectives were defined:

- to promote top quality science in areas relevant to the future competitiveness of the state.

- to evaluate opportunities and hazards, introducing appropriate safety regulations and debating ethical considerations at an early stage of progress.

- to promote the training of a new generation of biotechnologists.

FEDERAL FUNDING

At the beginning of 1986 it was announced that the total Federal funding for the period 1984 to 1989 would be increased to DM 1.14 billion. Roughly $1 / 3$ was targeted to institutions and another $1 / 3$ to four new gene centres, other centres of excellence and infrastructure, including support for new biotech ventures. The bulk of the remaining money is designated for development of facilities in 'bottleneck' areas such as cell culture technology, fermentation, enzymology, plant biotechnology etc.

One of the essential components of the present funding is a generous investment in the essential enabling science for biotechnology. The federal government has accepted that this is essential if the commercial focus of biotechnology is to be mastered. 


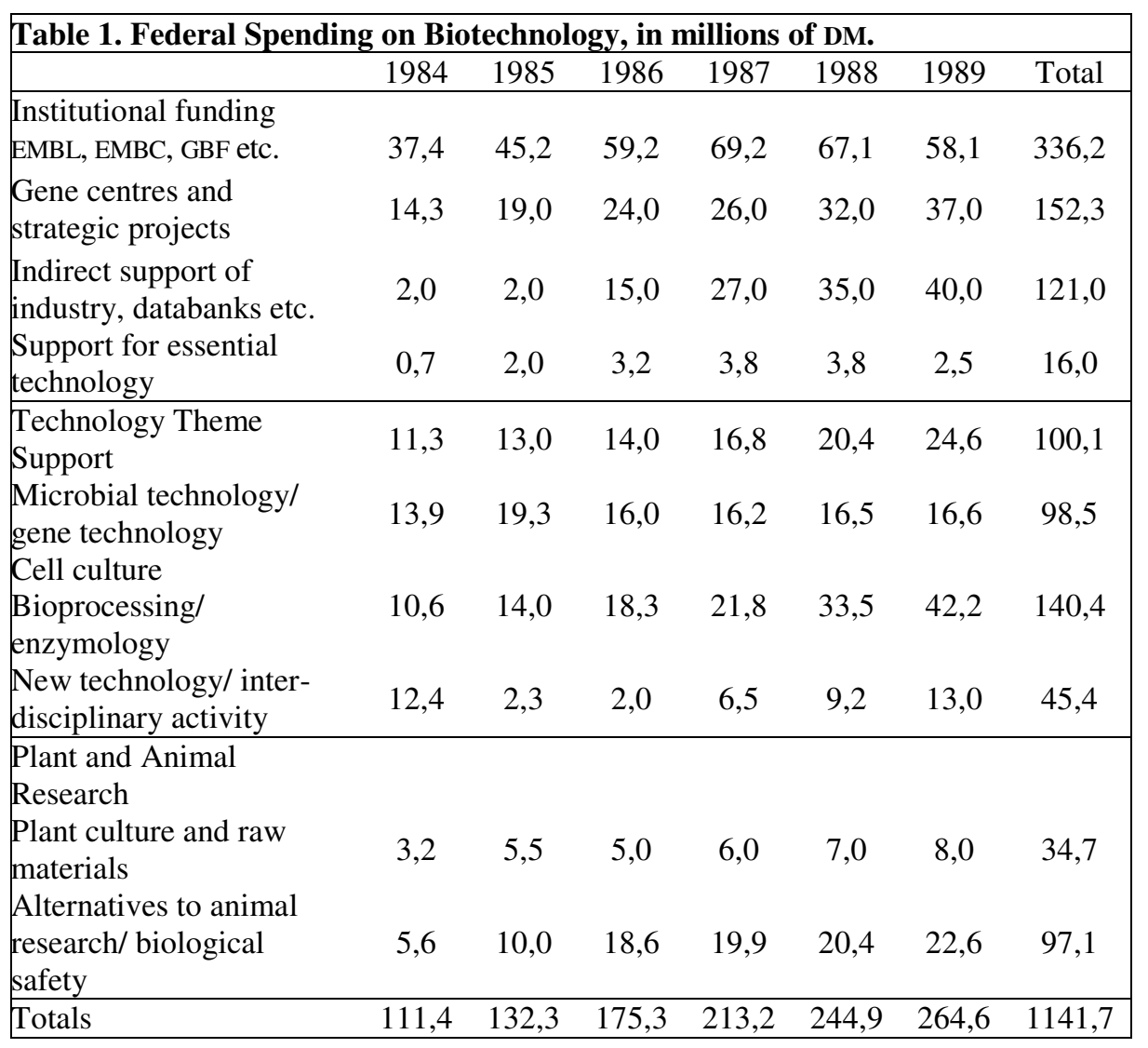

To achieve these ends the BMFT has instituted a process of consultation with Deutschen Forschungsgemeinschaft, DFG, the federal science research funding body; Max-Planck-Gesellschaft, the very wealthy research foundation with institutes both in Germany and abroad; and the Verband der Chemischen Industrie, VCI, the German Chemical Industries Association.

In addition to the broad themes outlined earlier, the BMFT has identified several specific objectives, some of which are detailed in Table 1, above. Many of these 'bottlenecks' require commitment of new manpower resources, available only education at high school and university level is appropriately orientated.

Already mentioned are:
- Genetic manipulation

- Bioprocessing

- Enzymology

- Interdisciplinary measures

At the forefront of much of this work will be the university sector and government research centres, most notably, GBF, Gesselschaft für Biotechnologische Forschung, in Braunschweig and the Kernforschungsanlage, KFA, Julich. These two centres backed by both federal and regional funds have become showpiece institutes. The GBF went through a difficult period in the early 1980s and there was even question of closure. Appointment of the Present Director, Professor Joachim Klein preceded a dramatic turn around in the fortunes of GBF. Strong backing from the regional government of Lower Saxony has been a major spur to success. Like GBF, KFA is strongly backed by local government, North Rhine Westphalia. Dialogue with industry will be an essential component of long terra project planning for both Centres. Most untypically, the BMFT is prepared to consider the funding of projects over a period of up to 15 years.

THE BIOTECHNOLOGY INDUSTRY IN GERMANY

Approximately 100 companies in Germany have a significant involvement in modern biotechnology. Many other companies, notably in the food and beverages sector, have a peripheral involvement. The scope of involvement is very large. Giant firms such as Hoechst are interested in biotechnology in a number of areas from insulin production to insecticide resistance. Small companies such as Biosyntech can offer services such as custom nucleotide or peptide synthesis. On the technical side engineering based companies can supply fermentor and bioprocess technology.

Total industrial biotechnology R\&D expenditure in FRG for 1985 (last year for which results are available) amounts to about DM 700 million, based on biotechnology related sales of DM 20 billion.

To date it is true that the bulk of investment and production has been in the pharmaceuticals and diagnostics sectors. In the long term there will be a gradual increase in the emphasis of agricultural applications and plant genetic engineering. The strong Green movement is a force to be reckoned with, even by the strongest companies. One embarrassing incident involving the Heidelberg based firm Gen-Bio-Tec occurred when they failed to notify the 
Safety Commission of their work on expression of anti-clotting agents in bacteria. Gen-Bio-Tec was at the time in receipt of major Federal and regional support. For weeks the future of that support was placed in doubt.

Facilities to enable new biotechnology start-ups are becoming more available. Venture Capital, in particular, is becoming readily available to firms with a sound technology. Unlike the USA, genuinely high risk investment is unavailable. In the past five years almost thirty significant new start-ups have been established in FRG.

Dechema plays a central role in representing the interests of German biotechnology companies and provides a forum for discussion and debate in the famous Achema congress series. Held every three years Achema is one of Europe's most important shop windows on chemical engineering and biotechnology. Themes treated include sociological issues arising from public concern at issues such as genetic engineering.

The Hannover Biotechnica series of fairs, held annually was launched in 1985 and is already rivalling Achema for prestige in the field of biotechnology. Although backed by Lower Saxony, the Hannover fair has no direct relation with the GBF, although GBF and other local enterprises are given very prominent pavillions.

SECTORIAL CONTRIBUTION OF BIOTECHNOLOGY

Pharmaceuticals is a major business area in FRG, with companies such as Hoechst, Bayer and BASF as giants in the first rank. Medium sized companies include Boehringer-Mannheim, Boehringer-Ingelheim and its pharmaceutical subsidiary Thomae. Henkel, Merck and Schering. All of these have involvements beyond pharmaceuticals. Specialist pharmaceutical companies of medium size would include Behring, Biotest and Knoll. Many of the new start-ups are active in pharmaceuticals and have staffing levels of 5 to 100. Examples of these include Bioferon and the Bissendorf Bio technology Group.

There is a strong emphasis on the latest developments in biotechnology. Pharmaceuticals in trials and production include, insulins, coagulation factors, monoclonal antibodies, urokinase, antiviral agents, interferons, lymphokines, interleukines, TPA, TNF, recombinant vaccines. Market projections for 1995 show a domination by products based on the new technology.
Agriculture is receiving more attention now. Both the Federal and regional governments are defining this as a priority area. Action by the European Commission is helping to focus attention on the prospects for a post subsidy agriculture. The creation of genetically engineered plants is a delicate issue in the FRG. Field release of such plants is subject to fiercely critical scrutiny by both ecologist groups and the governments. The incentive for carrying out such work in Germany is accordingly very small. In university departments, such as Hannover and Bielefeld and at the MaxPlanck Institute for Plant Breeding in Min, work nonetheless continues into such vital goals as increased nitrogen uptake by cereals and other crop plants.

Unless there is a campaign to stimulate awareness of the value of biotechnology for agriculture, it is likely that the industrial contribution to research in Germany will be limited.

Chemical Industry. The application of enzymes to the cost effective production of both raw materials and speciality chemicals in stable bioreactors is receiving dose attention. Centres such as GBF are collaborating with industrial laboratories so as to engineer temperature stable enzymes, capable of working effectively in both aqueous and nonaqueous solvent systems. Microbial leaching and concentration of high value elements and compounds is receiving attention from the metal extraction industry. Many of the large chemical companies are moving into more biological applications areas as the potential of biotechnology becomes apparent. Such activities would include applications of microbial polysaccharides and crude oil recovery.

\section{ENVIRONMENTAL PROTECTION}

The microbial breakdown of waste figures largely in a number of sewage specialist companies. The strong ecological groups in the FRG make it politically expedient for the government of the day to make considerable moves to meet their demands. Biological treatment of effluents with engineered microbes remains unlikely in the present anti-release climate.

University joint ventures are in favour with the government and there is considerable pressure on industry to participate. The new Gene Centres have been founded partly with industrial support.

The University Sector, including the Max-Planck Institutes and state funded institutes still carries out the bulk of research in biotechnology, 
particularly at the precompetitive level. As intimated earlier strategic collaborations with industry are increasing in number and quality, although fears about industrial confidentiality may cause some concern. With government support, general excellence in over 300 departments of biological sciences has crystallised into the formation of four Gene Centres located at Min, München, Heidelberg and Berlin. These centres were established around existing centres of excellence, but the inflow of central funds has allowed the elaboration of new building and equipment.

One of the central weaknesses in the FRG's biotechnology has been the traditional University/Industry divide. The FRG has jealously dung onto the demarcation, well after its abandonment by many other European states. Among academics pure research still has enormous 'cache' compared with applied industrial research. Salary differentials, while significant, do not mean the difference between a bearable and good standard of living. In the FRG academics earn a comfortable living. Biotechnology itself is one of the forces bringing about a reappraisal of the situation as fundamental rapidly becomes applicable. Unfortunately industrial support of 'academic research is concentrated on institutes such as GBF, Braunschweig or KFA Julich, rather than universities 'per se'. Institutes such as the German Cancer Research Centre in Heidelberg have played a useful role in creating a respectable image for applied research. EMBL, the prestigious international laboratory, also in Heidelberg, is also strengthening this consensus by establishing more links with industrial ventures, including the licensing of know-how.

The road to a doctoral level qualification is very long. A diplom awarded at age 25 or 26 must be followed by up to five years research before the award of a doctorate. There is much opposition to changing the system, although many percieve it to be overdue.

CONSEQUENCES OF THE BMFT BIOTECHNOLOGY INITIATIVE

In the context of enabling technology for biotechnology, the BMFT initiative has provided substantial funds for universities to do work in bottleneck areas such as: bacterial physiology, plant physiology and biochemistry and bioprocessing technology (see Table 1).

The Gene Centres are designed to radically upgrade German competence in the field by giving substantial funds and prestige to already recognised centres of excellence. The research aims of these groups are:
- elucidation of genetic structures;

- action and interactions of genes;

- control of gene expression.

The Köln Centre based on the Max-Planck Institute for plant culture research and the University Genetics Institute is concerned with plant genetics and the use of plants for the expression of foreign genes, plant cell culture and micropropagation, the genetic basis for nitrogen fixation. Other work focuses on viral genetics and general aspects of cell biology and biochemistry.

The Heidelberg Centre, located at the university with input from the Cancer Research Centre focuses on microbial genetics, virology and Immunology. Work is targeted at medical problems: diagnosis, therapy, neurobiology etc.

The Munich Centre links the University and the Max-Planck Institute for Biochemistry. Work focuses on the development of sequencing technology and chemical synthesis of genes. Ancillary work in immunology and cell biology builds upon this competence. Plant cell biology focuses on gene transfer.

The Berlin Centre continues the thrust of excellence in gene technology and draws upon the skills of the Max-Planck Institute for Molecular Genetics, which is world renowned. Analogous to the Gene Centres are two BMFT designated Centres of Excellence in bioprocessing technology. These centres are designed to provide a skill and knowledge base for the fundamental skills which underpin commercial processing technology. The first centre has been established in Lower Saxony and receives input from the universities of Braunschweig, Göttingen and Hannover, and the GBF, Braunschweig. GBF is the leading German centre for process and fermentation technology. Its diversification into other areas of biotechnology has secured a status unparalleled.

The Lower Saxony Centre will have its centre of gravity in Braunschweig and will concentrate on the enzymatic and microbial processing of carbohydrates. Antibiotic production processes, animal cell processes, culture development, cell reactions and measuring methodology. Computer and information systems research will support control system 
development and data treatment. Bioreactor development will be an almost automatic consequence of the skill base in Lower Saxony.

The second centre, associated with the University of Stuttgart started work in 1987 and 1988 and consists of five institutes focusing on Bioprocess Engineering, Biochemical Engineering, Applied Microbiology, Applied Genetics and Mammalian Cell Culture.

\section{OtHER STRATEGIC PROJECTS}

The development of biotechnology worldwide demands a flexibility of response from the German research base so as to maintain competitivity. Interdisciplinary fertilisation (electronics/enzyme technology) is seen as critical. New centres could and will be designated as appropriate. Topics under consideration include biocatalysis, chemical synthesis of peptides and genes, protein engineering, etc. New centres will include both institutional and industrial representation to a greater extent than is presently the case for the Gene Centres. GBF has broken this ground by establishing a healthy portfolio of industrially funded projects.

\section{INDIRECT MEASURES}

Might include the financing of studies on aspects of regulation, or the provision of training funds for specific problem areas. The provision of funds in this category is deliberately flexible.

\section{ENCOURAGEMENT OF ENTERPRISE}

The BMFT is keen not to lose the innovative potential of academic staff and especially staff in small and medium scale enterprises in the pharmaceutical and chemical industries, in the food industry. Such innovations could have applications in sectors such as plant biology, industrial scale production, commercial microbiology etc. Bioreactor technology could be encouraged by stimulating joint venture activity between equipment, engineering and research activities. To meet such need funds shall be available to encourage product orientated innovation in biotechnology.

ENCOURAGEMENT OF THE BIOTECHNOLOGY INDUSTRY

Industrial potential in the biotechnology industry is to be reinforced by targeted BMFT support. The basis of support is the provision of training and support for acquisition of the latest in biotechnological methodology. Such support should cushion the risk undertaken by industry active in these areas.
AREAS TO BE TARGETED FOR SUPPORT

- Cell culture

- Gene manipulation

- Process technology using plant animal and human cells and manipulated micro-organisms.

- Enzyme technology for medical and food applications

- Apparatus and equipment development

- Bioreactor development, measurement and control systems

All independent enterprises with an interest in the above areas should be eligible for support up to the level of $40 \%$ of costs to a maximum of DM600 thousand per enterprise. Other funds for personnel, equipment etc are available. Total budget for this programme was fixed at DM100 million over four years from January 1986.

\section{TRAINING FUNDS}

To provide the manpower necessary to sustain growth, the Federal government has designated training as being a major priority and accordingly has provide substantial funds. Training funds are targeted at three areas:

- International scientific collaboration

- Biological chemistry

- Biotechnology further training

Generally speaking the training is orientated towards the areas previously defined as important.

\section{ENCOURAGEMENT OF ACADEMIC/INDUSTRIAL COLLABORATION}

Particularly in the area of precompetitive research it is seen that a dose relationship between factory and university could be beneficial for the Federal Republic. Areas of particular interest in this context would be environmental projects and risk assessment projects that could take place without any threat to industrial security. The work in this area could be chosen on the basis of national and international importance. Flexibility in approach and execution of such projects is seen as essential. To this end the normally detailed and frequent review procedures will give way to a less tightly controlled assessment procedure. The basic project areas could lie in the same theme regions as previously outlined: 
- Microbiology and microbial genetic techniques;

- Cell culture and cell fusion technology;

- Enzyme technology;

- Biological processing (including food technology);

- Plant and animal research;

- Safety research.

Other areas may be defined with the growth of knowledge and experience. The dialogue between science and industry will in itself achieve further definitions. Many areas of development essential to long term industrial competitivity could be developed. In some cases collaborations similar in concept to the British and French club themes would be used to provide enabling technology to a number of client companies and universities.

To identify just a few project areas noted by the BMFT.

\section{Microbial Technology}

Gene transfer technology to improve microbial cell culture yields etc. Genetic stability, ecology and toxicology of mixed microbial cultures. Possible applications of mixed culture techniques.

\section{Cell Culture}

Development, control, standardisation of bioindustrially interesting cell lines

Development of cell storage techniques

Enzymology

Biocatalysis, stability and characterisation of immobilised and carrier associated enzymes, enzyme complexes and cells.

Bioprocessing

Bioreactor mechanics, construction and applications

Evolution of biosensors for process monitoring

\section{Plant and Animal Biology}

Development of plants for food, raw material and environmental applications

Diagnosis, prophylaxis and treatment of animal disease.

\section{Safety and Technology Monitoring}

Development of safer fermentation and bioprocessing technologies for genetically manipulated organisms and their products. Socio-economic aspects of biotechnological developments

\section{New Areas of Applied Biology}

Fusion of biomolecular and microelectronic technologies Enzyme design and protein engineering, gene synthesis

Other areas of significance include: microbial screening, effluent microbiology, microbial collections, gene technology projects, human and animal cell potential, plant cell evaluation, biocatalysis, enzyme production, biocatalyst based production, new bioreactor systems, upstream processing, control technology, plant breeding and raw materials, natural product screening, alternatives to animal research, ecological impact of genetically modified organisms, safety and genetically modified organisms.

INTERNATIONAL COLLABORATION

The BMFT places great importance on collaboration with other EEC member states, especially within the framework of EEC mediated collaborative programmes such as BEP (Biomolecular Engineering Programme), BAP (Biotechnology Action Programme) and projects such as ECLAIR which seek to study alternative, bioindustrial, applications for Europe's agricultural potential.

The OECD initiative in determining regulating principals for molecular genetics is welcomed by the FRG. Collaboration with the OECD is a valuable aspect of international collaboration in biotechnology.

Collaboration with industrial nations is largely focused on Europe and to a lesser extent the United States. Realisation of the Japanese Human Frontiers Programme may well involve German groups.

Collaboration with developing nations is a theme of several recent initiatives. Notably, the GBF Braunschweig has initiated a programme of training specifically targeted at the requirements of developing nations. 


\section{The Role of the GBF, Braunschweig}

The GBF was Europe's first dedicated centre for research and development in biotechnology. After a period of uncertainty, the appointment of the present director, Dr Klein has given GBF a powerful and widely appreciated authority in many areas of biotechnology.

Originally founded by the Volkswagen foundation, the GBF has since 1976 been cofunded by the Federal government $(90 \%)$ and the regional government of Lower Saxony (10\%).

The main research areas of the GBF are:

- Microbial products of synthesis and biotransformation:

- Molecular and cell biology of biologically active proteins;

- Industrial enzymes and protein design;

- Development of bioprocessing.

In addition the GBF has played host to the German Collection of Microorganisms, DSM, since 1979. A separate legal entity, DSM is poised for commercial exploitation as one of the world's foci of microbial strain deposition.

In addition to precompetitive applied research, the GBF has a number of confidential collaborative projects in hand. While GBF can not be as secure as an industrial laboratory, the industrial partners in such contract research have been well satisfied with the GBF's role in such collaborations.

Protein Design was launched as an interest in 1985. In the past year development of hardware and software components of the system has matured and this area looks set to become one of GBF's principal activities. Potential for partnerships with industry and commercial exploitation of this growing know-how is large. The pharmaceutical industry is particularly interested in the prospect of exploiting protein engineering for the production of new or modified biologically active peptides.

The fermentation and bioprocessing facilities of GBF are first rate and already act as a focus for industrial development and pilot studies. The 'Biotechnikum' is equipped with fermenters up to 5.000 liters capacity. Down stream processing facilities can be used to model processes up to semi-industrial scale - a valuable national resource. The 'Biotechnikum Service Unit' gives back-up to process engineering when no commercially obtainable support is available. Such back-up might include the production and isolation of materials not available on the market.

Sophisticated computing and spectrographic facilities back up all aspects of development work, and contribute to a growing excellence in the understanding and implementation of novel process control systems. Licensing of GBF technology is possible, although offered preferentially to German firms.

Almost all of the FRG's major chemical and bioscience companies have entered into collaboration with the GBF in at least one project over the past ten years. Roughly $1 / 3$ of GBF's industrial partners are foreign, the majority from Europe. The opening up of new industrial contacts and ventures is facilitated by an outward looking attitude characterised by seminars and invitations in both industrial and institutional laboratories. The German Chemical Industries Association has created a GBF support group to strengthen industrial appreciation of the resource.

GBF has about 425 staff of whom 160 are scientists. The 1987 budget amounted to almost 70 million DM, including a large 61 element of new building support, which should do much to alleviate the recent overcrowding problems.

GBF has noted the potential of developing countries to benefit from several biotechnological advances. Without adequate training and local expertise such advances cannot be applied. The provision of trained scientists is a choke point which GBF aims to remedy by an in-house training programme. Already three course have sent 60 third world scientists back to their home countries with an appreciation of the modern technologies and their applicability in a third world environment.

Of 250 applicants for the first course the 20 selected included five from Latin America. All costs, including air fare, were born by the GBF.

Lower Saxony has made clear its intention to become the foremost region for German biotechnology. Recently it became committed to supporting three biocentres collaborating with the GBF, Braunschweig Technical University, the University of Hannover and the University of Göttingen. This structure will give the area a solid mass of excellence. The only problem foreseen is that of staff recruitment. 
Growth in biotechnology is characterised by the rapid expansion of the Bissendorf Biotechnology group. Next to GBF they have launched a major peptide and protein production centre, Braunschweiger Biotechnologie.

\subsection{GREECE}

Presentations by Drs Tzotzos and Dourtouglou

\section{Presentation by George Tzotzos}

\section{INTRODUCTION}

Greece's economy has several similarities with that of Latin America. Emphasis is placed on services and traditional agri-industries, while Greece's chemical industry was heavy commodity and obsolescent; unable to incorporate biotechnological advances.

In Greece as a whole the worldwide trend, of movement away from manufacturing to service industries, is being observed. The Greek scientific community has two components, a small domestic element and a large and conspicuously successful international element.

To encourage the development of an infrastructure capable of supporting a Greek biotechnology industry the government launched incentives for the repatriation of Greek scientists. These took the form of two international centres of excellence

- The Institute of Molecular Biology and Biotechnology, IMBB, at Heraklion, Crete and:

- The Hellenic Institute Pasteur launched a hybridoma and monoclonal antibody facility.

Participation of Greek scientists and laboratories in European and EEC ventures such as EMBL/EMBO and the BEP and BAP programmes has increased the flow of knowledge and awareness in biotechnology.

With the support of the government the first Greek biotechnology company, Biohellas, has recently been launched.

These measures have provided a solid basis for encouraging the repatriation of Greek scientists working overseas. 


\section{What EXPERIENCE Has BeEN GAINED IN THE PASt Four YeARs?}

1. Finance, management and marketing are integral parts of the biotechnology process. Small economies cannot meet demand for these skills at an adequate level.

2. R\&D scale-up is investment intensive, making redundant the notion that biotechnology is cheap.

3. Expertise in microbial physiology and fermentation is embryonic in Greece and probably elsewhere too. Training in biochemical sciences is no panacea.

In the light of the above it appears unlikely that transfer of technology and strengthening of the biotechnology industry can be achieved without a coherent policy focusing on target definition, commitment of resources and openness to the scientific and entrepreneurial communities beyond national borders. The latter is of paramount importance particularly in cases where national economies are unable to sustain technological growth at the required pace. Greece's efforts to overcome the problems, briefly outlined above, is presented in Dr Dourtouglou's paper.

\section{Presentation by Dr V. Dourtouglou}

Greece has come to appreciate the potential of modern biotechnological innovations. Interest in government circles was first stimulated at the beginning of the 1980 s, when a national support policy for both private and public sector involvement in biotechnology was outlined.

Of primordial importance in assisting Greek biotechnological development is the provision of training. In the medium term such training should be geared to industrially relevant aspects of biotechnology such as:

- enzyme engineering;

- bioreactor use and development;

- diagnostic kit development;

- agricultural biotechnology, micropropagation etc.

With no advanced industrial base available to assist the development of biotechnology and no suitable funding structures in Greek financial markets, it must be assumed that only by 1994 will Greek biotechnology enter a positive cash-flow situation. The role of state intervention is therefore critical to the development of a domestic biotechnology enterprise.

ROLE OF THE STATE

A number of ministries have interests in biotechnology and the following all have a budgetary allocation for biotechnology.

- Ministry of Energy, Industry and Technology, General Secretariat for Research and Technology;

- Agricultural Ministry;

- Health and Social Security Ministry;

- Ministry of Environment and Urban Planning;

- Ministry of the National Economy.

As yet there is no formal interministerial co-ordination, but the Research and Technology Secretariat has drawn up a plan which considers other ministries and research interests in biotechnology.

The Research and Technology Secretariat may gain the authority to steer national biotechnology policy with the approval of all ministries.

Three laboratories in Greece can be considered to have significant resources in biotechnology. These are:

- IMBB Heraklion

- Centre for Biological Research of the National Research Foundation

- Hellenic Institute Pasteur, Athens

Since 1979, university research work has received government backing, but as explained elsewhere, Greek universities are viewed primarily as training, not research, establishments.

Despite the identification of biotechnology as a national priority, the production capacity of existing related industry has limited both project development and proposals.

With the support of the government, two investment banks a the Pharmaceutical Producers Association of Greece launched the first Greek biotechnology company, Biohellas, in 1984. Today two companies in Greece have a significant biotechnology commitment, the second being Vioryl. 
Having manifest the industrial application of biotechnology as a priority, the government passed legislation to aid investment in advanced technology. Guidance was given to universities and secondary education so as to achieve an output of graduates able to support commitment to high technology. The universities have responded by organising training programmes in rDNA and other aspects of biotechnology.

With $20 \%$ of the national workforce in agriculture, it was logical to place emphasis on agro-biotechnology, including the support of small companies active in micropropagation and biomass. Other areas include waste treatment and diagnostics of agricultural relevance.

To obtain a redeployment of skills, retraining and reorientation towards high technology is perceived to be of importance.

FINANCING BIOTECHNOLOGY

A rapidly growing slice of the total R\&D budget of 15.56 billion drachma is being spent on biotechnology.

\begin{tabular}{|cc|}
\hline Year & Dr Millions \\
\hline 1984 & 160 \\
1985 & 358 \\
1986 & 638 \\
\hline
\end{tabular}

A relatively large percentage of biotechnology spending is being devoted to agricultural applications, centred on a number of sites and institutes.

Healthcare biotechnology is an important area and relevant research is focused on the IMBB and the Hellenic Institute Pasteur. It is still too early to see the consequences of spending in health care and agriculture. In industry the first concrete manifestation of progress is Biohellas, but here too many projects are in development rather than commercial exploitation. Biohellas has a privileged relationship with IMBB, with a licence to commercialise IMBB developed innovations.

Vioryl is more independent of government support and has successfully commercialised pheromone technology. It is now trying to master monoclonal antibody production. Other interests include biocatalysis.
A number of small firms are commercialising agricultural aspects of biotechnology, in vitro technology and micropropagation. The Ministry of agriculture should be approached for information on these firms.

EEC support is helping both industrial and academic laboratories to build fruitful relationships with other biotechnology laboratories operating in the EEC. These ventures will make a large contribution to the Greek knowledge base in precompetitive research relevant to biotechnology industry.

There is, in conclusion, much in the Greek experience of biotechnology that could be of direct relevance to developing countries interested in the possible benefits of biotechnology based industrial ventures. 


\subsection{THE REPUBLIC OF IRELAND}

\section{Brendan Finucane and Staff of BioResearch Ireland, Dublin}

Prepared by the biotechnology group, National Board for Science and Technology (now replaced by BioResearch Ireland), presented by Brendan Finucane

\section{Introduction}

An Irish National Biotechnology Programme was initiated in 1983 by the National Board for Science and Technology, and the Industrial Development Authority. The programme's objective is to promote and assist the application of biotechnology in Irish industry, agriculture and other areas of social and economic development.

The major areas of application in Ireland are in agriculture/food, and in the healthcare and pharmaceutical industries. Agriculture occupies 15\% of the Irish workforce directly, and the food and drink industry employs $26 \%$ of the industrial workforce. Exports in 1986 of food and drink were worth over US $\$ 3.2$ billion or $23 \%$ of total exports. It is thus a very important sector and one in which biotechnology can play an important role.

The healthcare and pharmaceutical sector is also important for Ireland and has undergone considerable growth in recent years. The Industrial Development Authority, IDA, has been very successful in its efforts to attract pharmaceutical and healthcare companies to Ireland. Over 100 overseas companies in this sector now have Ireland based production plants, including 10 of the world's top 15 pharmaceutical companies. Exports totalled IR£ 1.5 billion in 1985 and are growing at 40\% per annum.

There has been a particularly encouraging growth in the Medical Diagnostics area of the healthcare industry. Among indigenous companies, Biocon, Bioprep and Noctech Ltd are manufacturing a range of products based on enzyme immunoassays, while Beckman, Technicon, Organon and Flemming $\mathrm{GmbH}$ are examples of transnational companies which produce diagnostic products in Ireland. The industrial strength of this sector and the fact that biotechnology has great immediate application made it an obvious area for national development.
There is also activity in other sectors, eg Biocon Ltd manufactures enzymes and other speciality chemicals for the food industry. Interbio Laboratories also manufacture microbial cultures for water and waste treatment and other purposes. A number of chemical and food firms are also using biotechnological processes in their manufacturing. These include Pfizer Chemical Corporation (Citric acid manufacture), Wheat Industries Ltd (Glucose/Dextrose Plant) and Carberry Milk Products (Alcohol production from by-product whey).

\section{Biotechnology Research Centres}

As in many countries, much of Ireland's expertise in biotechnology is located in universities and other higher level colleges.

Because almost half of the Irish population is under 25, Ireland has invested heavily in scientific and technical education. In line with our policy to develop Ireland as a centre for high technology industry, new colleges and new laboratories have been built to cater for technical education. Science, engineering and other technical graduates are an increasing proportion of the output of these colleges. They represent $41 \%$ of the primary degrees and $45 \%$ of higher degrees awarded by Irish colleges in 1985. The research facilities in biotechnology have also been improved and individual colleges have agreed on specific priority areas for biotechnology research. agencies:

Other centres of expertise include the following government funded

- Institute for Industrial Research and Standards, which performs research on fermentation process scale up, enzyme technology and monoclonal antibodies.

- The Agricultural Institute, which has a staff of 1300 in 7 major research centres throughout the country, is also involved in research and application of biotechnology in food and agriculture.

\section{Areas of Biotechnology Expertise}

The major areas of expertise in Ireland are:

- Genetic Engineering

- Diagnostic Technology 
- Specialty Chemicals and Pharmaceuticals

- Biopharmacology

- Mammalian Reproductive Technology

- Plant Biotechnology

GENETIC ENGINEERING

Research is conducted in 6 of our 7 colleges; but particularly in Trinity College, Dublin and the University Colleges of Cork and Galway.

Microbial Genetics is the main area of interest at the Dept. of Genetics, Trinity College Dublin, where the research team of Prof. David McConnell have performed work for many companies, including Arthur Guinness and Co., Biocon Ltd., and ICI. This Group have recently signed a research agreement with the Agricultural University of Beijing to jointly done the gene for Porcine Growth Hormone. The research for Arthur Guinness was to done the gene for glucanase into brewing yeast strains. Guinness have recently located all their corporate research in a new centre in Dublin.

Another interesting area in Trinity College is in vaccine development at the department of microbiology. Among other projects is one with the objective of developing a vaccine for mastitis.

In animal genetics research is in progress at University College, Galway, in collaboration with the Agricultural Institute to develop transgenic animals including fish. This work is funded by the EEC in association with French researchers.

The Dairy Microbiology Dept., at University College Cork, and the Agricultural Institute at Fermoy, have developed considerable expertise in the genetics of dairy starter culture organisms: Strains of bacteriophage resistant bacteria developed by this group are now used to produce almost all of the 50.000 tonnes of cheddar cheese produced in Ireland. Further work on the genetic manipulation of other important dairy micro-organisms is under way.

\section{DiagnOSTIC TECHNOLOGY}

Ireland has much expertise in this area. The dose contacts between the biological and clinical scientists in Ireland has been an important factor in the development of this area of technology.
The major centre for research on diagnostics is in University College Galway, where work is ongoing on solid phase immunodiagnostic technology, and on the development of kits for various human and animal hormone indicators.

Veterinary diagnostics is an area of particular interest because of our large livestock population. Work at University College Galway resulted in the development of the first animal progesterone assay to be put on the market. This was the progesterone measuring system from Noctech Ltd. This Irish company has produced Reprostrip, a rapid assay for progesterone.

Ireland also has a very important thoroughbred horse industry. Research on behalf of this sector is conducted by the Irish Equine Centre, a privately funded organisation, in association with university researchers. This centre is currently researching indicators of stress, eg travel stress, in performance horses with a view to developing diagnostic kits for equine health. Diagnostic kits are also in preparation in other centres for Epstein Barr Virus, Chlamydia and others.

\section{BIOPHARMACOLOGY}

Ireland has a large pharmaceutical and healthcare industry. To service the needs of this industry, both for technical services and for trained staff, Irish colleges have developed centres of expertise in several relevant areas.

Of particular interest are:

Development of in-vitro tests for pharmaceutical screening and for toxic effects. Among the projects in progress at the moment are invitro assays for detection of drug-related specific neural tube defects, eg spina bifida and also an assay for assessing efficiency and toxic effects of cancer chemotherapeutic drugs. Development of novel drug delivery methods.

\section{Mammalian Reproductive Physiology}

Ireland is one of the major milk and meat exporting countries in the world and breeding of sheep and cattle is therefore of great importance. Both the universities and the Agricultural Institute perform research on many topics of relevance to the breeding and production of cattle and other livestock. A topic which is of relevance to biotechnology is the area of mammalian reproductive physiology. The 
research group of Prof. Ian Gordon at University College Dublin, was among the pioneers of Embryo transplantation.

Work by this group and the associated group of Dr J Sreenan at the Agricultural Institute at Beldare, Co Galway continues on areas such as immunological control of reproduction, embryo sex determination, oestrus control and in-vitro fertilisation.

Plant Biotechnology

The major crops of interest to Irish biotechnologists are potato, cereals and ornamentals. Ireland has a large seed potato industry based on exports to Mediterranean and $\mathrm{N}$ African countries. The majority of these exports are two varieties which were bred at the Agricultural Institute, Oakpark.

Forestry research focuses on the use of mycorrhizae to assist the reafforestation of our marginal lands. Research on inoculation of seedlings with candidate strains of mycorrhizae is underway in the Forest and Wildlife Research Laboratory and at University College, Dublin.

\section{Biotechnology Infrastructure}

The major agencies responsible for the various elements of the Irish National Programme for biotechnology are contained in the table below.
National Board for Science and

Technology NBST, until late 1987

From beginning of 1988

Bio research Ireland

Industrial Development Authority, IDA

The Agricultural Institute - An Foras

Taluntais, AFT

Institute for Industrial Research and

Standard, IIRS

*These two agencies were merged in January 1988 to form EOLAS, the Irish Science \& Technology Agency.

The Irish National Programme for Biotechnology was jointly developed by the NBST and the IDA.

The NBST's role within the Irish National programme was primarily to develop national biotechnology expertise and facilities and to maximise its application to Irish industrial and economic development.

The NBST achieved this end by:

- Funding basic and precompetitive research in universities.

- Promoting and assisting university-industry research co-operation.

- Promoting and assisting international research co-operation.

A very important part of the programme is the improvement of linkages between industry and researchers in Irish universities and the development of international linkages. Irish researchers are actively encouraged to perform research for industry in other countries, and also to form partnerships with other EEC researchers from participation in EEC research programmes. 
The process of linking university researchers and industry has been one of the major activities of the NBST. To this end a newsletter, Irish Biotech News' was published and distributed widely in Ireland and abroad.

\section{Mechanisms for Biotechnology Promotion}

As mechanisms for co-operation are of specific interest to participants in SOBELA, it may be useful to point out some of those used in Ireland:

1. Publication of a newsletter - Irish Biotech News, which is distributed free of charge to both industry and researchers and highlights co-operative opportunities.

2. Running of seminars and workshops on topics of common interest. For each chosen topic both researchers and relevant industry representatives are specifically invited so as to encourage contacts.

3. Grants of up to $50 \%$ of the cost of university/industry co-operative research, are made available.

4. Funding assistance is given towards the employment of scientists and technologists by companies with a low level of technical employees.

NBST put a very high priority on international co-operation in research. Irish researchers have a particular problem in that our island position makes the travel necessary for co-operation more costly than on mainland Europe. To alleviate this, the NBST provide assistance towards visits by researchers to other research centres. This mechanism proved highly successful in developing collaborative research teams for applications to EEC research programmes. NBST also strongly promoted involvement in EEC and in other international programmes as a means of developing contacts and collaboration. We have also formed scientific and cultural exchange agreements with many countries.

\section{Regulation of Biotechnology}

A National Recombinant DNA Committee advises planning authorities and others on the safety of genetically engineered organisms used in the state. The committee is composed of experts, and representatives of the public, unions, industry and government. The guidelines of the National Institute of Health, NIH, in the USA have been adopted by the committee with some modification.

\section{Recent Developments}

In 1988 many of the activities of the NBST were merged with those of the IIRS to from EOLAS - the Irish Science and Technology Agency. EOLAS is geared to generating income for the state. BioResearch Ireland represents biotechnology activities within EOLAS, and is focused on three national centres:

- National Cell \& Tissue Culture Centre

- National Food Biotechnology Centre

- National Diagnostics Centre

The National Cell and Tissue Culture Centre is located in the National Institute for Higher Education, Dublin, which was set up in 1980. The focus of work is monoclonal antibody production and all aspects of animal cell culture, including toxicity testing applications. Contract research is going on with a number of companies in Europe and elsewhere.

The National Food Biotechnology Centre is located in University College Cork. Genetically manipulated organisms are developed to enhance food bioprocessing and flavours. Cheese microbiology is a particular strength.

The National Diagnostics Centre, located at University College, Galway joins many skill bases to develop innovative diagnostics, including DNA probes. Custom synthesis of oligonucleotides is a feature of this facility's competence that could be of interest for outside clients. 


\subsection{ITALY}

\section{Carmello Iacobello}

Recently there have been major changes in the organisation of Italian biotechnology. In 1985 biotechnology R\&D was fragmented without real direction or co-ordination. No national priorities had been defined.

Most of the nation's biotechnology programmes were at that time focused on human health and supported by the National Research Council, CNR.

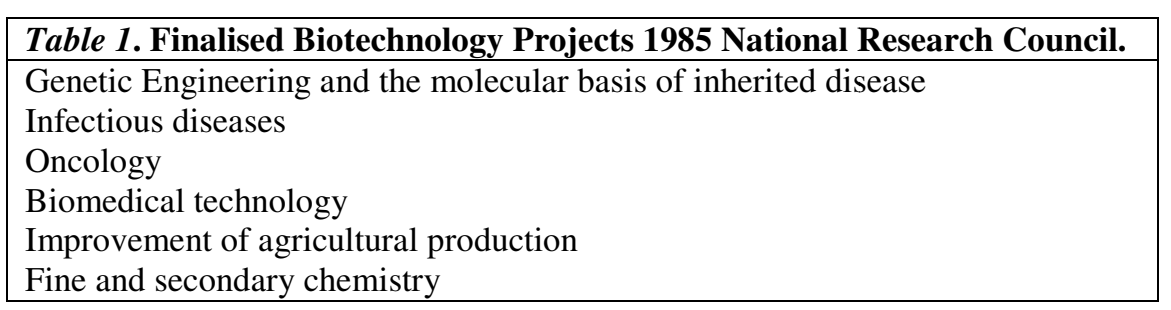

This initial set of projects gave rise to competence in several key aspects of biotechnology, such as monoclonal antibody production and molecular recognition. Significant short term advances were made in the area of gene manipulation and the production of recombinant products.

In the context of the fine chemistry projects several advances in enzymology were funded, and in the domain of agriculture some rationalisation of modern plant genetics was undertaken at national level.

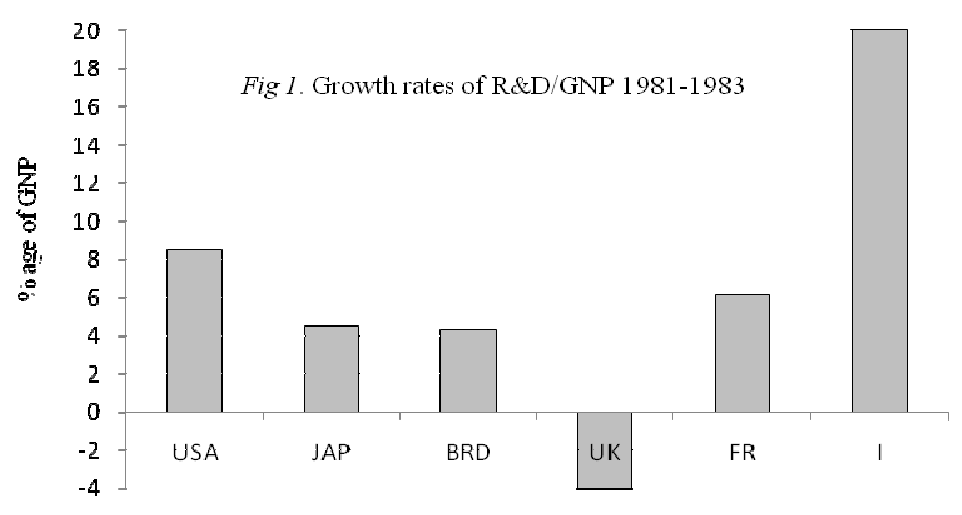

The investment made in this first round of funding was judged inadequate, but none the less it demonstrated Italy's commitment to meeting the levels of R\&D expenditure sustained by other developed countries.

Figure 1 compares the rate of growth of R\&D expenditure as a $\%$ age of GNP up to 1984. The data are derived from a report of the Italian Chemistry Federation, Federichimica, on biotechnology entitled 'Le Biotecnologie in Italia: un opportunita di sviluppo industriale'. Milano 1986.

In 1985 a National Biotechnology Committee had been created, supported by the Committee for Development and Innovation in the Chemical Industry Federation. These bodies recommended the pursual of a National Biotechnology Policy, charged with organising, funding and directing programmes.

The National Programme represented a logical development, for $24 \%$ of Italy's revenues are based on organic or biological products with a 1984 value of 112 billion US\$ (see Figure 2). This percentage is higher than for other countries and illustrates why biotechnology is of such keen interest; several key market areas of relevance to Italian industry are affected.

The areas illustrated in the following diagrams have several common features:

- They are big markets with potential for large expenditure;

- They are characterised by imported products;

- SMEs have a high profile in this market. They need a common development policy.

The Italian health care market was worth US\$6 billion in 1984, about $35 \%$ of that spending going on diagnostics, pharmaceuticals and biomedicals. By 1990 this area could be 25-35\% dependent on biotechnology products.

Agriculture accounts for total invoices of US $\$ 32$ billion, spent mostly on animal breeding, cereals and vegetables. Consumption increases are causing an import boom. The animal feed sector in particular, worth US\$26 billion (1984) is characterised by a significant excess of imports over exports. 
$\%$ of production from organic sources in respect to the global internal product (1984)

\begin{tabular}{|c|c|c|c|}
\hline Countries & $\%$ & \multicolumn{2}{|c|}{ Close-up of sectors in Italy (1984) } \\
\hline & \multirow[b]{2}{*}{$24 \% *$} & Sectors & $\%$ \\
\hline Italy & & \multirow{5}{*}{$\begin{array}{l}\text { - Agriculture } \\
\text { - Extractive } \\
\text { - Manufacturing } \\
\text { - Feed } \\
\text { - Texture } \\
\text { - Wood } \\
\text { - Phemistry } \\
\text { - Oaper } \\
\text { - Others } \\
\text { Health }\end{array}$} & $\begin{array}{l}5.1 \\
1.0\end{array}$ \\
\hline U.K & $22 \%$ & & 13.2 \\
\hline U.S.A & $20 \%$ & & 3.3 \\
\hline France & $19 \%$ & & $\begin{array}{l}1.0 \\
2.9\end{array}$ \\
\hline Germany & \multirow[t]{2}{*}{$18 \%$} & & $\begin{array}{l}0.7 \\
2.9\end{array}$ \\
\hline$* 24 \%=112$ & & $\begin{array}{l}\text { - Health } \\
\text { Total }\end{array}$ & $\begin{array}{c}4.7 \\
24.0\end{array}$ \\
\hline
\end{tabular}

Fig. 2. Comparison between various industrialized countries concerning their percentual production from organic sources. From the report of Italian Chemistry Federation 'FEDERCHIMICA' on Biotechnology 'Le Biotechnologie in Italia: un'opportunità di sviluppo industriale', Milano 1986.

Several factors influence this:

- Feed habits orient towards a strong feed industrialisation (with low cost);

- Trend to 'natural feed' with high quality food from direct agricultural sources and wide availability throughout the year (with high cost).

Biotechnology might solve the problem by providing high quality food at low prices. Production and storage technologies might also be favourably influenced.

Ecological considerations will play an increasingly important role in the industrialised nations. The processing and recovery of industrial and agricultural wastes is a market worth perhaps US\$15 billion within a decade. Lack of ecological surveillance could precipitate high costs in both social and economic terms.

Ecologically relevant companies have increased by more than $75 \%$ in number since 1980.
In the Chemicals sector the global market for Italian products was estimated at US\$26 billion. This potential is compromised however, by a massive dependence on imported products.

All sectors of industrial activity are therefore open to the influence of biotechnology. An industrial representative committee has considered the following theoretical areas of application.

- $40 \%$ of biotech products would be new, not realisable by existing technologies.

- $60 \%$ of biotech products could represent the consequence of improvements to existing processes.

- $70 \%$ of ideas generated could be realised in the short to medium term that is up to 5 years from now.

In 1985, in response to these ideas the National Research Council, CNR, created a Task Force to mobilise activity in well focused research areas. Focused on CNR and university laboratories the resulting programme: Strategic Project, Advanced Technology in Biology, was divided into three major subprogrammes:

- Biotechnologies

- Agro-industrial technologies

- Aquaculture

\begin{tabular}{|l|}
\hline Table 2. National Research Council: \\
Strategic Project Innovative Technologies in Biology' (1986-1987) \\
\hline Funding: Us\$2.1 million \\
Subprojects: \\
1. Biotechnologies \\
- Enzymology, natural or modified enzymes \\
- Agro-industrial biotechnologies \\
- Oligonucleotide synthesis and molecular probes \\
- Biosensors \\
2. Agrotechnologies \\
- Cultivated plant technologies \\
- Molecular and biological control of parasites and abiotic stresses \\
3. Aquaculture of agroecosystem productivity \\
- Artificial reproduction and genetic improvement in fish breeding \\
- Reproduction and breeding of new fish species \\
\hline
\end{tabular}


In the first two years the budget for this programme was low, only US $\$ 2.1$ million, but the idea was to orientate a number of research groups to just a few well defined technologies.

Following on from this programme is the: Special Project: Biotechnology and Bioinstrumentation, with funding of US $\$ 68$ million over the five year period, 1987-1991. This programme will focus on precompetitive aspects of biomedical and chemical areas. Addition of important new subprogrammes in vaccines, cell culture and transplantation biology is a feature. The CNR will involve universities and research institutes in the programme.
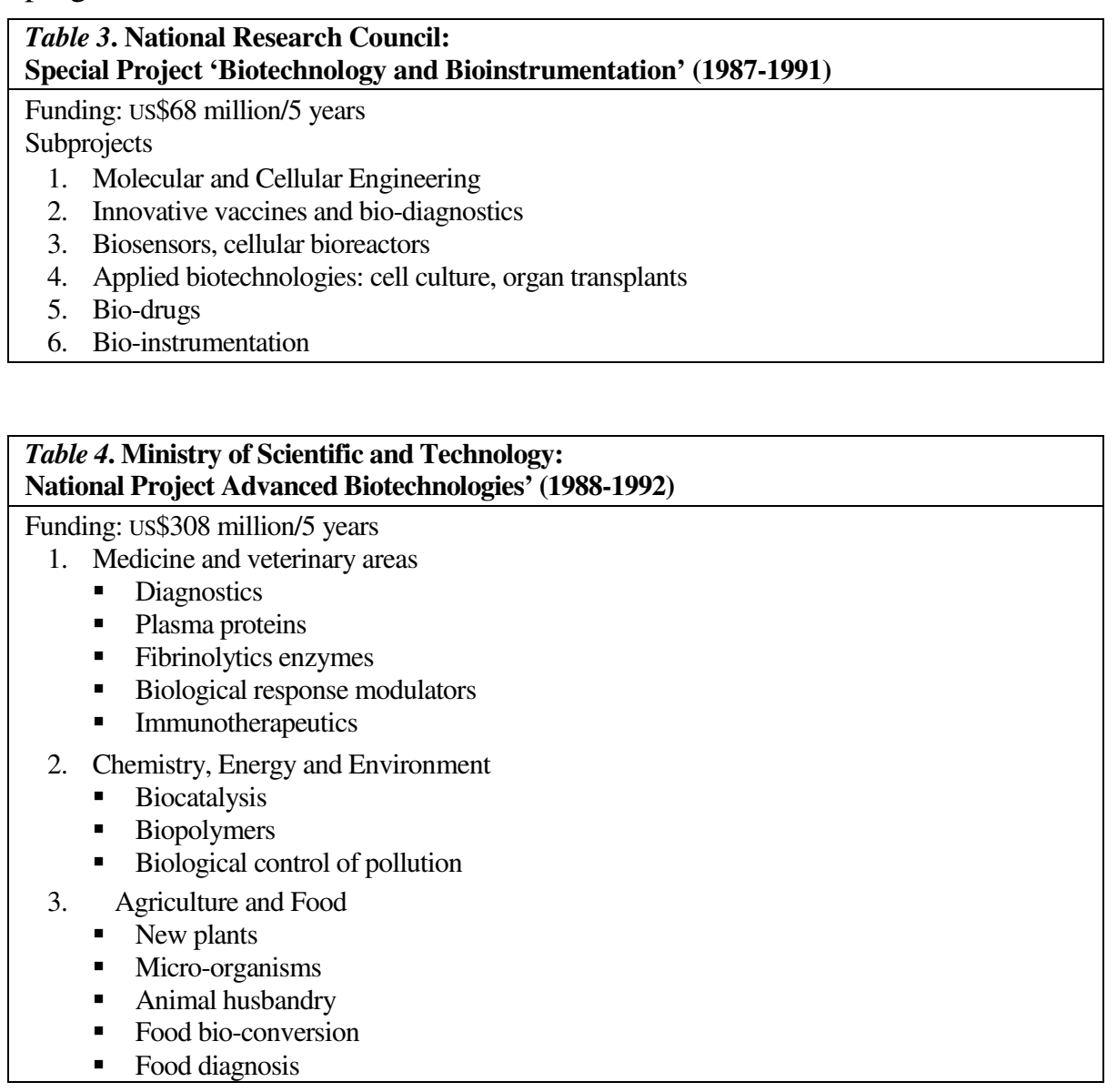

A third major programme designed to stimulate industrial competitivity and innovation through government support, is entitled: National Programme, 'Advanced Biotechnologies', funded by the Ministry of Scientific Research and Technology. This programme envisages expenditure totaling US\$308 million over the five year period to 1992 .

\section{Table 5. Nonmedical applications of biotechnology.}

\section{Chemistry, energy and environment}

A) New enzymes

B) Innovation on bio-conversion and enzyme catalysis

C) Polysaccharides from natural sources

D) Control and recovery of environments

E) Bioprocessing of minerals

Agriculture and Feed

A) In vitro plant generation

B) Introduction and expression in plants of exogenous genes

C) Plant nitrogen metabolism

D) Biological defence of plants

E) Improvement of growth and nutritional properties of breeding animals

F) Enzymes for feed industry

G) Treatment of agricultural wastes

H) Control of food safety

In Table 5, two of the areas considered above are examined in closer detail. There is broad accord with the aims expressed by the European Commission, particularly with regard to the stimulation of agro-industrial development.

The Italian response to the recent Commission 'Call for Expressions of Interest' on the theme, 'Stimulation of Agro-Industrial Development', was most encouraging (see Fig 3). Some $70 \%$ of the Italian 'expressions' were from industrial organisations (see Fig 4). 
Agro-industrial development - Results of call for interest

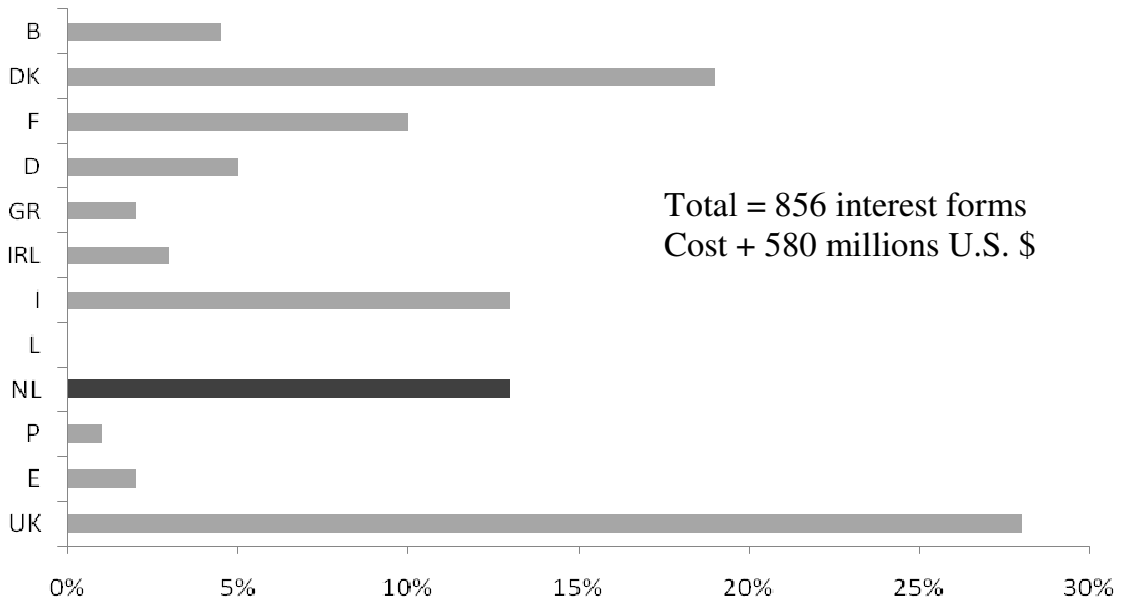

Fig. 3. Results of call for interest concerning the 'Stimulation of Agro-Industrial Development' from EEC expressed as national percentual of the total responses. From EEC document CUBE-XII/233/87.

\section{Industry Interest}

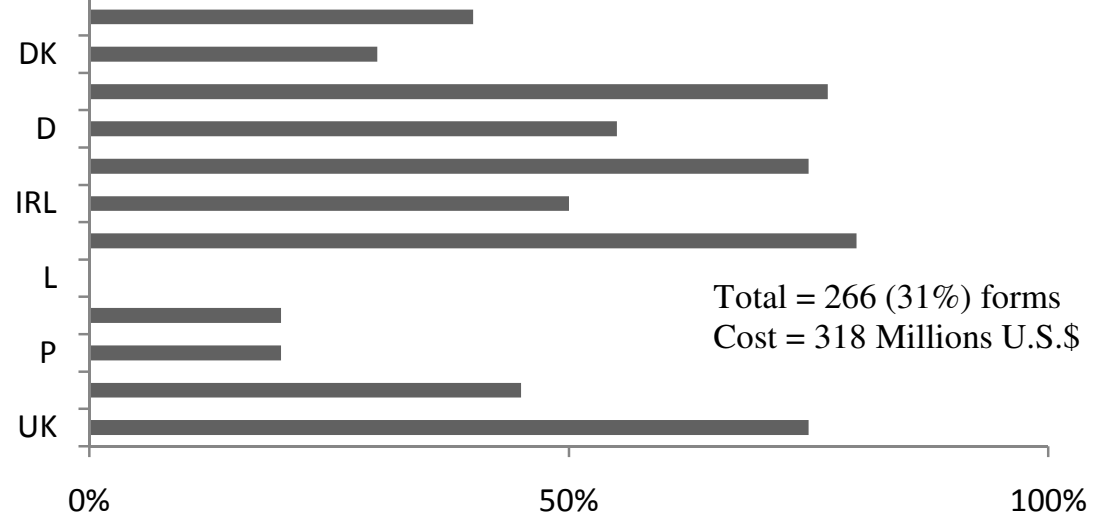

Fig. 4. Industry interest for stimulation of agro-industrial development. Results are expressed as percentual of total responses from each country. From eec document cube-xii/233/87
Other public programmes with an element of biotechnology are summarised in Table 6.

In the planning stage is an agricultural programme with a provisional budget of several hundred million US\$. Focus will be on crop production, animal breeding and adding value to agricultural by-products.

\begin{tabular}{|l|l|c|}
\hline \multicolumn{1}{|c|}{ Table 6. Other publicly financed programmes in biotechnology } \\
\hline \multicolumn{1}{|c|}{ Programme } & \multicolumn{1}{|c|}{ Focus } & $\begin{array}{c}\text { Value US\$ } \\
\text { million }\end{array}$ \\
Fine Special Projects: & & \\
Genetic engineering: & Biologically active products & 18 \\
Ministry of Science and & rDNA technology vs genetic disease & 23 \\
Technology, National & & \\
Programmes: & Monoclonal antibodies and DNA & 14 \\
Technology in oncology & probes & 4 \\
Pharmaceuticals: & Targeting of cytotoxic drugs & \\
\hline
\end{tabular}

In Figure 5 the present state of national funding programmes in biotechnology is recapitulated. The overall commitment of funds is seen to exceed US\$430 million over the present five year period. This major funding is intended to bridge the gap between industrial innovation and academic research, so strengthening the Italian presence in this key area of technology. 
Public fundings for Biotechnologies

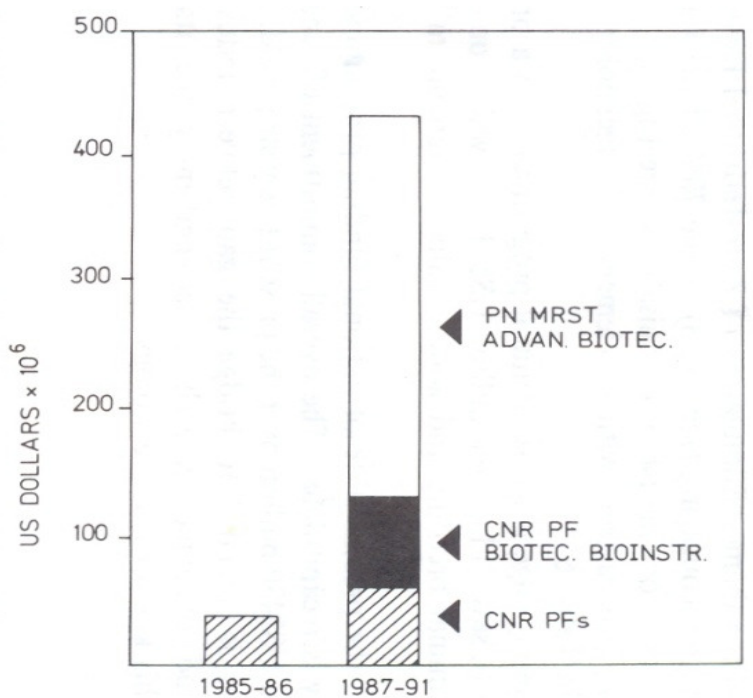

Fig. 5. Comparison between two periods of public fundings to biotechnology in Italy. PN MRST: National Program from Ministry of Scientific Research and Technology. CNR PF: Finalized Project from National Research Council.

\subsection{THE NETHERLANDS}

\section{Henk C. van der Plas}

In September 1984 Professor Schilperport, then Chairman of the Programme Committee on Biotechnology, PCB, suggested that in the 1990s the Netherlands might be the biotechnology delta of Europe. Is that fiction or reality?

The Netherlands posses an industrial base of about 100 biotechnology firms, together providing an R\&D potential of 1,100 manyears (in 1985). Sales of traditional biotechnology products in the dairy, brewery and antibiotics industries accounted for sales of about US $\$ 4$ billion. New products such as recombinant vaccines and diagnostics based on monoclonal antibody technology are contributing to 1987 sales of about US\$40 million.

A few major companies dominate biotechnology in the Netherlands. These have a base in traditional biotechnology and have rapidly included new technology in their ranges of competence. Many, much smaller companies have emerged recently, partly because of the relatively easy access to investment capital.

Figure 1 summarises the scope for biotechnology $R \& D$ in the Netherlands. The role of the major companies is clear.

Because of the small size of the country and the initiative of the government in pushing activities in biotechnology, there exists a solid network of contact and communication among all Dutch biotechnologists, in industrial, university or government laboratories.

The standard of excellence in Dutch universities is among the highest in Europe, and although there was considerable displeasure some 7 years ago when the government first sought to stimulate a productive orientation, almost all would now admit that the scheme has been successful. 
Composition of industrial base 1985 a total of 1100

manyears was commited to biotechnology R\&D

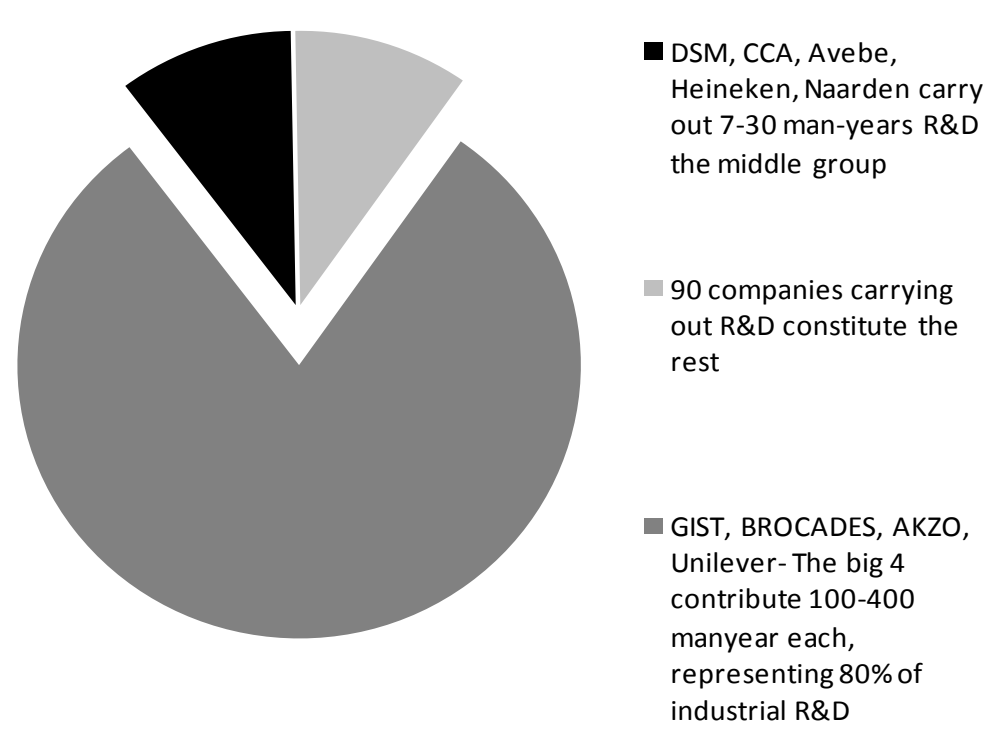

Fig. 1. Scope for biotechnology R\&D in the Netherlands

The small size of the country cannot hide the fact that it plays host to some of the more prominent multinationals. The financial power of big companies, combined with experience and marketing know how has made it possible to exploit the opportunities in biotechnology.

Small is effective for the Netherlands. Communications are no problem as all locations are geographically close.

The government has made biotechnology a priority area, not only because of the solid industrial base, but also because biotechnology provides fast growing market opportunities in many industrial sectors.

\section{The Role of the Government}

The government launched its Innovation-Oriented Biotechnology Research Programme in 1981. This formed part of a series of similar such programmes in a number of strategically critical areas including: membranes, polymers, composites, carbohydrates, engineering ceramics etc. The primary goal of these innovation oriented research programmes, IOPs, is to stimulate research in universities and institutes. The goal is three pronged, seeking:

- to stimulate research.

- to structure the knowledge infrastructure through division of tasks, co-operation and market orientation.

- to set up a communications network.

Let me explain these three points. Stimulation of biotechnological research at universities and institutes is being accomplished by provision of an extra US $\$ 20$ million between 1981 and 1990. The money is shared out by a high level body, the Advisory Committee on Biotechnology, ACB, which, although government appointed, works at arm's length from the government. Its membership includes representatives of both industry and research institutes. The indirect, co-ordinating, effect of this extra financial stimulation is, in my opinion, even greater than the direct impact.

The Advisory Committee on Biotechnology seeks to realise the entire threefold goal simultaneously. As in some countries, government funded university research in the Netherlands is being trimmed, owing to budget constraints. The division of tasks is therefore an indispensable element for structuring the knowledge infrastructure (e.g. to avoid overlap).

Biotechnology is a multidisciplinary science. Co-operation between research teams is a sheer necessity, because only integration of knowledge can produce practical applications. The third element of restructuring the knowledge infrastructure, finally, is more market orientation. Extensive consultation with industry was found to be a simple and effective way of learning exactly what the market needs.

An inventory of the wishes and needs of industry, as regards both research objectives and research teams, served as a basis for this industrial orientation. The inventory was made through confidential interviews, the results of which were generalised. This guaranteed an open industrial orientation.

The third goal, that of building up a communications network, is vital for the rapid growth of a new technology, which cannot develop without dose co-operation between everyone concerned. 
Central to the IOP network is the Advisory Committee on Biotechnology, $\mathrm{ACB}$, which co-ordinates the overall stimulation of the four sub-programmes on Biotechnology under the supervision of four separate Programme Committees, PCs. Each of the four PCs receives money from the Ministry most closely involved.

The ACB together with the four Programme Committees has also succeeded in creating the conditions for good fines of communication between research institutes, industry (including investors) and government.

In the first stage of the IOP, from 1981 through to 1984, financial stimulation was used to raise the level of biotechnological research on a broad scale, while building up a communications network. At the same time inventories were taken to determine the direction of the infrastructure structuring.

In the second stage from 1985 to 1990 , structuring is being selectively programmed and anchored in the infrastructure, so that industry will be able to continue making optimal use of the government funded knowledge infrastructure after the programme has ended.

The following tables show the range of activities encountered in government funded institutes and universities.

\begin{tabular}{|ll|}
\hline Table 1. The Major University Biotechnology Centres in the Netherlands. \\
\hline Centre & Activity \\
\hline BDL, Biotechnology Delft-Leiden & Incomplete oxidations \\
(Technical University Delft \& State & Plant cell biotechnology \\
University Leiden) & Yeast physiology/genetics \\
& Environmental biotechnology control \\
& Bioreactor design and downstream \\
& processing \\
Agricultural University Wageningen & Biocatalysts \\
& Food and animal feeds \\
& Waste and environment \\
& Plant cells \\
& Animal cells \\
BCA, Biotechnolog Centre & Opimisation of product formation by \\
Amsterdan (Free Universit & micro-organisms \\
Amsterdam \& University of & (yeast \& prokaryotes) \\
Amsterdam) & Plant biotechnology \\
& Monoclonal antibody production \\
& Enzymology \\
State University Utrecht & Vaccines \\
& Peptide and polypeptide hormones \\
State University Groningen & Monoclonal antibodies \\
& Fine chemicals and stereo specific \\
& reactions \\
& Development of host-vector systems for \\
& industrial micro-organisms \\
& Biological oxidation, biodegradation of \\
& waste \\
& Optimisation of dairy micro-organisms \\
& \\
& \\
& \\
& \\
&
\end{tabular}




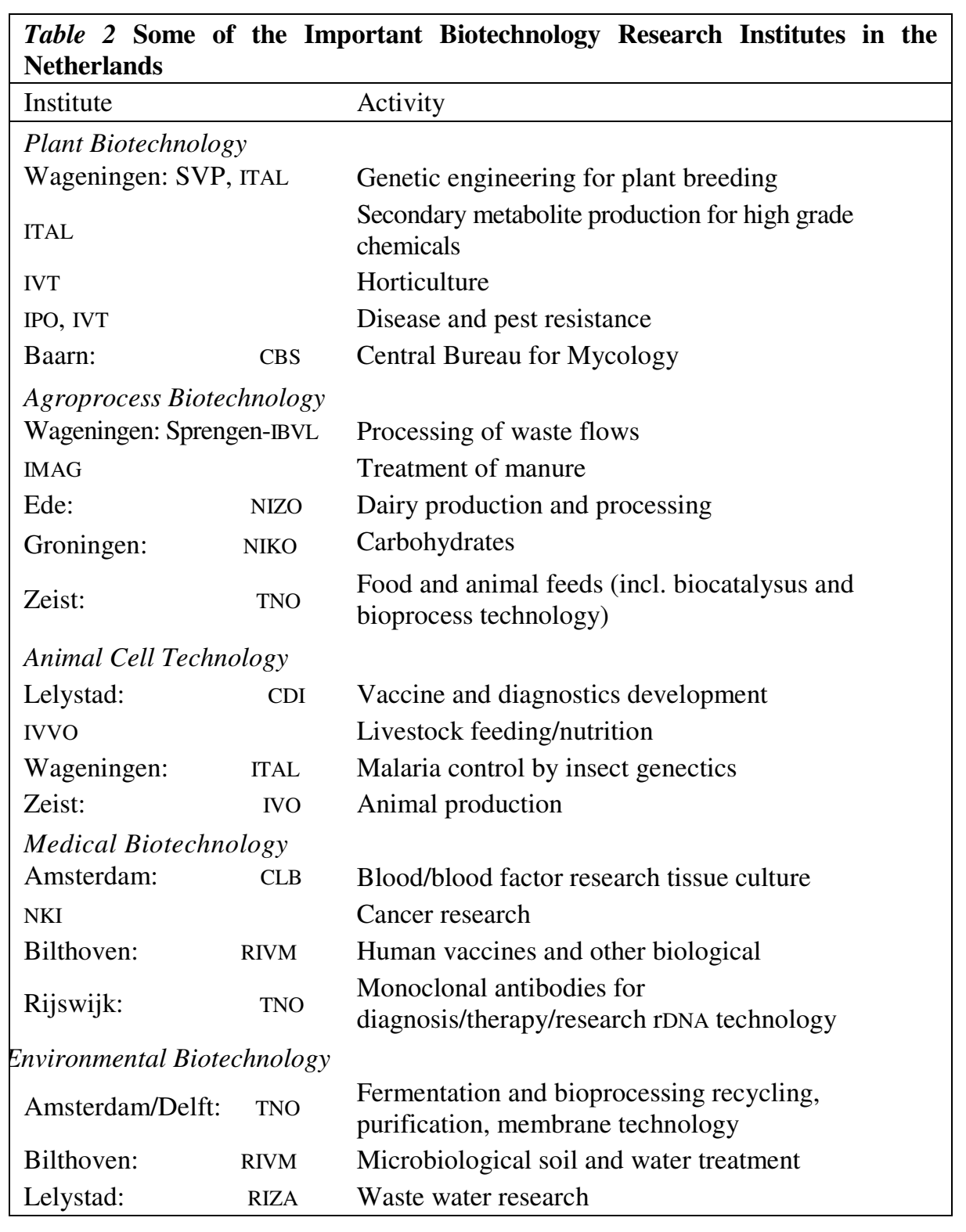

\section{INDUSTRIAL BIOTECHNOLOGY POLICY}

Since 1983 the Dutch government has encouraged industry to participate in ambitious R\&D programmes. Two forms of subsidy have backed up this encouragement.

- the INSTIR subsidy scheme

- case by case assessment

INovation STImulation Regulation, is a scheme which offers wage support for R\&D. Given the massive cost of wages in modern industry this incentive dramatically lowers cost thresholds and has been provided for a number of promising technologies, including biotechnology.

Although university collaboration was not a precondition of these subsidies, it is a testimony to the establishment of the communications infrastructure that, in practice most projects were carried out in collaboration with universities or institutes.

The recent economic upturn has made $R \& D$ financing much easier for companies, who are now less in need of government support. Since 1987 the Dutch government provides incentives only for technologies in which the support policy results in the highest added value.

Biotechnology is one of the four high tech areas that continues to benefit from public support. The technology policy enabling the knowledge infrastructure through the IOP is being followed up in the form of a programme policy concerned directly with industry.

At this stage the goal is to increase the number of firms engaged in new biotechnology operations from 10 or 20 to 100 ! More than 100 potentially promising firms that we now have are being prevented from achieving high-tech production in the near future, not so much by lack of money, but by a low level of in-house research activity.

Subsidies do not play major role in the government's programme policy, although they do perform a valuable supportive role. The programme for the 100 companies target covers a number of synergic and mutually complementary activities. 


\section{INFORMATION AND CONTACT}

A vital factor in pulling firms across the threshold towards new technologies is information. This part of the programme is already in full swing, with the publication of booklets and a biotechnology magazine in Dutch. Printed information does not suffice. Personal contacts through consultants paid for by the Economic Affairs Ministry often produce better results. The consultant acts as a broker between industry, the knowledge infrastructure and government.

\section{IOP BIOTECHNOLOGY}

Already discussed in the earlier part of this presentation.

STIMULATION OF INDUSTRIAL R\&D PROJECTS

An important criterium for selection is co-operation with a university or institutional research group. This industrial stimulation is therefore closely linked with the IOP stimulation.

\section{ESTABLISHMENT OF NEW COMPANIES}

Can foreign companies be persuaded to set up in the Netherlands, as a consequence of providing the appropriate infrastructure? We have been successful, as the establishment of subsidiaries of the American biotechnology firms, Centocor, Mogen International, Promega and recently EuroCetus demonstrates.

\section{EDUCATION}

Without suitably skilled manpower, no innovation is possible. We are busy setting up a postgraduate training facility for biotechnology engineers, a joint initiative of Delft and Leiden.

\section{INTERNATIONAL CO-OPERATION}

For a small country like the Netherlands, cross frontier co-operation is important, particularly within the context of the European Community, EC, and EUREKA. Non-European collaboration also receives dose attention from the government, particularly the third world countries. The Netherlands have initiated biotechnology collaborations with Indonesia, India and Thailand.

\section{OPTIMISING THE CHANCES FOR SUCCESS}

General policy actions relating to the approval of biotechnology products, patent matters, supplies of cheap raw materials for the fermentation industry and last but not least - social acceptance.

The Dutch government is working for industrial innovation in biotechnology along these lines.

\section{What Has BeEn ACHIEVED?}

A number of products have emerged from the Dutch Biotechnology initiatives. The following are just a sample that illustrates the breadth and potential of the Dutch biotechnology enterprise.

- Anaerobic purification of waste water: a co-operation between universities, TNO and Gist-Brocades

- Development of a vaccine against diarrhea in calves and piglets: a co-operation between RIVM and Amsterdam University.

- Pregnancy test using monoclonal antibodies: Organon

- Preparation of D I L amino acids by enzymatic separation of $D, L$ mixtures: Dutch States Mines, DSM.

- Production of aspartame: DSM, Toyo Soda

- Biofilters for air filtration, production of chymosin with rDNA technology: Gist-Brocades, NIZO

Many other products and processes are well on the way to realisation. The last table gives evidence to support the assertion that growth in biotechnology will be gradual, but steady. At this point I return to the claim that The Netherlands might become a Biotechnology Delta in the 1990s. It is still premature to say that this is more than fiction, but we are working hard to create a really strong base for industrial biotechnology in the next decade. We are full of confidence and so far, if I may say so, we have not been unsuccessful!

I hope this introduction to Dutch biotechnology has roused your interest and that it may lead to the next step of entering into dose cooperation with Dutch partners. The Netherlands is ready for it. 
For anyone wishing to learn more about Dutch biotechnology, a highly informative and illustrative brochure can be ordered, as well as a list of names and addresses of Dutch firms and institutes active in the field.

\begin{tabular}{|lcccc|}
\hline Table 3 Biotechnology Sales for Various Industries: (figures in millions of Guilders) \\
\hline \multirow{2}{*}{ Industrial sector } & Total & \multicolumn{3}{c|}{ Biotechnology sales } \\
\cline { 2 - 5 } & 1982 & 1985 & 1990 & 1995 \\
\hline Fine Chemicals Human \& Veterinary & 6500 & 460 & 555 & 655 \\
Health Care & 2500 & 750 & 1000 & 1350 \\
Food and Beverages & 64000 & 8500 & 9400 & 10800 \\
Equipments and Instrumentation & 13000 & 275 & 310 & 350 \\
Engineering Contractors & 1500 & 90 & 160 & 210 \\
\hline Source: CIVI & \multicolumn{5}{|c}{} \\
\hline
\end{tabular}

\subsection{Portugal}

Julio Novais

In Portugal, biotechnology has become integrated into the traditional biology dependent industries. Microbiology and enzymology are now finding new applications. Many scientists have returned from training and employment overseas. This new resource of largely European trained scientists is now helping to create new poles of academic and industrial excellence.

The promise of biotechnology is being hindered in Portugal by the lack of entrepreneurial tradition. Human potential and favourable political conditions do not alone create new industries and economic development.

The government is sympathetic and started the implementation of a Mobilisation Programme in 1987. Funding levels for biotechnology have increased each year and are being complemented by funds from the European Commission and with A.I.D.

This presentation attempts to identify the impact of biotechnology on Portuguese industry and agriculture as well as its potential in research and education.

INDUSTRY

The industries involving biotechnology can be divided into two sectors, one more traditional and the other of a more modern kind which can be situated in the post antibiotic era.

In the first case, it is justifiable to start by referring to the wine industry, which has acquired great importance both internally and for export income. Port, Madeira and some Rosé wines contribute most.

The fruits of yeast research are now being enjoyed. Strain selection and slow fermentation conditions are being optimised so as to minimise undesirable contamination or side products. The sparkling wine industry is exploring the possibilities offered by immobilised yeast cells and continuous fermentation. 
In the cheese industry microbial enzymes are used in large scale production, but the best cheeses, called Serra, are still produced traditionally. Cardoon flowers are immersed in sheeps milk, a process prone to contamination and quality variation. Family production methods are being studied in the laboratory so as to identify proteases. It is hoped that it may be possible to produce cheese 'in vitro' with suspended and immobilised cardoon cells.

The old olive oil industry could be improved with better extraction processes and regeneration of the older plantations. New technologies such as micropropagation could play a useful role.

The beer industry has achieved a sophisticated understanding and control of the processes of malting and fermentation.

Antibiotic production is a significant export earner, with more than 90\% exported. The major products include: penicillin, tetracycline, oxytetracycline, erythromycin, gentamycin and ampicillin.

A new ampicillin process was developed in Portugal, whereby 6aminopenicillinic acid was formed by passing penicillin through novel bioreactors containing immobilised penicillin acylase. The technology has been successfully exported.

The fine chemicals industry carries out R\&D, often in collaboration with university laboratories. Products have included steroids and some diagnostic kits

Baker's yeast is produced at two locations, while glucose and glucose/fructose syrups are obtained with enzymatic processes.

Alcohol factories depend upon imported molasses (some 15\% produced domestically). This traditional industry is now moving towards an incorporation of the new biotechnologies.

Environmental considerations have not been overlooked. Several wastewater treatment plants have been constructed using a variety of technologies: activated sludge, percolating filters and a variety of ponds. Several cattle and poultry raising installations have built tanks for anaerobic digestion, using the resultant biogas for ambient heating or electrical energy production.

\section{AGRICULTURE}

Portuguese agriculture is a very traditional discipline and the only biotechnological input has been from classical genetics. In the future biotechnology will affect agriculture in two ways. Firstly, the fruits of research will influence the growth and multiplication of plants, possibly by species improvement by gene transfer and classical hybridisation etc. The sum of many developments in Nitrogen fixation, in vitro propagation and so on might radically modify the culture of a given region. Already some hybrid cereals have dramatically improved the productivity of some regions. In vitro propagation has so far been applied only to high value decorative plants and exotic fruits. Many technologies are unexploited, for example the knowledge of coffee developed in former colonies.

The second major influence may come about when agriculture is in a position to provide industrial raw materiais. The introduction of new cultures or the modification of old ones may bring about changes. At the moment trials are underway with an inulin producing Jerusalem artichoke. Suitable for fructose, or by fermentation, alcohol production this could become both a food and energy source.

Native biological resources are not overlooked. Plants of the semi arid interior might be used to produce commercial quantities of lipids from marginal lands. Euphorbia is presently being studied as a candidate for exploitation.

\section{RESEARCH}

In recent years there has been an important increase in biotechnology research. Little has yet emerged from this new development. In traditional areas such as yeast physiology and fermentation, Portuguese scientists have established a high standard of excellence. Fields of application would include yield improvement and alternative methods of fermentation product extraction, so as to reduce the energy costs of distillation.

Immobilised enzymes and micro-organisms are quite routine applications in the fields of antibiotic production and sparkling wine manufacture. 
Plant cell culture has yielded important developments in the areas of callus production, micropropagation and suspended cell culture. Other applications are in development.

In the area of environmental biotechnology a town of 13.000 population is successfully demonstrating the use of high photosynthetic rate ponds for sewage treatment.

At least three of the nation's research centres have been looking at the technologies of fermentation and down stream processing. Purification and separation of fermentation products using ultrafiltration membranes, and supercritical extraction of natural products exemplify this interest.

The bio-conversion of energy is being studied by groups whose focus is on energy mediating enzymes such as the hydrogenases. In vitro reconstitution of such activity could yield commercial benefits.

Other small groups are looking at genetic engineering, immunology, virology, monoclonal antibodies, etc.

Most research is carried out in university laboratories and public and private institutes. Industrial concerns only rarely have established an R\&D competence, relying instead on outside agencies. This must change if industry is to face a sound future.

An Institute of Chemical and Biological Technologies is being commissioned with the purpose of establishing links between biotechnology, agriculture and the agro-food industries.

EDUCATION

Several new courses have been inaugurated to train graduates in the skills required by tomorrow's institutional and industrial needs. The New University of Lisbon launched an Applied Chemistry course with a strong biotechnology component. In the Technical University of Lisbon, the Instituto Superior Técnico, a biotechnology course is taught during the five year Chemical Engineering degree. In Oporto a food engineering course was started four years ago within a Faculty of Biotechnology.

At postgraduate level two courses exist, at the New University of Lisbon, in conjunction with the Gulbenkian foundation and at the Instituto Superior Técnico.

\section{LINKS WITH LATIN AMERICA}

Portugal has a long standing tradition of openness to the outside world, a consequence of the past colonial tradition and associated migrations.

Brazil and Portugal have particularly dose ties, resulting from a common history over several centuries and a common language. At present high level talks are aimed specifically at creating a collaborative relationship in the field of biotechnology. Joint workshops have been held, with a view to establishing common programmes.

One type of link that may develop between Portugal and Latin America involves technology transfer from biotechnology using industries. A new antibiotics factory in Brazil, CIBRAN was designed in Portugal and at least initially was dependent upon Portuguese technology.

Portugal's interest in fermentation and downstream processing, alcohol and biocatalysis may be of particular interest. Support for developing these technologies has come from the European Commission.

Tropical agriculture, pest control and disease are points of common interest and expertise with a potential for fruitful co-operation.

Educational links are particularly favoured with Brazil. Portuguese universities receive many Brazilian students onto their M.Sc. courses and are willing to accept Spanish or Portuguese speakers onto $\mathrm{Ph} . \mathrm{D}$. degrees. Both Latin American and Portuguese workers have shown the willingness to travei so as to learn or teach new technology.

The mobility of research workers and teachers seems of fundamental importance if Portugal and Latin America are to keep pace with modern developments. It is essential to create bridges between Europe and Latin America. The funding of a programme to this end would be of great value. 
Annex: List of Organisations Active in Biotechnology in Portugal

\begin{tabular}{|c|c|}
\hline $\begin{array}{l}\text { Industry } \\
\text { Antibiotics }\end{array}$ & $\begin{array}{l}\text { Cipan } \\
\text { Soc. Port. Leveduras Selecionadas }\end{array}$ \\
\hline Fine Chemicals: & $\begin{array}{l}\text { Quatrum } \\
\text { Hovione } \\
\text { France-Farmaceutica }\end{array}$ \\
\hline Baker's Yeast: & $\begin{array}{l}\text { Propam } \\
\text { Soc. Port. Leveduras Sellecionadas }\end{array}$ \\
\hline Starch: & Copam \\
\hline Breweries: & $\begin{array}{l}\text { Centralcer } \\
\text { Unicer }\end{array}$ \\
\hline Plant Micropropagation & In Vitro Plants \\
\hline \multicolumn{2}{|l|}{ Research } \\
\hline Yeasts: & $\begin{array}{l}\text { Instituto Gulbenkian de Ciencia, IGC } \\
\text { Universidade do Minho } \\
\end{array}$ \\
\hline Alcohol Fermentation: & $\begin{array}{l}\text { Instituto Superior Técnico, IST } \\
\text { Faculdade de Engenharia da Universidade do Porto } \\
\text { Laboratório Nacional de Engenharia e Tecnologia } \\
\text { Industrial, LNETI }\end{array}$ \\
\hline Environmental Biotechnology: & $\begin{array}{l}\text { Universidade Nova de Lisboa, UNL } \\
\text { IST } \\
\text { Universidade de Aveiro } \\
\text { LNETI }\end{array}$ \\
\hline Immobilised Biotacalysts: & $\begin{array}{l}\text { IST } \\
\text { Universidade de Coimbra }\end{array}$ \\
\hline Algal Biotechnology: & $\begin{array}{l}\text { Instituto Nacional de Investigação das Pescas, INIP } \\
\text { LNETI } \\
\text { IST }\end{array}$ \\
\hline Energy from Biomass: & LNETI \\
\hline $\begin{array}{l}\text { Bioreactor design and Downstream } \\
\text { Processing: }\end{array}$ & $\begin{array}{l}\text { FEUP } \\
\text { IST } \\
\text { UNL } \\
\end{array}$ \\
\hline Hydrogen and Methane Production: & UNL \\
\hline Genetic Engineering & $\begin{array}{l}\text { IGC } \\
\text { Instituto de Ciencias Biomedicas, ICBAS }\end{array}$ \\
\hline Plant Cell Biotechnology & \begin{tabular}{|l|} 
Faculdade de Ciencias Lisboa, FCL \\
Estação Agronômica Nacional, EAN \\
\end{tabular} \\
\hline Tropical Plants: & $\begin{array}{l}\text { Centro de Investigações do Café } \\
\text { EAN }\end{array}$ \\
\hline
\end{tabular}

\begin{tabular}{|l|l|}
\hline Plant Genetics: & $\begin{array}{l}\text { EAN } \\
\text { Estação de Melhoramento de Plantas de Elvas } \\
\text { IGC } \\
\text { Universidade de Tras-Os-Montes e Alto Douro }\end{array}$ \\
\hline Fine Chemicals, Diagnostic kits: & $\begin{array}{l}\text { LNETI } \\
\text { IST }\end{array}$ \\
\hline Food Biotechnology: & $\begin{array}{l}\text { LNETI } \\
\text { Escola Superior de Biotechnologia, Porto } \\
\text { Instituto Superior de Agronomia }\end{array}$ \\
\hline Wine Research: & $\begin{array}{l}\text { ISA } \\
\text { Estação Vitivinícola Nacional }\end{array}$ \\
\hline Aqualculture: & $\begin{array}{l}\text { ICBAS } \\
\text { INIP }\end{array}$ \\
\hline Monoclonal Antibodies: & $\begin{array}{l}\text { IGC } \\
\text { ICBAS }\end{array}$ \\
\hline Lignocellulose degradation: & $\begin{array}{l}\text { ISA } \\
\text { LNETI }\end{array}$ \\
\hline Biogas Production: & $\begin{array}{l}\text { LNETI } \\
\text { UNL }\end{array}$ \\
\hline Virology: & IGC \\
\hline Human Biotechnolgy: & Instituto Nacional de Saúde Pública \\
\hline Animal Biotechnology: & $\begin{array}{l}\text { Escola Superior de Medicina Veterinária } \\
\text { Laboratório Nacional de Investigação Veterinária }\end{array}$ \\
\hline Immunology: & Universidade de Coimbra \\
\hline
\end{tabular}

Further information on Portuguese biotechnology centres can be obtained from the speaker or from the following institutions:

JNICT - Junta Nacional de Investigação Científica e Tecnológica, Av. D, Carlos I, 126-1o, 1200 LISBOA, PORTUGAL

Sociedade Portuguesa de Biotecnologia, c/o Instituto Superior Técnico, 1096 LISBOA CODEX, PORTUGAL 


\subsection{SPAIN}

Armando Albert

Biotechnology, understood as the application of the principles of science and engineering to the treatment of materials by means of biological agents, for the production of goods and services, comprises a wide field of study.

The economic and social importance is now unquestionable, especially if it is understood that in our country the production value of the potential users amounts to some 15\% of the Gross Domestic Product.

\section{Mobilising Programme}

Spain has a scientific community capable of incorporating biotechnology into its production systems, and into an improvement of its services. For this a series of objectives have been defined and the necessary economic resources for the Biotechnology Mobilising Programme have been made available. This Programme was initiated by the government in response to the perceived gap in the organisation and execution of biotechnology research and application. The situation was explained in the volume: 'Programa Movilizador de Biotecnologia', published by the Ministry of Science and Education in Rine 1985.

So far the execution of the Mobilising Programme has been satisfactory, with objectives being attained. The state has made funds available and no major contradictions in proposals and financial realities have emerged.

\section{Present Situation of the Biotechnology Sector}

More than 250 groups are working on biotechnology in the public sector (universities and government research laboratories) and nearly 50 firms have expressed an interest in biotechnology R\&D. The situation indicates sufficient activity to generate a biotechnological 'critical mass' in the near future. The response to the Mobilising Programme has been encouraging and early results are promising.

\section{STAFF TRAINING}

Spain supports over 100 research fellows. A further $80+$ fellows have spent at least one year in foreign centres.

CENTRO NACIONAL DE BioteCNOLOGia, CNB

Initiated in 1987 this centre should become fully operational this year, representing a total investment of about us $\$ 25$ million. Director, Michael Parkhouse has been appointed and recruitment of other senior staff is going on.

Fifty research projects are being financed in public sector laboratories, and a further 10 projects involving companies, with a total budget of about US\$8 million.

The research projects fall into the area of application orientated basic research. 18 studies are ongoing, 8 in genetic engineering, 9 in human and animal health, 9 in chemical and agro-food industry, 9 in Agriculture and 5 in biomass and pollution control.

Industrial projects focus upon aspects of human and animal health, the chemical industry and the food industry. The Centre for the Development of Industrial Technology, CDTI, has taken up the responsibility of supporting $20 \mathrm{R} \& \mathrm{D}$ programmes with a total value of about US\$30 million.

The conclusion of the Mobilising Programme has stimulated the view that it is necessary to continue and increase efforts in this area with a R\&D National Programme in Biotechnology, along the lines indicated below.

\section{Planned Actions}

The following major themes encapsulate the National Programme.

\section{Human Resources - Staff Training}

The Mobilisation Programme confirmed the need to increase efforts in training. During the five year period of the National Programme it is proposed to train a further 225 biotechnology $\mathrm{PhDs}$, and to send 100 to 150 scientists to foreign centres of excellence, with a view to covering deficiencies in areas such as: biochemical engineering, downstream processing, cell culture, etc. 
This effort must be accompanied by the establishment of relevant courses for specialist engineers and technicians. It is anticipated that the National Biotechnology Centre will play a decisive role in this training effort.

At least 100 scientists are going to be recruited into the public sector so as to reinforce Spanish biotechnology. At least 35 of these new posts will be in the CNB.

\section{Instrumentation and Utilities}

This part of the programme will concentrate on two actions:

Support for the acquisition of equipment and instruments of middle to high price for the $\mathrm{CNB}$ and other public sector laboratories.

Creation of regional centres of excellence in biotechnology, associated with the $\mathrm{CNB}$ and other public institutes in their scientific environment. Financing is expected to be a mixture of national and regional. The creation of at least five such regional centres is foreseen.

\section{Financing of $R \& D$ Projects}

According to needs identified and the scientific and technological possibilities, research and technology development will be supported, with emphasis on the following priority areas:

a) basic research in biotechnology (3 areas)

b) agro food and agro-industrial aspects (6 areas)

c) health (4 areas)

d) industrial technology (5 areas)

e) biodegradation and pollution control (3 areas)

Ninety projects in universities and public laboratories, and between 35 and 40 concerted $R \& D$ projects are expected to be partly financed by industry, over a three year period within the five years of the programme.

\section{International Relations}

The participation of public research centres in European Community programmes will be actively supported. Special fellowship programmes will be established for graduates speaking Spanish or from the same geographical area. In the CITED-D, the Research Programme related to the 500th anniversary of the discovery of America, a number of projects in biotechnology have been established with Latin American collaborators.

\section{National Biotechnology Centre}

The creation of a National Biotechnology Centre was one of the specific objectives of the Biotechnology Mobilising Programme. Designed to house some 300-350 scientists this Centre of Excellence will require solid support during the launch phase. Such support will be provided by the Mobilising Programme.

Such is the significance of this venture that it is best considered apart from other aspects of the Mobilising Programme, although of course it will interact with all parts of that Programme. Staff Training

STAFF TRAINING

The Centre should be able to commence training of high calibre staff by the middle of 1989, through the organisation of courses and specialised workshops. A graduate fellowship programme will be initiated at the outset, with due regard to the specific needs that must be met in Spain. In accordance with its international interest the National Centre of Biotechnology will have a specific programme of scholarships for graduates from Latin American and African countries. About 15 such scholarship places are envisaged.

In the early stages it is envisaged that senior staff will be supported by 4 Visiting Professors, 15 graduate technicians and engineers, 20 laboratory technicians and some 20 young postdoctoral scientists.

EQUIPMENT AND UTILITIES

During the launch phase some 400 million ptas will be required.

PROJECT FINANCING AND COLLABORATIVE RESEARCH WITH INDUSTRY

The National Biotechnology Centre is expected to participate on a competitive basis for projects and funds managed by either government or industry.

\section{Management}

The Mobilising Programme is to be managed by a Programme Committee consisting of scientists and technologists. They will take the 
responsibility of making proposals according to scientific merit, technological interest and economic practicability in the following areas:

1. Personnel selection for their training in Spain and in foreign centres of excellence;

2. Infrastructure endowment (utilities and equipment);

3. Selection and funding of research projects and contracts with industry after appropriate peer review procedures;

4. Evaluation and follow up of results obtained;

5. Modifications to the Programme in consultation with both academia and industry;

6. Temporary programming of the aforementioned actions and coordination with related programmes, especially those of the CDTI;

7. Direct promotion of $R \& D$ programmes of special interest not covered by existing recommendations.

\section{Priorities}

In accordance with the needs identified by the Programme Committee, taking into account the scientific and technological competence available in Spain the following fields will be promoted by the Programme:

General Interest:

- Development of systems for genetic manipulation in organisms of interest for biotechnology;

- Development of animal and plant cell cultures related to their potential applications in biotechnology;

- Development of enzymatic and other biochemical processes with potential biotechnological application.

Agriculture and Food Area:

- Genetic improvement in plant breeding:

- Nitrogen fixation;

- Improvement of fermentation processes (wines, dairy products, fermented drinks);

- Improved microbial starter cultures;

- Bioconversion of lignocellulose materials

- Pesticides.

Health Area:

- New generation antibiotics;

- Immunology: vaccines, diagnostics, antigens, allergens;

- Blood proteins;

- Peptides, proteins and enzymes.

Industrial Area:

- Microbial mining;

- Recovery of heavy metals;

- Organic acids;

- Bioconversion-bioreactors.

Biodegradation and Pollution Control:

- Residue and effluent biotransformation;

- Microbial ponds for water purification;

- Microbial purification of metal contaminated waters

Predicted Cost of the Programme

\begin{tabular}{|lccc|}
\hline Item & Millions of pesetas & Millions of ECU & \% of total cost \\
\hline Staff training & 1622 & 11.2 & 18 \\
Researchers and contracted personnel & 1380 & 9.5 & 15 \\
Infrastructure & 2000 & 13.8 & 22 \\
Projects & 1600 & 11.0 & 17.5 \\
R\&D industrial concertation & 2240 & 15.5 & 24.5 \\
Business plan, other expenses & 270 & 1.9 & 3 \\
Totals & 9112 & 62.9 & 100 \\
\hline Note: running costs (salaries, maintenance etc.) of the research system are not included in the \\
budgeting
\end{tabular}




\subsection{THE UNITED KINGDOM}

Roy Smither

\section{Introduction}

During the last half century biotechnology has undergone radical changes. Historically British scientists and technologists have played a key role in this development.

\begin{tabular}{|ll|}
\hline Table 1. A few dates in the history of UK biotechnology \\
\hline 1796 & Smallpox vaccination, Jenner \\
1843 & World's first agricultural research station founded at Rothamsted \\
1923 & Isolation of insulin, Macleod e al \\
1928 & Discovery of penicillin, Fleming \\
1946 & Large scale penicillin production, Glaxo \\
1950 & Food preservative antibiotic, nisi, NIRD \\
1950 s & Modified penicillins, Beecham \\
1953 & Cephalosporins, Oxford \\
1957 & DNA structure, Crick, Wilkins and Watson \\
1958 & Interferon, NIMR, London \\
1961 & Insulin structure, Sanger \\
1967 & Foot and mouth disease vaccine, ARC \\
1975 & Marek's disease vaccine, ARC \\
1980 & Monoclonal antibodies, Milstein \\
1980 s & Pruteen, ICI \\
1980 s & Fungal protein for human consumption, RHM \\
1984 & Cloned oil palm trees, Unilever \\
\hline
\end{tabular}

\section{Government Spearhead}

In 1980 the Spinks Report paved the way for accelerated development in both industrial and academic biotechnology. More than 20 recommendations were made, of which most have been implemented. The Department of Trade and Industry, DTI, took over the lead responsibility for biotechnology and in 1982 the Secretary of State launched a campaign to foster the development of biotechnology in industry with the objectives shown in Table 2.

\section{Table 2. Five key objectives of DTI support}

- Raise awareness of opportunities for biotechnology - consultancy support

- Raise level of industrial research \& development - innovation support

- Improve biotechnology infrastructure - culture collective, information services

- Identify and tackle strategic weaknesses - expensive agricultural raw materials

- Identify and promote sectors of biotechnology that represent particularly

important opportunities for UK

To implement these priorities the Government Chemist established a Biotechnology Unit, BTU, staffed by civil servants and secondees from industry. With eight staff the BTU has been effective in ensuring the proper appraisal of proposals for support from industry. The BTU has also been pro-active in identifying and promoting biotechnology sectors of industrial significance, described in more detail later.

\section{Key Objectives}

\section{Awareness}

The Department's initiative in supporting biotechnology is part of a wider scheme known as Support for Business', which also embraces other key technologies. Various levels of support were available to companies (ranging from large multinational to the novice, one man start-up) to employ a consultant to provide specialist skills that the company did not possess. The BTU had more than 100 candidate consultants which it could call upon. Discontinued now, largely because of its success, the DTI provided almost $£ 0.64$ million for consultancy support. Waste treatment proved to be a surprisingly interesting sector. Consultancy support was followed up to assess the impact achieved. A high level of success was achieved as judged by further development within a company, according to the follow-up studies.

Other awareness raising activities include the launch of a pilot scheme to provide fermenters to secondary schools, support to the Open University to produce a series of videos, and the publication in 1984 of the Directory of British Biotechnology. A second edition was produced by a private company at the end of 1986. 


\section{Research and Development}

Support for innovative research encourages companies to spend more on high risk projects that would not have proceeded otherwise. This involves the largest element of spending to date. A grant of up to $25 \%$ of eligible costs is payable to a single company, but no single project has received support for more than three years. About half the 200 proposals received have been funded. Company support for the projects outlined is estimated at around $£ 50$ million (April 1987 figures) with DTI support at $£ 13.179$ million. Additional support for collaborative research exceeded $£ 10.323$ million.

Although biotechnology is moving at a fast pace, it is too soon to see any commercial benefits, although some R\&D projects are beginning to bear fruit. Two examples of the fruits of R\&D support are (i) ICI Agricultural Division - production of polyhydroxybutyrate, PHB, from micro-organisms. (ii) Amersham International - the development of the Amerlite, luminescent immunoassay system.

\section{Infrastructure}

Although the DTI takes the central role in supporting industrial biotechnology, many other Departments are concerned with aspects of health, agriculture, environment, energy etc. Co-ordination is maintained by the Interdepartmental Committee on Biotechnology, ICBT, for which the BTU supplies the secretariat. This co-ordinating activity has resulted in the production of a simple guide to UK regulations and regulatory bodies, a document of particular value for companies new to biotechnology. The BTU also provides the secretariat to the Industrial Consultative Committee on Biotechnology, chaired by a DTI Minister and consisting of senior industrialists. Its terms of reference are to identify and recommend to government, priorities and policies that encourage the exploitation of biotechnology by UK industry.

The BTU underpins certain strategic technologies by major funding of two public sector laboratories, widely regarded as centres of excellence: Harwell and the Centre for Applied Microbiological Research, Porton.

To facilitate access to data from the UK's 9 microbial culture collections, the BTU has instigated the formation of MicIS, the
Microbiological Information Culture Service. MiCIS went 'on line' in March 1987 and enables subscribers to make cost savings on microbial selection. It is hoped that MiCIS might eventually become part of a pan-European data bank.

A DTI survey on regulation revealed that the UK regime is regarded as sensible, pragmatic and generally preferable to other national regimes. It allows innovation to flourish, while offering adequate safeguards to the worker and consumer. Patenting has produced problems, particularly with regard to the basic patentability of biological innovations. Plants cannot be patented in the UK, although the DTI's view is that the protection offered under the Plant Varieties Act is no longer adequate. The ICBT is of the view that UK law on patents should be harmonised with the European Patent Convention in restricting access to cultures deposited for patent purposes. The DTI feels that UK law must change to harmonise it with the situation in the USA and elsewhere.

With regard to control of genetic manipulation, the DTI is concerned to avoid the imposition of new controls on industry, except where clearly justified. In view of the anticipated large increase in type and frequency of environmental release, it is likely that the existing Advisory Committee for Genetic Manipulation case-by-case review system may need revision. The OECD report of 1986 provides a framework for new controls. The DTI has recommended to the European Commission, EC, that risk assessment should figure largely in new biotechnology programmes.

The DTI is prepared to co-ordinate UK industrial input into the EC risk assessment programme and assist in making links with European and other countries. It is keen to stimulate interest in an awareness campaign about biotechnology aimed at the general public, to dispel any ill-formed public perceptions, especially with reference to planned release.

Most organisations active in biotechnology have representation on appropriate committees. Two bodies stand out at present, the British Coordinating Committee for Biotechnology, $\mathrm{BCCB}$, representing professional bodies and the Association for the Advancement of British Biotechnology, $\mathrm{AABB}$, acting for industry and open to companies, non-profit organisations and individuals. 


\section{Priority Sectors}

Because the scope of biotechnology is so broad, the BTU has analysed the technology on a sectoral basis, taking into account the following aspects: market characteristics, UK sectoral characteristics, technology development characteristics, the relevant UK technology base and a suggested strategy for future development. An action plan gives five sectors a priority status:

- Enzymes (biotransformations)

- Diagnostics (biosensors)

- Agriculture

- Food

- Process plant/instrumentation

It is believed that these sectors, taking into account UK strengths and weaknesses, will afford the country major opportunities in future.

Gradually the major biotechnology firms are agreeing with the notion that collaborative research, particularly at the precompetitive stage, is a sensible and viable solution to very costly research, especially when the DTI is prepared to fund up to 50\% of programme costs. Successful ventures include the development of biosensors by Amersham International, Thorn EMI and the National Institute of Medical Research and also the development of the novel food, mycoprotein developed in collaboration by Rank Hovis McDougal and ICI. Examples of the larger consortia are listed in Table 3, below. The largest of these, the Plant Gene Tool Kit' is a £3million/3 year programme involving 11 companies, 2 universities and 2 research institutes, which will develop routine methods for the transfer of genes into plant material. Each participant has free access to all research results.

\begin{tabular}{|c|c|c|}
\hline \multicolumn{3}{|c|}{ Table 3. DTI Sponsored consortia } \\
\hline Consortium & Objective & Members \\
\hline rDNA and antibiotics & $\begin{array}{l}\text { To improve understanding } \\
\text { and control of antibiotic } \\
\text { production }\end{array}$ & $\begin{array}{l}4 \text { firms }+ \text { SERC at } 6 \\
\text { universities }\end{array}$ \\
\hline $\begin{array}{l}\text { Institute of } \\
\text { Biotechnological Studies }\end{array}$ & $\begin{array}{l}\text { To extend useful life of } \\
\text { immobilised biocatalysts } \\
\text { in bioreactors }\end{array}$ & 7 firms at 3 universities \\
\hline Leicester Biocentre & $\begin{array}{l}\text { To improve expression of } \\
\text { foreign proteins in yeast }\end{array}$ & 5 firms at 1 university \\
\hline Plant gene tool kit & $\begin{array}{l}\text { To develop gene } \\
\text { manipulation techniques } \\
\text { for crop plants }\end{array}$ & $\begin{array}{l}11 \text { firms at } 2 \text { universities } \\
\text { and } 2 \text { institutes }\end{array}$ \\
\hline $\begin{array}{l}\text { Enzyme supplementation } \\
\text { of animal feeds }\end{array}$ & $\begin{array}{l}\text { Make low grade animal } \\
\text { feeds suitable for non- } \\
\text { rumants }\end{array}$ & $\begin{array}{l}7 \text { firms at } 2 \text { research } \\
\text { organisations }\end{array}$ \\
\hline $\begin{array}{l}\text { Rapid microbiology using } \\
\text { ATP bioluminescence }\end{array}$ & $\begin{array}{l}\text { Development rapid } \\
\text { detection and enumeration } \\
\text { systems for bacteria in } \\
\text { industrial situations }\end{array}$ & $\begin{array}{l}5 \text { research organisations } \\
\text { and many firms }\end{array}$ \\
\hline
\end{tabular}

Even when 5 or 6 firms collaborate, large research programmes are expensive. This expense can be reduced if a university or research organisation is used as the focus for the establishment of a club with a specific research activity. This situation allows members to tackle problems of general interest, producing state of the art reports for the benefit of members. It is expected that membership fees cover at least 50\% of the costs so that viability is ultimately linked to industrial interest. The BIOSEP club focusing on downstream processing and separation technology involves over 50 companies, some foreign. The DTI supports a number of clubs and could consider the support of others.

The organisations that can be supported are listed in Table 4 .

\section{Training}

The universities and Research Councils undertake most of the basic research and provide the kernel of trained manpower for industrial biotechnology. The quality of basic research in the UK is high and arguably 
second only to the USA, with its huge resources. Generally the UK provides the right blend of talent for its industrial needs, although there may be shortfalls in specific areas such as immunology. The education system in the UK is flexible enough to be able to respond rapidly and redress any adverse trends. Education is thus in a state of dynamic equilibrium, carefully pivoted to cope with the increasing demands of industry.

\begin{tabular}{|l|}
\hline Table 4. Who Does the DTI Support? \\
\hline Single companies directly \\
Companies $\quad\left\{\begin{array}{l}\text { Other companies } \\
\text { Consultants } \\
\text { Research organisations } \\
\text { Educational establishment } \\
\text { Hospitals }\end{array}\right.$ \\
Consortia of companies (and other organisations) \\
Clubs \\
Centres of Excellence \\
Certain public bodies \\
Certain foreign companies wishing to research and manufacture in the UK
\end{tabular}

Clearly to achieve the right blend of academic and industrial talent requires large resources and a co-ordinated approach from government. To this end the BTU, along with a strong DTI Regional office network, works closely with the four relevant Department of Education and Science (DES) Research Councils. Significant liaison is maintained with the Biotechnology Directorate of the Science and Engineering Research Council, SERC, set up in 1981 with separate resources for funding research. The emphasis of the Directorate's support is for high quality science and technology in the university sector, which, while addressing basic problems, will also provide information from which industry would benefit in the short or long term. Its priority sectors listed below, Table 5, sensibly complement those of the BTU. Much of SERC supported research is also through the medium of club or collaborative activities.

To ensure that the UK does not miss out on some of the exciting work conducted at the AFRC and MRC research institutes, each research council has spawned a company, backed by city investment, which has exclusive rights to certain areas of work conducted in their respective institutes Celltech, which exploits much of the MRC monoclonal antibody developments is now the world leader in bulk monoclonal production Agricultural Genetics Company, AGC, unlike Celltech, does not have its own laboratories, but acts in a venture capital role to ensure exploitation with industry of high calibre research in certain AFRC institutes.

\begin{tabular}{|l|}
\hline Table 5. SERC biotechnology directorate, priority sectors. \\
\hline Process engineering \\
Bioconversions \\
Animal cell biotechnology \\
Plant cell culture \\
Whole plant biotechnology \\
Host-vector systems \\
Biosensors and bioelectronics \\
Protein engineering \\
\hline
\end{tabular}

\section{Public Sector Funding of Biotechnology}

Since the definition of biotechnology, as used by different funding bodies is variable, it is difficult to estimate precisely how funds have been allocated.

\begin{tabular}{|c|c|}
\hline \multicolumn{2}{|c|}{ Table 6. Government R\&D funding of biotechnology in the UK } \\
\hline Source & Commitment £million \\
\hline Medical Research Council, MRC & 27 \\
\hline Agricultural and Food Research Council, AFRC & 21 \\
\hline Natural Environmental Research Council, NERC & 1 \\
\hline Science and Engineering Research Council,, SERC & 3 \\
\hline University Grants Committee, UGC & $3 *$ \\
\hline Ministry of Agriculture, Fisheries and Foods, MAFF & 4 \\
\hline Department of Trade and Industry, DTI & 6 \\
\hline Other government departments & 2 \\
\hline Total & $67^{*}$ \\
\hline
\end{tabular}

The MRC distinguishes between work with a clear intent to produce something of commercial value and basic research, but classes it all as biotechnology. In contrast, SERC spending by the Biotechnology Directorate is included above, but the support to relevant bioscience research is far greater. 


\section{International Collaboration}

The DTI is keen to encourage international collaboration in certain areas of biotechnology. The UK plays an active part in the EC Biotechnology Action Programme and would like to see this further developed, providing it involves industrial collaboration. Things should be better in the EC Framework Programme as there are agreed priority sectors, clear objectives for evaluation and a relationship between Framework and Eureka. Eureka's philosophy involves the exploitation of advanced technologies with a global sales potential best achieved collaboratively within Europe, where companies lead in identifying and conducting projects. Biotechnology has had until now a rather low profile in Eureka for a number of reasons. Within certain sectors such as pharmaceuticals, the notion of near market collaboration is countercultural, as the companies have a long tradition of self sufficiency. However DTI has come dose to stimulating collaboration in vaccine development. There could well be more potential for Eureka in the diagnostics area, where technology is changing at a prodigious pace and all European companies are threatened by US majors. A particularly important, but hidden, aspect of Eureka, relates to its value as a lever for regulatory change.

There is also scope for bilateral collaboration between companies in different countries. Examples include Celltech and the Japanese companies, Sumimoto Corporation and Sankyo, as well as Delta Biotechnology and the US company Stroh.

I have outlined UK collaborative programmes covering a wide range of biotechnological interests. The UK would be willing to internationalise these if other countries would make equal contributions. The areas identified as contenders for international involvement include protein engineering, the genetic manipulation of plants as well as the industrial use of agricultural surpluses. Equally we would be happy to consider other countries' suggestions and help to identify possible industrial participants for such collaboration, especially under Eureka.

\section{Inward Investment}

Many overseas companies are becoming interested in the UK as a centre for investment and R\&D in biotechnology, not least because of its record of a commonsense approach to product regulation, and effective and predictable approval processes. US biotechnology companies have already invested in manufacturing facilities for healthcare, biochemicals, biosensors and micropropagation. They have been attracted by the same combination of excellent manufacturing sites, strength in life science R\&D, and high quality clinical trials that have made the UK the predominant European country for US pharmaceutical investment for many years. Examples are Welcome and Schering Plough who both recently obtained UK Government approval for the sale of $\alpha$-interferon, a major event in the development of therapeutics through biotechnology.

The BTU works closely with the Invest in Britain Bureau to attract further investment. Seminars have been held in the USA, Japan and other Far Eastern countries to persuade companies in those countries that the UK is the natural focus for investment to meet the needs of the European market.

\section{Conclusion}

It is the belief in the UK that the prime motivator of biotechnology is industry, although this is complemented by a fair fiscal and regulatory regime. The country has a lively and successful biotechnology industry, with tariff free access to the European Market of over 400 million people. It is a centre for growth in which products can be developed and marketed quickly. It has a strong academic base and a large pool of highly trained manpower. With its regional investment grants and its highly developed private financial sector, the UK is one of the preferred locations for biotechnology.

There are numerous opportunities for improved international collaboration and the UK is ready to do its part in seeking parties for projects appropriate for collaborative research.

\section{Postscript}

Since January 1988 a change in DTI policy has transformed the focus of industrial support for technology, including biotechnology.

The emphasis is away from providing support to individual companies and now concentrates on exploitation of technology through collaboration. There are several ways in which the DTI, with other government Departments in some cases, will encourage and finance collaborative research: 
LINK encourages companies to undertake joint, pre-competitive but industrially relevant research with the academic base. Biotechnology programmes have been agreed in eukaryotic genetic engineering ( $£ 4.7 \mathrm{M} / 4$ years), biotransformations ( $£ 4.0 \mathrm{M} / 4$ years), selective drug delivery and targeting (£3.0M/5 years) and food processing sciences

(£14.0M/5 years), whilst a further programme of protein engineering is in the pipeline.

National collaborativel general industrial reasearch programmes encourage collaboration between companies in precompetitive research outside the specific focus of LINK, and may or may not involve academics.

EUREKA encourages industrially led projects with EC or other European partners. These should both strengthen European technological capability in world markets and contribute to the completion of the Single European Market (1992)

Up to $50 \%$ government funding is available for all of these schemes. 


\section{COMMENTS}

Luis Ramiro Alfonsin

\section{By His Excellency Mr., Ambassador of Argentina to the EEC}

It is an honour for me to be able to participate in this Seminar on Biotechnology in Europe and Latin America' in the company of a group of scientists, industrialists and government officials.

Some aspects of biotechnology are presented as one of the most stimulating sciences of our time.

In Latin America, one has managed to successfully manipulate some of the most traditional aspects of biotechnology, such as the improvement of plant and animal species.

Our progress is not as obvious in other sectors of more recent discoveries such as new genetic engineering techniques.

Some scientists agree that progress in biotechnology will have a negative effect on developing countries. Others think that it will be difficult for poor countries to benefit from numerous advances which take place in this sector.

I personally think that no futurologist feels at his ease when his forecasts do not come true. But whatever the final result, Latin America will not be able to remain outside the development of biotechnology. This is why I enthusiastically congratulate the organisers of this seminar for their idea to gather men and women of both continents showing an interest in these themes.

Many of the businesses created to use genetic engineering for the discovery of new processes or products have resulted from the vision and enthusiasm of the scientists who have imagined the potential results from these recently introduced tools. It seems that it was not very difficult for these pioneers to communicate their enthusiasm to investors willing to take the risk and to accompany them in their dreams. This was followed by hardship, frustrations, and elusive results for which one has had to make an effort in order not to be despondent. This is how this young industry has had to mature in a very short time and without giving way to despair, has had to learn to be satisfied with more realistic objectives or be more patient, but always keeping in mind the possibility of making surprising discoveries.

One sees today an industry which is starting to move steadily, even if this sector is not suitable for people without courage or for those who do not want to take risks.

I imagine that from the point of view of the scientist, the researcher, the present climate of biotechnology is something like an ideal environment. It appears as an enormous sector presenting great possibilities which researchers, as well as entrepreneurs and scientific research policy makers, should distance before deciding where to direct the efforts and the resources, which are always limited.

It is certain that Europe will attempt to dedicate itself to highly sophisticated small scale productions wherein costs and ingredients coming from plants or animals have a relatively small importance.

I think that there are three different sectors in which biotechnology can bring fundamental advances for humanity.

Undoubtedly what is most important is the pharmaceutical sector which appears to present an almost unlimited range of possibilities both for medicines as well as for diagnoses. Possible progress in the pharmaceutical sector is the one most stimulating our imagination and our hope. Results which were hardly envisageable have been obtained this century. This brings to mind insulin, tissue plasminogen activator, vaccines against malaria or Chagas' disease which preoccupies us so much, or more efficient vaccines against foot and mouth disease and of course, the whole area of immunology and fight against cancer.

A different fundamental sector for biotechnology is the production of basic chemical products from material of organic origin. One should start to be ready for the time of scarcity of reserves of raw materials. For several decades, Argentina has produced acetone, butane and ethane from cereals and sugar through fermentation. Brazil produces large quantities of ethane through fermentation of sugar. Microbial processes could help to solve problems relating to environmental contamination and at the same time produce fuel and chemical products. In contradiction to these advances, it is surprising to see large projects proposed that are based on European 
agricultural production which is produced at terribly high cost and which requires enormous subsidies in order to be able to be used for these industries. It seems to me more reasonable to install these industries in countries with a more efficient system of agriculture where the investors will not depend on political change, protectionism or to subsidies.

The other interesting sector for biotechnology is agricultural production. Possibilities for improvement are also nearly infinite and the needs of humanity are very urgent in this sector. However, Europe also needs to correct immediately the expensive inefficiency of its agriculture. It would be wrong to continue to produce at exceedingly high costs whilst sheltering itself inside a protectionism which causes prejudices. Europe needs to start looking for new varieties of cultures which do not require as many fertilisers or pesticides to be ready when the time comes to honestly compete at a world level. The research in new symbiotic systems has to be intensified which will enable the exploitation of atmospheric nitro-gens for surface plants reducing costs and water contamination. It is very interesting to discover new varieties adaptable to zones of little rainfall or finding methods of cultivation which reduce water requirements. The utilisation of bacteria in the fight against the effect of frost seems very promising and it should be possible to introduce new cultures to areas having short summers. Europe could profit from annual cultures producing cellulose at acceptable costs. It is also interesting to find saline resistant cultures.

The European consumer will want many agricultural products to regain the flavour and the quality they had in the past and which were lost because of technical methods that can be only used in the community market which allows high prices independent of quality.

With so much work to be achieved, it does not seem reasonable to devote efforts and scarce funds to try to increase production by high cost technical methods which make it impossible to resist honest competition. The Latin American technicians want to collaborate in this scientific research. Latin American agriculturists are not afraid to compete on an equal footing with European agriculturists. It is not possible to compete with funds from the North American Treasury or Community budgets.

This does not mean that Latin America must give up participating in the development of sophisticated techniques. On the contrary, we feel obliged to reduce the gap which separates us from the industrialised countries in the biotechnological sector, as well as in other scientific and industrial sectors, especially if we take into consideration the fact that the development of some products, without economic interest for the developed countries, may be of vital importance for us.

Europe and Latin America can collaborate and be complementary in this exciting adventure of biotechnology. I think that there will be advances in research, development and production which could be realised at a lower cost in Latin America than in Europe.

This first meeting will help to make experts from both continents familiar with each other. I expect that this meeting will be successful. Interesting ideas for all participants will be brought forward. I hope that at the end of the meeting they will already be thinking of the next seminar. Along these fines, I allow myself to urge the organisers, enriched by the experience gained during this meeting, to continue with the idea of maintaining this kind of contact which will certainly be of great interest to both regions. 


\subsection{OVERVIEW OF LATIN AMERICAN ACTIVITIES IN BIOTECHNOLOGY}

Karl Simpson

It has been too easy for Europeans to dismiss Latin America as being a collection of underprivileged third world states. It is true that debt continues to be a pressing problem for almost all of Latin America's economies, but in 1988 Brazil and Mexico seem to be regaining the confidence of the world's financial centres. Argentina's recent re-entry into democracy is a further cause for optimism and in Chile (ignored in SOBELA) there is growing hope of a democratic conclusion to Pinochet's regime.

Each of the Latin American states, but most notably, Argentina, Brazil, Mexico and Venezuela, has a substantial business class, enjoying access to European standards of education, health and consumer commodities. Industrial output, while largely low-tech, has increasingly focused upon new technologies emerging from the R\&D based cultures of the USA, Japan and Europe.

In several areas of biotechnology a number of Latin American nationals have made substantial contributions. Cesar Milstein (Argentinean citizen) gained his Nobel Prize for work on hybridomas. It cannot be overlooked that in the event of substantial improvement in living and working conditions, Latin America may be able to call upon the skills of many technically qualified expatriates working in centres of excellence throughout the world. Both Argentina and Brazil have traditions of excellence in basic research and have a number of long established and internationally recognised laboratories.

In 1984 the United States Office of Technology Assessment, OTA, suggested that the Latin American market for biotechnology would be exploited by the USA and Japan. Europe, they reasoned would not be able to establish a presence. By 1988 it has become clear that Europe has moved and is now establishing a strong position in Latin America, although Japan's involvement is very strong. Paradoxically it is the USA that has failed to capitalise upon its proximity to Latin American markets. This has been aggravated by a hostile reaction to Latin America's generally 'Laissez Faire' approach to intellectual property protection.

A growing sense of community is emerging in Latin America and this is manifest by an increasing number of joint activities in areas of strategic interest such as biotechnology. The states of the Andean Pact have effectively devolved national responsibility to the supra national responsibility of the Pact. Professional Associations such as Brazil's ABRABI (Associação Brasileira de Empresas de Biotecnologias) are spreading throughout the region.

A sense of realism prevails in most of the states. It is realised that commitment to biotechnology is not immediately going to force a dominant position in world markets. It seems more likely that the short term advantages of developments will be a reduction in foreign imports, such as AIDS diagnostic kits or insulin. In the long term it is possible that relatively cheap labour costs and a well educated professional class might permit the exploitation of world markets on an equal footing with companies in Europe, the USA and Japan.

One of the consequences of SOBELA may well be the establishment of joint ventures that realise these hopes in the short term.

In the following lines we paint a very brief picture of biotechnology in the states presented at the SOBELA meeting.

\section{Argentina}

The election of a civil government in 1984 gave impetus to the National Biotechnology Programme, PNB, launched in 1982. Nobe Laureate, Dr Luis Federico Leloir, heads the Executive Committee of the PNB. With major support from the National Department of Science and Technology and the National Council for Scientific and Technical Research, as well as significant input from other ministries, the PNB is orientated towards servicing the needs of industry. Human health and livestock health and improvement have been defined as priorities for the PNB. In the period 1984-86 US\$1.6 million was divided between 90 projects in 70 centres. From a European point of view such expenditure would seem to be spread very thinly. 
Training is a key issue in the Programme and grants are made available for scientists to train in foreign countries. The EEC has been asked for financial support in this area. The PNB is orientated towards international collaboration and links with several countries in Europe exist already (Belgium, France, Federal Republic of Germany, Italy and Sweden). Internal cooperation and particularly the cementation of strong industry/university links are essential if the Programme is to meet its goals. Individual entrepreneurs are expected to take the initiative in establishing such finks, while the PNB will support the activities of a representative body, the Argentine Forum of Biotechnology. Launched in 1986 its President, Dr Aldo Ferrer is also President of the Bank of the Province of Buenos Aires.

A fiscal package has been agreed which accords credit certificates to a value of $60 \%$ of the cost of approved projects. This is also available to foreign entrepreneurs investing in Argentina.

Argentina has developed particularly dose links with Brazil, manifest in the foundation of a joint centre for biotechnology. On this background of activities there is an increase in interest and investment in industrial biotechnology.

\section{Brazil}

With an academic tradition in the biological sciences dating back to the mid 19th century Brazil has a commanding lead over its neighbours. São Paulo, active from the beginning has become the focus for institutes operating in the areas of vaccines, immunology etc. Successful public health campaigns are making progress in the control of typhus, leishmaniasis and other diseases. Agrobiotechnology has achieved some notable successes, using very traditional technologies. Brazil has established commercially valuable Maize hybrids.

There is a strong commercial base for exploiting innovation in biotechnology. Agroceres, the seeds company, was founded in the 1940s. In the 1960s Brasilsul and Agropecuária were founded. These companies can trace their evolution to the work of plant geneticist, Cruz Martins in the 1920s. Other distinguished Brazilian geneticists include Dr Theodosious Dobzhansky.
Companies with an interest in biotechnology have guaranteed Brazil self sufficiency in insulin production, and are looking closely at the local manufacture of products including the interferons. Arable and stock farming is served by many universities and institutes, several of which now boast competence in gene manipulation. Selection of soya cultivars has resulted in an $80 \%$ increase in nitrogen use efficiency in the last 20 years. Genargen has established germ plasm banks, which will help offer protection from North American, Japanese and European companies hoping to exploit Brazil's vast phytochemical resources.

Biotechnology in Brazil cannot ignore the Proalcohol Programme, although this is coming under increasing internal criticism. The programme did much to stimulate local biotechnology related industry and incited contacts with companies such as Denmark's Novo, who became interested in the prospects of selling starch converting enzymes. Perhaps the long-term benefit of the programme will have been the accumulation of know-how in all aspects of the sugar complex.

Although the Ministry of Science and Technology accepts responsibility for control and co-ordination of Brazilian biotechnology, the government, as in Argentina, looks to entrepreneurs to provide the industrial impetus to the programme. More so than anywhere in Latin America industrialists have come forward to launch companies in areas ranging from micropropagation of plants to AIDS diagnostics.

Examples of companies include: Biobras, interested in the manufacture of genetically engineered insulin. Bio-Planta in association with Native Plants have set up an agrobiotechnology research centre. Cibran, the antibiotics company is implementing rDNA technology in its R\&D facility. Embrapa is a public sector company which has a commitment to the exploitation of Brazil's germ plasm resources.

In the public sector the Oswald Cruz Foundation and the Butantã Institute make a major contribution towards biotechnology R\&D. Many of the new companies will participate in the formation of regional poles of biotechnology, where private/public sector integration will be a feature. This activity mirrors what is going on in France.

In Brazil there is a growing concern that biotechnology may threaten the future of employment in the agricultural industry. Increased 
productivity may seriously damage the organisation of society in areas removed from major cities.

\section{Mexico}

Although Mexico has a number of university departments with competence in several aspects of biological science it is true to say that industrial exploitation of biotechnology is dominated by first generation technology. Such technology is manifest in the production of beers and spirits. Second generation technology is used for the production of antibiotics, amino acids and aspartame sweeteners, but all of this technology has been imported from foreign countries.

Several small scale industrial enterprises have been launched to capitalise upon the market for the products of this technology. Enzymology, based in Monterrey, is a company manufacturing aspartame, phenylacetic acid and related chemicals. Bioenzimas, in Saltillo, Coahuila, is an agrobiotechnology company with interests in improved grain yields, insecticides, giberellic acid and agricultural enzymes.

Modern biotechnological innovations such as micropropagation are being initiated by a small number of firms including: Industrial biogenetics, involved in the micropropagation of strawberries, asparagus and violets; Genin, who are working on immobilised enzyme bioreactors and the Forestal Center of Genetics, dedicated to genetic improvement of forests by micropropagation.

Gene manipulation and hybridoma technology are found only in government funded laboratories and universities. In these centres biochemistry and related sciences have been established since the 1930s. Biochemical engineering degrees are awarded by more than 20 institutions, with 7 centres offering postgraduate training.

\section{The Andean Pact}

\section{Bolivia, Columbia, Ecuador, Peru and Venezuela}

The Andean Pact is a structure similar to the EEC. Most of the member states do not have the resources required to fund major programmes in high technology. Under the auspices of the Pact central facilities and concertation measures optimise those skills and technologies available. An Andean Biotechnology Programme has existed since 1986. Within the members of the pact there is considerable variation in wealth and scientific competence. The Andean Council for Science and Technology has principal responsibility for concertation of biotechnology actions within the Andean Pact.

Bolivia is not advanced, but does have a programme focusing on Embryo transfer between species of South American Camelidae. Work is carried out in the Instituto de Genetica Humana, where a programme on the molecular biology of diarrhoea is also active. In 1985 Peru and Bolivia launched the Andean Mining/Metallurgical Programme, PMMA. One aspect of this titled, biohydrometallurgy, concentrates upon the extraction of metals by microbial leaching.

Columbia has a very ambitious National Biotechnology Programme, but given the present level of trained personnel and appropriate facilities it is difficult to see how the programme can be implemented in its present form.

Ecuador has indulged in some limited biotechnological work since 1983, but a realistic government cannot contemplate a significant National Programme. Training is singled out as the most important requirement in the National Plan for biotechnology. Government laboratories are carrying out R\&D in aquaculture, in collaboration with commercial interests. Inexa SA is a small company carrying out meristem culture in collaboration with university laboratories. Pronatec SA is studying the commercial exploitation of natural extracts. Life SA in collaboration with the Instituto Nacional de Higiene is manufacturing vaccines for animals. Levapan is developing fermentation technology. There is hope that it may be possible to stimulate the pharmaceuticals industry by applying rDNA technology and other aspects of modern biotechnology.

Peru has little infrastructure capable of supporting advanced applications of biotechnology. It is the mining industry which has turned to bacterial leaching as a possible tool for the extraction of metal from unworkable deposits. The government sector has some activities in plant biotechnology. A joint programme with Bolivia, supported by the Federal Republic of Germany expands upon national competence in microbial leaching.

Until recently Venezuela has had the privilege of having the highest per capita earnings in Latin America. Decline in oil revenues is forcing a re- 
evaluation of national goals. Biotechnology is seen as a tool with considerable potential and a programme launched in 1984 concentrates on three major areas: Agriculture, Medicine and Industry. In Agriculture the focus of effort is upon the production of pathogen free plants through somatic hybridisation and tissue culture. The potato and yucca plants are the targets for exploitation. Medical priorities include assault upon regional diseases and the development of competence in monoclonal and polyclonal antibody production to back up a domestic competence in diagnostics targeted at cancer, AIDS and epidemiology. rDNA technology is on the agenda for developing gene probes and therapeutic agents.

\subsection{Argentina}

José La Torre Sara B. de Rietti

\section{Structure and Operation of the National Biotechnology Programme}

The National Programme of Technology (PNB) was created at the end of 1982, even if it only became popular in 1984 with the inauguration of the constitutional government of Doctor Raul R. Alfonsin. The information supplied by this Programme is rich in experience but corresponds to a starting phase. Argentina has a long tradition in biosciences (with three Nobel Prizes) as well as an important pharmaceutical and biochemical industry. In 1984, during the initial phase, there were already numerous high quality research centres in areas linked to the development of biotechnology. Even if the National Programme of Argentinean biotechnology is new, its foundations are solid. The Programme has been organised as an advisory, co-ordinating and financing unity with minimal administration and wide ranging executive powers. The head of the National Department of Science and Technology (SECYT) is directly responsible for the PNB and its management is co-ordinated through the Secretary of Sciences and Technology. The programme has an Executive Committee of four members and an Advisory Committee of twenty members headed by the Honorary President, Dr Luis Federico Leloir, Nobel Prize for Chemistry.

The Advisory Committee represents public and private research centres and State and University Institutes as well as the body linking the industrialists of the biotechnological sector. All the members of the Executive Committee, and nearly all of the members of the Advisory Committee, are specialists in disciplines finked to biotechnology from the various regions of the country. The actual composition of the PNB appears in Appendix A of this report.

\section{R\&D Financing in Biotechnology}

One of the basic functions of the PNB is the granting of subsidies for $R \& D$ related to biotechnology. The word basic is used because $R \& D$ 
administrators know that it is a very powerful instrument in the implementation and shaping of policies. The funds are provided from subsidies budgeted by the SECYT and by support from the National Council for Scientific and Technical Research (CONICET) operating in co-ordination with the Programme.

This specific financing is an addition to that granted by other organisations and sectors of the SECYT with similar aims. One can thus mention the support of the CONICET for selective basic and applied research which at least doubles the value of the PNB grants, and the role of the National Institute of Farming Technology (INTA) which has considerable resources and programmes. Other support is offered by National Programmes of the SECYT related to biotechnological aspects of Food Technologies and Non-Conventional Energies, and subsidies granted by the SECYT through 'Apoyo Institucional', in the same way as the PNB.

The financial support of the PNB is mainly directed to the centres and laboratories of the public sector. In all its other activities, such as the interaction between science and production or international co-operation, those depending on private companies and institutions are also included. In this way the PNB is a common point for public and private initiatives whose realisations very often result from a disinterested collaboration of researchers and private industrialists. Subsidies are granted as a function of standards and priorities established for each programme.

Interested parties have to present a Pre-Project for which approval is indispensable to allow detailed examination of the Project. It is advisable to co-ordinate Pre-Projects with similar topics into an Integrated Research Programme. Financial support is organised as far as possible for a maximum period of three years subject to a control of academic and budgetary administration, which is made by the PNB.

The priorities established by the Programme for the distribution of subsidies are based both on the research topics and their connection with the general development of the sector and with the level of technical innovation reached including the socio-economic impact of the Project. For the productive importance of research it is essential that the results are applied in the most direct way to the production of goods or services.

One of the basic objectives of the Programme is to place the scientific work at the service of the productive activities. This is especially so as Argentina, in its present state of development, cannot afford the luxury of maintaining expensive, non-productive, basic research in a sector such as biotechnology, which historically presents for the country an interesting academic development, and that at the same time offers an enormous productive potential at an international level.

As far as the research topics are concerned, their priority has been established after many long debates and preference has been given to those concerning human health and agricultural livestock production. Productive applications rather than specific research topics have been considered as a determining condition for the approval of a project but this does not exclude a proposal favouring the development of any weakness of the sector.

In particular, priority topics of research are the following: 1) Development of biotechnological processes with special emphasis in the ones which concern the application of advanced biochemical engineering; 2) Biological fixation of nitrogen; 3) Plant biotechnology with special emphasis in molecular biology of plants and cultures of plant tissues; 4) Production of vaccines and biopharmaceutical products; 5) Diagnostic reagents.

Between December 1984 and December 1986, the PNB approved subsidies for a value equivalent to more than US\$1.6 million distributed between more than 90 research projects and various plans for equipment at more than 70 centres and research laboratories throughout the country of which a substantial number are related to biotechnology.

\section{Vocational Training}

Argentina has a rich tradition of professional education in biosciences and has trained high level researchers who work on very advanced topics in several parts of the world. However, in order to cope with this challenge of providing a scientific and technical infrastructure capable of supporting the development of production methods incorporating biotechnological advances, an effort is required in training and re-education which implies a qualitative and quantitative change. The PNB is aware of this situation and in co-ordination with the CONICET has developed an intensive plan of external grants which will be valid from 1987 onwards. The support of the European Community will be sought for the development of this plan and the process of promoting an intense horizontal co-operation with Latin-American countries has begun. 
The PNB has given its support to this for the last three years by the promotion and financing of various activities directed towards the training and re-education of the researchers such as: intensive theoretical courses, seminars and conferences organised by research centres, university and private institutions which has been able to work with foreign or Argentinean specialists living abroad. International co-operation and a growing emphasis on the activities of CONICET has channelled support towards this goal. The purpose of the programme is to intensify activities finked to training in biotechnology in which international co-operation plays an important role. All methods such as doctorate or postgraduate grants and specialists missions are utilised to gain foreign or external support. In the particular case of Argentina the training must reach all levels of university lecturers as well as all aspects of administration because of the scarcity of specialists capable of dealing with scientific projects of the complexity or the extent required for new technologies.

\section{International Co-operation in Biotechnology}

From its inception, the PNB has given preferential attention to everything which is connected to international co-operation in biotechnology. With the objective of using offers of co-operation from countries of higher scientific technological development, Programmes have allowed the realisation of meetings and scientific seminars which officials, researchers and foreign entrepreneurs have attended. In particular, the French-Argentinean meeting in Buenos Aires in 1986 has brought about an important exchange of ideas and created contacts between the biotechnological enterprises of both countries. The 1986 cooperation agreement with Sweden has included five biotechnological projects which have been completed by Argentinean and Swedish Institutes implying an important economic and technical contribution. In 1984 an agreement was made between the Argentinean Republic and the Kingdom of Belgium which foresees the realisation of twelve joint projects including one on wheat covering aspects linked to biotechnology. Additionally, Italy and the Federal Republic of Germany have expressed intentions for co-operation which are expected to be realised before the end of 1987. To promote regional co-operation, taking into account the integral complementary economic policy of the Argentinean Government, the PNB has allowed joint meetings of officials, researchers and entrepreneurs linked to biotechnology with other Latin-American countries, especially Brazil.

It has actively taken part in setting up the Regional Programme in biotechnology for Latin-America and the Caribbean patronized by the PNUD, UNESCO and UNIDO and has a large responsibility for commercialisation, which is of great importance for the development of biotechnology. The first director of the Argentinean-Brazilian Centre in Biotechnology (CABBIO) serving a three-year term is a member of the Executive Committee of the PNB.

\section{Models for Internal Co-operation}

The PNB has started a number of interdisciplinary co-operative activities inside Argentina to realise policy.

The fundamental objective of the Programme is to obtain as close a contact as possible between the productive sector and the research centre as well as the various State run or supported laboratories. This inter-relation is established through active participation of representatives of private enterprises and activities promoted by the Programme, either in national or international meetings or in a Commission or Working Group. The Programme also stimulates the activities of the committees of scientific and industrial co-operation which are encouraged by the CONICET. These committees specify agreements, tasks and results of the R\&D Centre and the nature and amount of payments made by the company consisting of fixed yearly amounts or sales commissions for a fixed period.

Finally, in order to enlarge the market or to incorporate advanced technology which allows the support of large industries the PNB organises meetings between Argentinean and foreign industrialists such as those bilateral meetings between France and Brazil. An example, involving France at the end of 1986, was the mission linked to the biotechnological sector of the EUREKA plan, during which co-operation between Argentinean and French companies was established.

The link between universities and enterprises is established through agreements created by CONICET when there are R\&D centres or university laboratories capable of completing such co-operation. In general, the national universities, particularly the best ones, have experienced a serious 
recession because of the political vicissitudes during the decades prior to the present Constitutional Government which provoked a reduction of the teaching and more qualified scientific staff whose real contribution to the development of biotechnology helps consolidate a recuperation process with which the SECYT is deeply involved.

As for the proposed entrepreneurial models, the PNB prefers the actual entrepreneurs to take the initiatives required in each case. On the contrary it has been concerned with the creation of a representative body where both private associations and enterprises as well as public sector centres linked to biotechnology have a say. This is how the Argentinean Forum of Biotechnology was created in October 1986 whose president is also president of one of the main state banks of Argentina and is presently part of the Consulting Committee of the PNB. The SECYT has created a law promoting development and technological innovation in production. The PNB has taken part in these discussions which were presented to the Congress of the Nation in 1986 and which establish the basis of an institutional rule in this field. Three possible modalities for the execution of entrepreneurial technological R\&D projects have been established: 1) total execution of the project by a national centre of $R \& D$ contracted by the company; 2) execution of the project by the company and a national $R \& D$ centre in which each of the parties must realise distinct and complementary tasks and 3) total execution of the project by the company under fixed conditions determined by the law and subject to a technical and accounting verification by the SECYT. The concept of the national R\&D centre covers laboratories, professor-ships and state institutions (such as the INTA) and others allowed by the SECYT.

The benefit for the company consists of the delivery of fiscal credit certificates for the payment of national tax equivalent to $60 \%$ of the cost of the approved project. This type of benefit is also available to companies of foreign capital established in Argentina and the approval for these projects is given by the SECYT. This is subject to priority criteria fixed by law which takes into consideration the contribution to the national economy and to the promotion of exports.

\section{Scientific and Technological Co-operation between Europe and Argentina}

As already mentioned, Argentina has realised co-operation agreements linked to biotechnology with Belgium, France and Sweden and is in a very advanced preparation stage of programmes for which it shows a great interest, with Italy, and the Federal Republic of Germany.

To reinforce the existing co-operation and the permanent how of information the following is suggested:

a) The initiation of intensive training, education and coaching of the R\&D staff at all levels including the administration of projects within the framework of the plans drawn up by the PNB.

b) The completion of joint R\&D projects in biotechnology on topics considered as priority ones by the PNB with the exchange of specialists and contribution to the technological equipment needed by Argentina.

c) The establishment of industrial plants which bring advanced technologies and employ local personnel at all levels. They are obliged to dedicate a substantial percentage of profits to R\&D for which local professionals trained by investors are responsible and a substantial percentage of production to export.

d) Association of European companies with Argentinean companies in which the effective transfer of technologies brought by the European side is certain.

e) Establishment of international services of scientific and technological data bases related to biotechnology which are accessible to public and private entities in Argentina.

f) Creation of information and documentation committees in European cultural diffusion agencies operating in Argentina.

In particular, support is needed to set up a R\&D centre for industrial farming production in the rich damp pampa of Argentina equipped with a system of enormous productive potentiality. The scientific and technological training tasks of the new centre will be closely linked to the production activities of the area characterised by the very interesting 
problems of dealing with the natural environment, plant and animal health and productivity.

\section{ApPENDiX A: DePARTMENT OF SCIENCE AND TECHNOLOGY}

NATIONAL BIOTECHNOLOGY PROGRAMME

\section{Secretary of Science and Technology Dr Manuel SADOSKY}

Co-ordination of the programme

Dra Sara BARTFELD de RIETTI

\section{Executive Committee}

\section{Dr Oscar BURRONE}

Dr Jose LA TORRE

Dr Alberto MARCIPAR

Dr Faustino SINERIZ

Consulting Committee

Dr Luis Federico LELOIR, Honorary President.

Dr Carlos R. ABELEDO, President of the CONICET.

Dr Israel ALGRANATI, Head Researcher of the CONICET, Institute of biochemical research 'Foundation Campomar', Buenos Aires.

Dr Diego DE MENDOZA, Director of the Department of Microbiology of the Faculty of Biological and Pharmaceutical Sciences of the U.N. of Rosario.

Dr Alberto DIAZ, Director of Biosidus SA.

Dr Rodolfo J. ERTOLA, Director of the Centre of Research in Industrial Fermentations, La Plata.

Dr Aldo FERRER, President of the Bank of the Province of Buenos Aires and of the Argentinean Forum of Biotechnology.

Dr Juan GOTTIFREDI, Rector of the U.N. de Salta and Secretary of Sciences and Technology of the National Interuniversity Committee.

Dr Oscar GRAU, Co-ordinator or the Latin-American Network of Biotechnology.

Eng Horacio IRAZOQUI, Director of the Institute of Technological Development for the Chemical Industry, Santa Fe.
Eng Agr Guillermo JOANDET, National Director Assistant and Researcher Consultant of the INTA.

Dr Alberto KORNBLIHTT, Assistant Professor, sector of Molecular Genetics, of the Faculty of Exact and Natural Sciences of the University of Buenos Aires.

Eng Agr Carlos LOPEX SAUBIDET, President of the INTA.

Eng Hugo MACCIONI, Independent Researcher of the CONICET. Titulary Teacher, Chair of Biology, Faculty of Medicine, U.N. of Cordoba.

Eng Enrique MARTINEZ, President of the INTI.

Eng Agr Luis MROGINSKI, Independent Researcher of the CONICET. Institute of Botanics of the North East, Corrientes.

Dra Elsa SEGURA, Director of the Institute of Research of the Department of Public Health. Director of the Institute of Research for Chagas'illness 'Dr Mario Fatala Chaben'.

Dr Hector TORRES, Director of the Institute of Research in Genetic Engineering and Molecular Biology and Dean of the Faculty of Exact and Natural Sciences of the University of Buenos Aires.

Dr Raul E. TRUCCO, Director of the PROTEP Programme (CONICET-CITEP), Mar del Plata.

Dr Ruben H. VAlLEJos, Director of the Centre of Photosynthetic and Biochemical Studies, Rosario. 


\subsection{BRAZIL}

Antonio Paes de Carvalho

\section{Background to Brazil's Biotechnology Policy}

Brazilian biotechnology began in the middle of the last century when pioneer work was carried out in São Paulo on various specialized fields of microbiology, notably bacteriology, mycology, protozoology, phytopathology and virology. As a result of the work of these pioneer groups the first institutes devoted to research on bacteriology, vaccines, and clinical, pharmacological and immunological analyses sprang up in São Paulo.

Brazil benefited greatly from the results of these early initiatives which paved the way for successful public health campaigns against epidemics of yellow fever, trypanosomiasis, leishmaniasis, bubonic plague and typhus. Important institutes such as Oswaldo Cruz, Adolfo Lutz, Butantã and Pasteur were also set up, and these are now fully competent to maintain national progress in the field of biotechnologies applied to health.

In agriculture the technical progress made in the early days of biotechnology studies applied to seed production made Brazil the second country in the world, after the United States, to obtain uniform and highyield hybrid maize from fines developed from local genetic stock.

As a result of this process of development and consolidation of various branches of traditional biotechnology, in particular those related to agriculture, the first private enterprises in the seed production markets such as Agroceres sprang up in the forties followed, in the sixties, by Brasilsul Agropecuária.

As regards the development of genetics, the basis of modern biotechnology, Brazil's historical development has its roots in the work of Cruz Martins, in 1924, together with the Instituto Agronômico de Campinas. The development of Brazilian genetics is also connected with international names such as Dr Dreyfus, Dr Krüg, Dr Brieger and Dr Dobzhansky who were the pillars of Brazilian genetics and left behind many disciples who became top-level researchers.
Again in the field of health, Brazil is carrying out initiatives in diagnosis methods and biopharmaceuticals of high molecular weight; it is self-sufficient in insulin and is carrying out research into the production of interferon and also has the technology to produce blood derivatives, including human albumin and anti-haemophilic factors.

\section{Arable and Stockfarming}

This represents a great development potential for the country since we now have a number of excellent research institutes and universities covering various areas such as genetic engineering, cell and tissue culture (USP, IAC, UNICAMP, EMBRAPA, IAA, UFRJ, UFVIÇOSA, ESAL, IAPAR), and biological fixing of nitrogen and mycorrhiza (inoculants) (UAPNPBSOLO/ EMBRAPA, UFRGS, CENA, IPT, IAC, UFV and others).

The most impressive example of nitrogen fixing is the result obtained by the constant research carried out over the past twenty years with soya cultivars which, today, can extract $80 \%$ more than their nitrogen needs by biological fixing.

Noteworthy Brazilian technological developments in the field of plant health, owing to their importance and possible uses, are techniques for disease detection, pest control, resistance to herbicides and resistance to diseases and weeds, from endogenous technological development. As regards pest control in particular, it should be stressed that Brazil is one of the first countries in the world to undertake a large-scale project to spray nearly 600.000 hectares with bacullovirus.

Mention should also be made of the experience of Cenargen whose work has proved to be of growing importance for the systematic identification and establishment of active germplasm banks.

\section{Bioconversion and Energy}

The example of Proalcool, among others, is a clear demonstration of Brazilian potential for making use of its bioclimatic conditions, coupled with its technological development, to resolve, using native resources, the serious question of alternatives to oil. In this area, the Department of Industrial Technology of the Ministry for Industry and Trade is investing mainly in the field of alcohol fermentation, aimed at the production of fuel 
alcohol and the genetic improvement of yeasts (direct fermentation of starch to alcohol; this work is being carried out by the Institute of Chemistry of the USP).

This being the case, the Department of Biotechnology of the Ministry of Science and Technology sees itself as an agent of integration and co-operation and acts as national co-ordinator of the Government's biotechnology activities. In this context it should be private enterprise which acts, with public-sector support.

The policy proposed by the Department of Biotechnology, leading up to 1990 , assigns the following roles:

a) Public sector

a.1. guidance, co-ordination and stimulation of biotechnology activities;

a.2. supervision of national work in the sector, so as to take account of the priority economic- and social-development programmes in a long-term strategy;

a.3. participation in production sectors, on a complementary basis, in the national interest and/or in cases where private enterprise is unable or unmotivated to act;

a.4. provision of guarantees for national production;

a.5. establishment of appropriate conditions for full scientific and technological skills to be developed in the sector by the strengthening of research centres and training of teams with guaranteed resources for these activities;

a.6. stimulation and guarantees for the development of national technology and the economic, financial and commercial strengthening of Brazilian enterprise, to ensure that it can compete on an open market.

b) Private sector

b.1 exploitation of the results obtained from technological research in biotechnology, bringing products within reach of society;

b.2 suggestions to the Government, on an interactive basis, of the areas most needing investment for national production; b.3 Raison with areas in which knowledge is generated, with a view to providing conditions for the satisfactory assimilation and dissemination of knowledge.

In order to give substance to this proposal for the integration of scientific and technological development work, by complementing and incorporating the other fields addressed by the Ministry of Science and Technology (CNPq and FINEP), the Department of Biotechnology will have to allocate some US\$60 million for the period 1987-89 over and above the biotechnology budgets of the other areas of the Federal and State authorities (source: SBIO plan of objectives). Approval was recently given for the allocation of resources for the award between now and 1989 of 4650 grants in the country and 2700 abroad, with the aim of stepping up training of researchers and technicians in biotechnology, at home and abroad.

One of the principal means of distributing the above-mentioned resources will undoubtedly be the implementation of the Biotechnology Integration System.

The Biotechnology Integration System (BIS) is a national technical and scientific cooperation network which brings together, under a number of subject headings, the centres of scientific and technological production, devoted to the same line of research or the subsequent development of a product or provision of services using biotechnology.

The system will examine, on the one hand, the critical areas of science and technology to be introduced in the country, with a view to reducing the present difference in level between the national and international contexts and, on the other hand, will have to bring existing know-how in science and technology within the reach of the national production sector, for the development of goods and products.

In this system, input data will be taken to be the information and requests resulting from scientific and technological production, at national and international levels, the production sector, the administrative authorities and related institutions and, in particular, the directives issued by the national government, as embodied in the state biotechnology programmes, which are being implemented in various parts of the country, such as Rio de Janeiro, São Paulo, Minas Gerais, Rio Grande do Sul, Parana and Bahia. 
The input data also include those opportunities offered by international co-operation programmes, with special emphasis on horizontal cooperation, the main example of which, to date, is the Brazil-Argentina cooperation programme.

At the operational level, the BIS will make use of BICs (biotechnology integration centres).

BICs will be structures for co-ordinating centres of acknowledged research capability, organized at state or regional level, intended to support biotechnology application projects integrated with the production sector.

The BICs will take part in the Biotechnology Integration System within the context of activities and lines of research of national interest, managing their activities entirely independently of the sys-tem as regards local and regional integration initiatives.

The administration of the system will be the responsibility of the Department of Biotechnology, and general coordination will involve full representation of institutional bodies and the operational sectors.

The system will have a matrix configuration and will offer as output data the products established in its planned objectives, with feedback based on a system of continuous assessment, to be implemented by general co-ordination.

Therefore it is expected that, coupled with the other initiatives taken at federal and state level, the biotechnology integration system will be a key means of bringing about the quantitative leap that Brazilian biotechnology needs.

\subsection{MeXICO}

Rodolfo Quintero Ramirez Rosa Luz Gonzalez Aguirre

\section{Introduction}

Biotechnology in Mexico is represented by a mixture of research and development as well as industrial and promotional activities realised at different levels of scientific and technological complexity. To evaluate its development and position in the country as well as estimating the potential and possibilities of technico-economic multi-lateral co-operation, it is necessary to define and delimit this techno-logical sector using the parameters available. The definition of biotechnology used in this document is as follows:

A multidiscipline which has evolved from the initial objective of manipulating micro-organisms in the production of goods and ser-vices to include the use of enzymes, as well as vegetal or animal cells, aggregates or components thus amplifying its practical utilisation and now including the modification of superior organisms such as plants and animals. All this was made possible thanks to technological breakthroughs such as: recombinant DNA, cell fusion, cell and protein immobilisation, molecular synthesis with enzymatic characteristics which have all reinforced fermentation technology, culture of plant and animal cells and enzymatic technology(Quintero, 1985)

A classification of the different types of biotechnology is shown in Table 1 (González and Zermeño, 1986; Quintero, 1985). Based on these elements, the first part of this work presents a general view of the situation in Mexico describing the biotechnological activity in research and development, industry, vocational training and legislation.

In the second part, some potential options for technico-economic cooperation between the members of the EEC and Mexico are discussed within the framework of shared interests and equality of rights and duties. 


\begin{tabular}{|c|c|c|c|c|}
\hline \multicolumn{5}{|c|}{ Table 1. Categories of Biotechnology } \\
\hline Parameter & First generation & Second generation & Third generation & Alternative \\
\hline Age & Ancient & Modern & Modern & New Application \\
\hline $\begin{array}{l}\text { Scientific } \\
\text { Content }\end{array}$ & $\begin{array}{l}\text { Elementary and } \\
\text { Advanced }\end{array}$ & $\begin{array}{l}\text { Elementary and } \\
\text { Advanced }\end{array}$ & Advanced & $\begin{array}{l}\text { Elementary and } \\
\text { Advanced }\end{array}$ \\
\hline $\begin{array}{l}\text { Technological } \\
\text { Content }\end{array}$ & $\begin{array}{l}\text { Elementary and } \\
\text { Advanced }\end{array}$ & Advanced & $\begin{array}{l}\text { Elementary and } \\
\text { Advanced }\end{array}$ & Elementary \\
\hline $\begin{array}{l}\text { Type of } \\
\text { organism or } \\
\text { its part }\end{array}$ & Micro-organisms & Micro-organisms & $\begin{array}{l}\text { Micro-organism } \\
\text { Plant cell } \\
\text { Animal Cell }\end{array}$ & Micro-organism \\
\hline $\begin{array}{l}\text { Origin of } \\
\text { Organism }\end{array}$ & Natural & Natural & $\begin{array}{l}\text { Natural } \\
\text { Artificial }\end{array}$ & Natural \\
\hline $\begin{array}{l}\text { Type of } \\
\text { product }\end{array}$ & Food, Chemistry & $\begin{array}{l}\text { Food, Chemistry } \\
\text { Health, Energy } \\
\text { Agrochemicals, } \\
\text { Contamination } \\
\text { Control }\end{array}$ & $\begin{array}{l}\text { Farming and } \\
\text { Forestry, Food } \\
\text { Chemistry, } \\
\text { Health, Energy, } \\
\text { Contamination, } \\
\text { Control }\end{array}$ & $\begin{array}{l}\text { Farming, Food } \\
\text { Energy }\end{array}$ \\
\hline $\begin{array}{l}\text { Interaction } \\
\text { with Socio- } \\
\text { Economic } \\
\text { setting and } \\
\text { Environment }\end{array}$ & $\begin{array}{l}\text { Control of nearly } \\
\text { all variables that } \\
\text { can be influenced }\end{array}$ & $\begin{array}{l}\text { Control of nearly all } \\
\text { variables that can be } \\
\text { influenced }\end{array}$ & $\begin{array}{l}\text { Control of nearly } \\
\text { all variables that } \\
\text { can be influenced } \\
\text { The process is } \\
\text { adapted to the } \\
\text { setting }\end{array}$ & $\begin{array}{l}\text { The process is } \\
\text { adapted to the } \\
\text { setting }\end{array}$ \\
\hline $\begin{array}{l}\text { Technology } \\
\text { Users }\end{array}$ & $\begin{array}{l}\text { Reduced and } \\
\text { Intermediary }\end{array}$ & $\begin{array}{l}\text { Reduced and } \\
\text { Intermediary }\end{array}$ & $\begin{array}{l}\text { Reduced, } \\
\text { Intermediary and } \\
\text { Intensive }\end{array}$ & Intensive \\
\hline $\begin{array}{l}\text { Range of } \\
\text { Application }\end{array}$ & $\begin{array}{l}\text { Growth Level of } \\
\text { Demand }\end{array}$ & $\begin{array}{l}\text { Growth Level of } \\
\text { Demand } \\
\text { Modification of } \\
\text { Demand } \\
\text { New System of } \\
\text { Demands }\end{array}$ & $\begin{array}{l}\text { Growth Level of } \\
\text { Demand } \\
\text { Modification of } \\
\text { Demand } \\
\text { New System of } \\
\text { Demands }\end{array}$ & $\begin{array}{l}\text { Growth Level of } \\
\text { Demand } \\
\text { Modification of } \\
\text { Demand }\end{array}$ \\
\hline $\begin{array}{l}\text { Developed } \\
\text { Applications }\end{array}$ & Simple & Simple Complex & Simple Complex & Simple \\
\hline Source: Gon & & & & \\
\hline
\end{tabular}

\section{The Present Situation Development and Industry}

FIRST GENERATION INDUSTRIAL BIOTECHNOLOGY

Industrial biotechnology of the first generation constitutes the most important category in Mexico in terms of market size. The main products are fermented drinks, milk derivatives, cereal derivatives, industrial yeasts for baking, alcohol (for industry or for consumption), acetic acids and edible mushrooms (Table 2). The most important application of this type of biotechnology is found in the fermented drink sector of which beer is the greatest user (González and Zermeño, 1986; Quintero, 1985)

Research and development in this biotechnological technique is scarce and production is oriented towards an internal market. Generally speaking, traditional Mexican biotechnology in the last decades has been in a state of saturation due to a sustained population growth with a better standard of living and because international trade has been of a marginal nature (González and Zermeño, 1986).

Despite the fact that there are different ranges of products, the traditional biotechnology industry is of a strongly oligarchical nature. The competition between these industries from one point of view and the actual maturity of technology from another, has led the stronger enterprises to rationalise and standardise production through more and more automated processes.

The most consolidated industries such as those for fermented drinks like beer, wine products and liqueurs are important sources of employment not only in production and distribution of these products but also of the raw materials, and are factors of economic development of other products. This industry has reached a state of prolonged saturation. Part of the industry handles high production volumes which helps improve product quality and productivity and which represent the most important conditions to maintain and improve the internal market as well as to enter into international markets (González and Zermeño, 1986). 


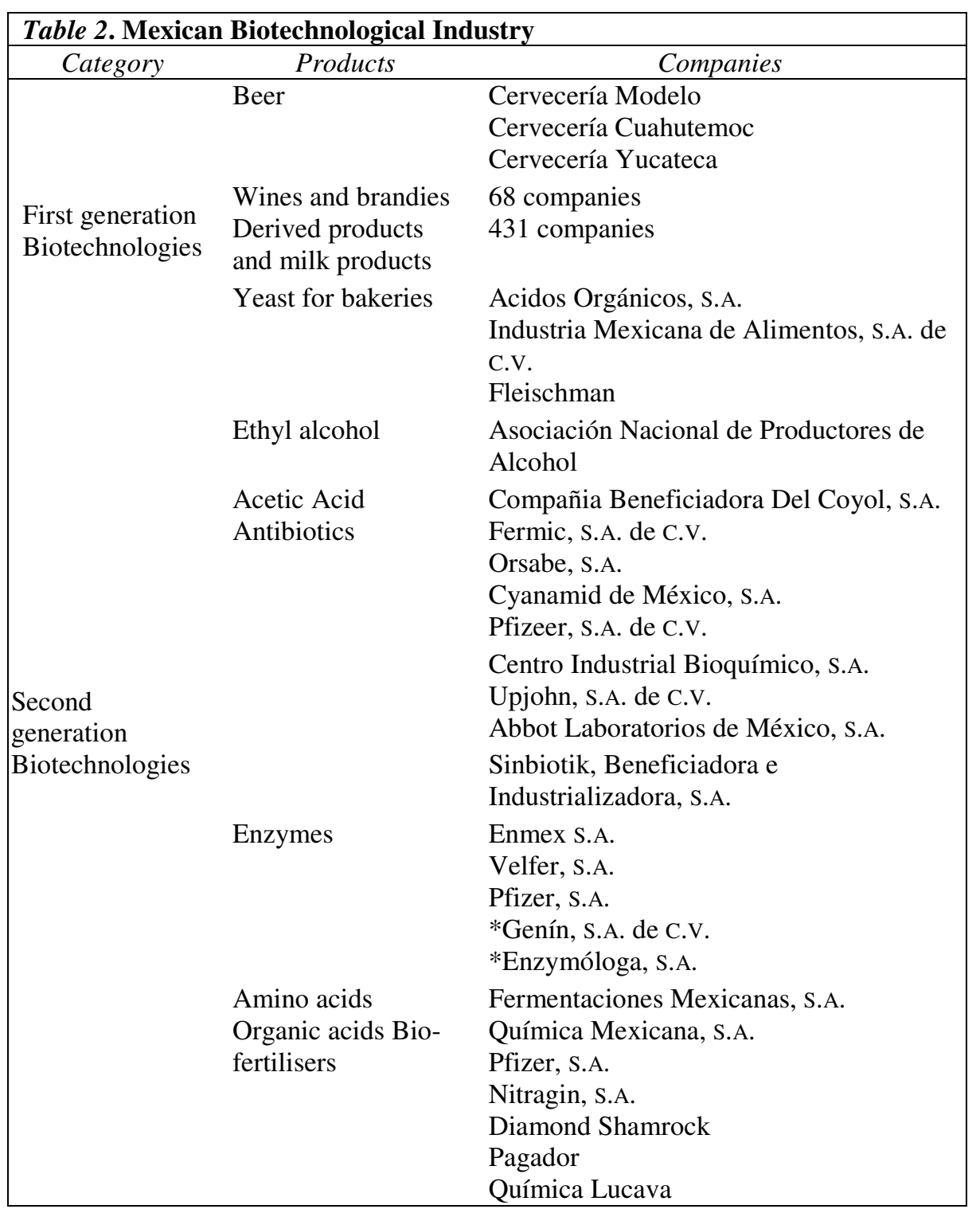

\begin{tabular}{|c|c|c|}
\hline Category & Products & Companies \\
\hline $\begin{array}{l}\text { Second generation } \\
\text { Biotechnologies }\end{array}$ & Vaccines & $\begin{array}{l}\text { Gerencia General de Biológicos y } \\
\text { Reactivos } \\
\text { Laboratorios Dr. Zapata } \\
\text { Other companies** }\end{array}$ \\
\hline $\begin{array}{l}\text { Third generation } \\
\text { Biotechnologies }\end{array}$ & Micro-propagation & $\begin{array}{l}\text { Biogenética Industrial, S.A. } \\
\text { Mexicana de Propagación de } \\
\text { Plantas }\end{array}$ \\
\hline \multirow[t]{3}{*}{$\begin{array}{l}\text { Alternative } \\
\text { Biotechnologies }\end{array}$} & Methane & $\begin{array}{l}\text { Digestors exist in various parts of } \\
\text { the country }\end{array}$ \\
\hline & Silage & Various parts of the country \\
\hline & Cell usage & Various parts of the country \\
\hline \multicolumn{3}{|c|}{$\begin{array}{l}\text { * Dedicated to technological development. } \\
\text { ** Dedicated to the final packaging. } \\
\text { Source: Quintero, } 1985\end{array}$} \\
\hline
\end{tabular}

Such increments in quality and productivity could be achieved by small technological innovations. These are likely to take place in the near future since a number of fermented drink manufacturers have shown an interest in national research groups working on solutions to service problems in the industry.

The consumption of food products such as edible mushrooms and milk derivatives can be increased by encouraging lower cost and smaller scale production processes than those predominant in the country.

The culture of mushrooms and other macro mycological products can be developed both for export and internal consumption at production sites that make use of favourable climatic conditions and by intensively using manpower (Leal, 1985).

It must be emphasised that the production of edible mushrooms constitutes one of the rare possibilities of biotransforming lignocellulosic residues without submitting them to a pre-treatment which is presently still very expensive. This is of great importance because of the abundance of this type of residue in the country (Table 3) (Leal, 1985).

The production of macro mycological products with this approach requires that the culture technology is adapted to the local conditions from the point of view of both availability and investment as well as cost and 
skill of local labour. The same applies to the development of new methods for the preparation of substrates from local raw materials, new types of materials and locally adapted climatisation (Leal, 1985).

\begin{tabular}{|lc|}
\hline \multicolumn{2}{|c|}{ Table 3. National Agricultural Production in 1978 (NPTSD, 1984) } \\
\hline Agricultural harvest & Production (tons) \\
\hline Corn straw & 16.613 .532 \\
Sorghum straw & 2.492 .874 \\
Wheat straw & 1.723 .670 \\
Bean straw & 1.320 .716 \\
Sugar cane straw & 1.205 .557 \\
Wheat husks and brans & 750.172 \\
Barley straw & 534.746 \\
Oat straw & 131.321 \\
Non-commercial fruit and vegetables & 79.855 \\
Rice husks & 59.309 \\
Peanut straw & 43.379 \\
Chickpea straw & 25.134 \\
Total & 24.980 .265 \\
\hline Source: Leal, 1985. \\
\hline
\end{tabular}

Milk derivatives such as traditional cheeses can be integrated into the production of milk, which in turn forms part of the normal agricultural production, through fermentative processes using the subproducts or the excesses as forage. This improves the profit of small producers and reduces competition in the production of the basic grains which form the popular diet (Viniegra, 1986).

The above implies the availability of specialised equipment, technical assistance and a means of commercialisation for the small cheese cooperatives. These services are necessary to encourage and sustain the production chain at an elementary technological level and include information, transport and distribution methods in order to commercialise the products in a way adapted to the local conditions (Viniegra, 1986).

SECOND GENERATION BIOTECHNOLOGY

This type of biotechnology is actively used in the production of antibiotics, amino-acidic enzymes and in the treatment of effluents as shown in Table 2. All the technology used comes from abroad (González and Zermeño, 1986).
A well equilibrated investment in this category of global bioindustries does not apply to groups of products in the same way. For this reason foreign investment appears to dominate the area of enzymes and certain antibiotics. However, there are national and public enterprises which are dedicated to the production of amino acids as well as penicillin and some of its derived products (Quintero, 1985).

Because of the international effervescence in biotechnology a number of new, mostly small sized, national enterprises have appeared in this biotechnical category (Table 4). It must be emphasised that newly created enterprises have a more open attitude towards research and development contrary to the vast majority of second generation biotechnological enterprises in which this type of activity is almost non-existent.

\begin{tabular}{|ll|}
\hline Table 4. New Biotechnological Organisations in Mexico \\
\hline Enzymology (Monterrey, N.L.) & $\begin{array}{l}\text { Phenylglicina (enzymatic), phenylacetic } \\
\text { acid, phenylalanine and aspartame (of its } \\
\text { interest) }\end{array}$ \\
Bioenzimas (Saltillo, Coahuila) & $\begin{array}{l}\text { Improved grains, insecticides, gibberellic } \\
\text { acids and other agricultural } \\
\text { biotechnological products (enzymes) }\end{array}$ \\
Industrial biogenetics (México D.F.) & $\begin{array}{l}\text { Micropropagation of strawberries, } \\
\text { aspergus, Violet (tissue cultures) }\end{array}$ \\
Genín (México D.F.) & $\begin{array}{l}\text { Technological development of } \\
\text { immobilised enzymes }\end{array}$ \\
Forestal Center of Genetics (Texcoco, \\
Edo of México) & $\begin{array}{l}\text { Genetics improvement and forest } \\
\text { micropropagation }\end{array}$ \\
\hline Source: Quintero, 1985 & \\
\hline
\end{tabular}

Research groups are concentrated in universities, centres and institutions of higher education (Table 5). It is in this type of biotechnology that the country has the largest and most qualified research group even if most of its efforts are devoted to applied research and technological development. However, no technological development in this area has been applied to production methods (González and Zermeño, 1986; Quintero, 1985).

In the case of enzymes and new pharmaceutical products the internal market is insufficient and the competition in international markets is very difficult. With amino acids, the important conditions for industrialisation exist but expansion presents problems with economic 
resources. This type of problem also affects the unicellular proteins and the microbial polysaccharides. In the case of xanthans, for example, the technology has developed in this country and has reached a semicommercial level with a specific application for the product. However, at a national level, there are insufficient economic resources to make use of it even if it shows a high profitability in the current conditions in Mexico (González and Zermeño, 1986; Quintero, 1985).

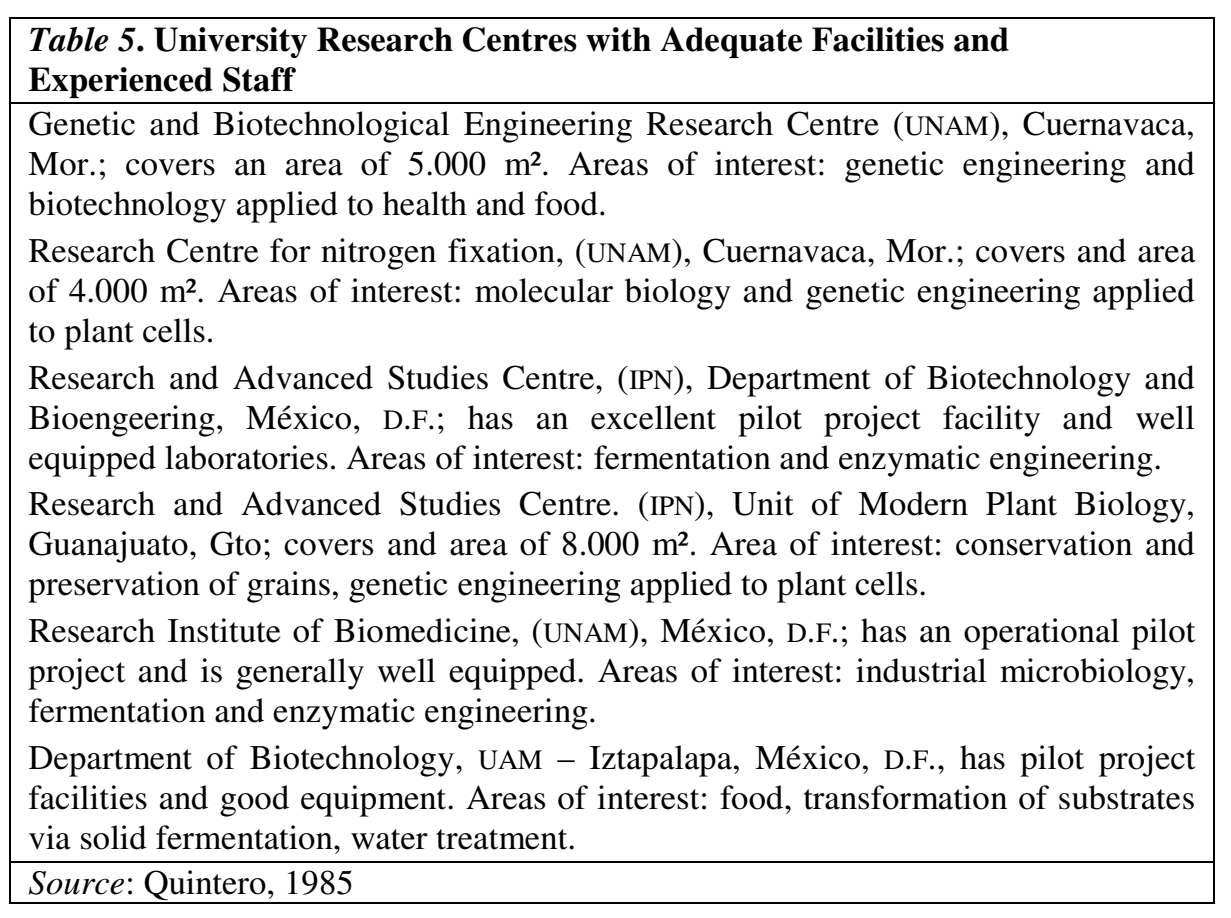

Other countries show a great interest in acquiring this technology. This could be very positive for national production to increase its confidence in the local development and the resources obtained from royalties could be used to finance national developments.

The lack of economic resources is critical within all categories of biotechnology but particularly for second generation types as, even if they have rapidly restricted themselves, they offer better short term possibilities because of the world wide scale of development (González and Zermeño, 1986; Quintero, 1985).

\section{THE NEW OR THIRD GENERATION BIOTECHNOLOGY}

Micro-organism manipulation work is exclusively restricted to research in centres and higher educational institutions. It is currently being linked with industrial projects especially for the improvement of pharmaceutical processes.

It must be emphasised that pharmaceutical products form the objective of the majority of research projects. They are internationally highly competitive with high development costs and require a long time before commercialisation. Such projects are: human insulin, growth hormones, some vaccines, diagnostical tests, interferons, etc.

There are many qualified research groups in the field of plant cells, particularly cultures of plant tissues (CVT), in the country which, although they presently work on micro-projects, could devote their work to topics of importance in the agricultural sector. Two of the recently created enterprises belong to the plant biology area which covers the technologically less sophisticated aspects of CVT such as the micropropagation (González and Zermeño, 1986; Quintero, 1985).

The genetic engineering of plants is becoming a well structured sector. A centre has just been opened and what is most important is the integration of very high level human resources. For animal cells the human and technical resources are scarce compared with the previous sectors and they are mainly dedicated to the development and industrial production of vaccines against measles and poliomyelitis but with some work on embryo transplants at a commercial level.

These elements, even if briefly presented, allow the following prospects for third generation biotechnology to be considered.

\section{MICRO-ORGANISMS}

This sub-category could have an important role in the improvement of micro-organisms both for known second generation processes and for future modifications to processes used in the manufacture of existing products. Both cases link the existing research groups in the country and firmly localise their participation in the chain of complete biotechnological processes. The second option requires an understanding of the present 
productive methods and capacity in the technologies which are intended to be substituted (González and Zermeño, 1986).

New products, and particularly pharmaceutics, have greatly reduced prospects as the human and economic resources (especially the latter) are limited and the risk involved in new developments is very high.

\section{Plant CELls}

Simpler applications such as micro-propagation of "cultivaresvaliosos' have a considerable potential market because highly skilled scientists are available to develop the techniques and, if moderately skilled technicians are trained, the use of the available climatic conditions, the market access and the cost of labour will enable the country to both compete with external markets and open new markets. Also, the economic resources required to make use of these productive activities are not excessively high compared to those required by other types of developments (González and Zermeño, 1986; Robert, 1985).

The production of 'metabolites secundarios' using plant cells in biological reactors for the processing of raw materials of for agricultural, food and pharmaceutical products is a sector in which highly skilled scientists are available but in insufficient number to cover all the stages necessary for complete technological development. Moreover, an adequate infrastructure is needed to allow development to be taken beyond the laboratory stage (González and Zermeño, 1986).

There are, however, important limitations related to the type of products. For example: the development of new pharmaceutical products is very expensive, very long, and involves many risks. The production of natural substances for food use, such as flavours, aromatics and colorants is less costly and faster than the previous processes but experiences high international competition which demands a very careful selection of development projects.

Without any doubt the most important potential application related to plant cells is a genetic improvement. Both in Mexico and internationally, agricultural production currently faces a series of limitations which are: a lack of cultivable land, environmental stress, sickness and plague (González and Zermeño, 1986; Robert, 1985).
For each of these limitations, plant biotechnology has an answer which could be the development of varieties adapted to ever better controlled conditions (which is not much different from the 'green revolution') or varieties more and more adapted to socio-economic and environmental conditions. This type of answer could revolutionise agricultural production, have large repercussions on industry and the economic and social activity of each country. This would particularly apply to those less industrialised countries which, for their development requirements and the diffusion of this kind of technology, could have access to the benefits that the latter could relatively easily provide (González and Zermeño, 1986; Robert, 1985).

In the particular case of Mexico, the conditions allow both solutions to be applicable. There are highly qualified scientists available who can develop either of the technological solutions. The food policy adopted will determine which solution will be emphasised (González and Zermeño, 1986)

Before ending this topic, it is very important to note that genetic manipulation research groups are aware that they do not replace the traditional work of agronomists and botanists. For this reason, a contact with them is being sought and mechanisms are being pre-pared to promote interdisciplinary research.

Finally, the existing animal cell groups, even if very scarce, have extensive experience in producing vaccines and they have recently succeeded in using a national development for the industrial production of anti-measles vaccines with diploid cells and are actively working to modify the production of polio vaccines (the diploid cells instead of monkey renal tissues). The experience of these groups forms an excellent basis for the promotion of this sector especially for the improvement of processes.

\section{ALTERNATIVE BIOTECHNOLOGY}

Less conventional biotechnologies, which try to use residues in order to produce biogas or cattle feed, should also try to solve the problems of regional contamination caused by specialisation in cattle and agriculture. However, the scale of production must be maintained in order to reach intermediary dimensions. To presume that these biotechnologies exist in the rural environment only at the level of one or several families is very optimistic (González and Zermeño, 1986; Quintero, 1985). 
From this viewpoint, alternative biotechnology is better considered as a subcategory of all other biotechnologies rather than a separate category in which its scope of application would be very limited and the technological content more basic (González and Zermeño, 1986; Quintero, 1985).

Based upon previous success, the development and growth potential of certain biotechnologies applied to aquaculture, the cultivation of mushrooms or other species and food processing will be stimulated as conventional technology is more compatible and the impact much greater. What is most important is to acquire experience and create a basis to be able to benefit from the possibilities offered by biotechnology. This also means a change in the tendency towards specialisation. As long as diversity is increased by more integrated processes which are less intensive in capital and energy and more adapted to the environment, the profits related to the scale of production will be less and less important and the level of development of the country will be raised with less socio-economic and environmental costs than the current mode of development (González and Zermeño, 1986; Quintero, 1985).

\section{Vocational Training}

The history of scientific training in biotechnology in this country dates back to the second half of the thirties at the time when the studies of enzymology and biological chemistry were created and oriented towards industrial biological processes. Both studies later became biochemical engineering (1957). Nowadays, a degree in biochemical engineering can be obtained at more than twenty educational institutions distributed throughout the country (Quintero, 1985, 1986)

Postgraduate training began early in 1970 and the seven institutions which offer such courses are fisted in Table 6. All offer master of science degrees and, recently, two of them offer doctorates. Most of the postgraduate programmes cover the most general sectors of biotechnology (fermentation and enzymatic technology, genetics and genetic engineering) and two are dedicated to plant biotechnology. At first degree as well as at postgraduate level the main subjects are oriented towards the food sector without particular specialization (Quintero, 1986)

\begin{tabular}{|clll|}
\hline \multicolumn{3}{|l}{ Table 6. Postgraduate Biotechnology Programme (Leal, 1985) } & \\
\hline No. Institution & Programme & Degree \\
\hline 1. Research and Advanced Studies Centre/D.F. & Biotechnology & $\mathrm{M}$ \\
2. Research and Advanced Studies Centre/D.F. & Biotechnology & $\mathrm{M}$ \\
3. Research and Advanced Studies Centre/Irapuato & Biotechnology & $\mathrm{M}, \mathrm{D}$ \\
4. Technological Institute of Mérida/ Scientific & Biotechnology & $\mathrm{M}$ \\
& & \\
5. Centre of Yucatan & Bechnological Institute of Veracruz & Biotechnology & $\mathrm{M}$ \\
6. Technological Institute of Veracruz & $\mathrm{M}$ \\
7. Research Institute of Biomedicine, National & Biotechnology & E, M, D \\
& Autonomous University of México & \\
\hline E = Technical training & & \\
M = Master's degree & & \\
D = Doctorate & & \\
Source: Quintero, June 1986. & & \\
\hline
\end{tabular}

Historically, vocational training in biotechnology has only covered biochemical engineering with postgraduate degrees in biotechnology and bioengineering but the available number of positions related to biotechnology is much higher in the country. In plant related biotechnology there are more than 100 higher education establishments for agriculture and biology with an equal number of experimental sectors.

There are several institutions which offer a master's degree in a speciality linked to biotechnology and which have had doctorate programmes in biochemistry, cellular and molecular biology, genetics, microbiology, chemistry and biology. Moreover, since the Mexican government considers biotechnology as a priority sector, it assigned special resources for all of the scholarships granted in 1985 for postgraduate study abroad by the National Council of Sciences and Technology (NCST) of which $17 \%$ corresponded to biotechnology.

The basis of the above indicates that degree level training in biotechnology is actually based on the possibilities of absorption by the existing biotechnological industry which requires technicians of an average level of education. In the case of the first generation, the specialised technical assistance is obtained from abroad through suppliers of machinery and equipment; in the case of the second, most enterprises are branches of multinationals which import this technical assistance and, as far as both the 
third and alternative ones are concerned, they are non-existent. (González and Zermeño, 1986).

Finally, at postgraduate level, the system is new and has produced in the last ten years more than twenty master's degrees in sciences and more than forty without any degrees. An exhaustive diagnosis was recently completed in the food sector in which biotechnology is included for practical reasons. As a result of this work, specific recommendations have been made for each of the postgraduate programmes in the country relating to food with the expected result being a sharp increase or development in the short or middle term of this level of biotechnology. Relative to this, it is important that scientific training at a national level must be directed towards the interdisciplinary work and to the development of integrated biotechnological processes through educational programmes and research linked to the production sector (VTG, 1985).

\section{Legal Aspect}

The country's legal requirements relating to technological and economic multilateral cooperation are: patent and trademark laws, laws relating to registration and control of technological transfer and those concerned with foreign investment.

The patent and trademark law dates back to 1976 and has recently been reformed and expanded partly in dose relationship with biotechnology. According to Mexican law the following are not subject to patents:

1. The plant and animal species, their varieties, and the essentially biological processes necessary for their creation, including those of a genetic type.

2. The biotechnological processes for pharmaceutics, general medicines, drinks and food for animal consumption, fertilizers, anti-plague products, herbicides, fungicides or biologically active products.

3. Chemical products, chemico-pharmaceutics, general medicines, food and drinks, food for animal consumption, fertilizers, herbicides, fungicides and biologically active products.

4. Food and drinks for human consumption as well as processes to obtain or modify them.
According to the present Mexican legislation, a patent does not cover biotechnological processes and products; however, it is possible to obtain a certificate of invention for processes and products mentioned in paragraphs b) and d).

The invention certificate is a non-exclusive right granted by the Mexican State for a period of 14 years to allow the holder to commercialise an invention. Anyone else who is interested in commercialising the product pays the certificate holder the corresponding duties. This certificate is used when a patent is not granted because the invention is of social benefit where a monopoly is not permitted.

The invention certificate allows royalty payments to be made even if it is not possible to practically apply the invention because it does not oblige the exploitation of the invention.

This is not the same with a patent where exploitation of the invention should start within three years from the date of it being granted. If it is not exploited, the patent becomes invalid and the invention becomes part of the public domain.

Mexican law states that one can register a certificate of invention concerning any invention susceptible to be protected as a patent. This has been done to give an incentive to individual creativity via advantages and to protect the rights of research and development workers who are concentrated in universities. If the only means to protect their inventions was through patents, they would lose their rights if they did not manage to exploit them within a three-year period.

Technological transfer in Mexico is regulated by laws covering the control and registration of the transfer of technologies and the use and exploitation of patents and trademarks (LCRTT). The main objective is not exclusively to maintain control over technology transfer but also to ensure that its own technological work is promoted. The organisation responsible for the enforcement of this law is the Secretariat for Commerce and Industrial Promotion (SCIP), which controls the National Register of the Technological Transfer (NRTT).

Item 2 of this law catalogues the legislation used within the national territory where registration is compulsory. Those related to technical and economic multilateral co-operation in biotechnology are 
presented in Table 7. These acts or agreements are covered by Mexican laws, by treaties or international agreements of which Mexico is part and which are applicable to the case.

Table 7. Licences, Contracts and Activities Related to the Multilateral Cooperation in Biotechnology that have to be registered with the 'RNTT'.

- Licence for use or authorization for improvement or exploitation of an invention which is patented or covered by an invention certificate.

- Licence or authorization to use commercial names.

- Communication of technical knowledge through plans, diagrams, models, instructions, specifications, personnel training and education or any other means.

- Technical assistance of any type.

- Provision of basic or detailed technical assistance.

- Operational services or company administration.

- Advising, consulting and supervising services if controlled by foreign nationals, or their representatives, independently or their residence.

- Computer programs.

The following are required to apply for registration with the NRTT: Mexican nationals as well as foreigners living in the country, foreign agencies or foreign branches established in Mexico as well as nationals residing outside the country but who are involved with agreements or contracts which affect the country.

Registration is necessary to be able to benefit from the profits, the encouragements, the assistance or the facilities foreseen in the governmental plans and programmes, as well as for the establishment or expansion of industrial enterprises. The legislation contained in article number 2 which has not been registered with the NRTT (or which has been cancelled by the SCIP) is null and void and cannot be made valid in front of any authority and its application cannot be requested by the national courts.

The law also provides a chapter covering the causes allowing the NRTT to reject an application for the following reasons: the protection of the applicant regarding any detriment to his financial situation, his administrative autodetermination or any restriction to his R\&D activities.

Within the legal framework, and in policies directly related to foreign investment, the law enforced since 1973, which promotes Mexican investment and regulates foreign investment, together with the policy of selective promotion of foreign direct investment, which started in 1984, clearly promotes the direct foreign investment in biotechnology. From this viewpoint, it is important to note that one of the most regulated foreign investment sectors, that of secondary petrochemical derivatives, has recently been freed from the restriction of using national capital for the majority of investments relating to the expansion of the range of products. Current technological advances (including biological technology) have made this possible using either different processes or raw materials which are not petrochemical. In Figure 1, the percentage participation of foreign direct investment is presented according to the country of origin.

\section{Options for Technico Economic Co-operation}

Biotechnology has direct applications in most of the sectors of economic activity and can be used at different scientific and technological levels with a variety of raw materials for similar types of products. This results in a group of technologies with different characteristics and requirements and with a tendency for interchange between them. The countries meeting on this occasion are all at different levels of technological advancement. For this reason it is important to consider any proposal related to these differences and this is why the possibilities of application of the various options are closely related to the scientific and technological capacity of the participants and to the level at which their political, economic, and social interests can merge.

\begin{tabular}{|lc|lc|}
\hline \multicolumn{1}{|c|}{1984} & $\%$ & \multicolumn{1}{|c|}{1985} & $\%$ \\
\hline United States & 66,0 & United States & 67.4 \\
Federal Republic of Germany & 8.7 & Federal Republic of Germany & 8,0 \\
Japan & 6.3 & Japan & 6.1 \\
Switzerland & 5,0 & Switzerland & 5.3 \\
Others & 14,0 & Others & 13.2 \\
\hline Sources: SCFI, 1986 & \\
\multicolumn{2}{|l}{ Fig. 1. Foreign investment per country of origin (percentage) } \\
\hline
\end{tabular}

It is important to underline that, in Mexico, studies have been made for some time to define the sectors which require efforts to be made to develop and diffuse biological technology whilst taking into account the requirements, the scientific and technological capacities, the economic 
resources and the availability of raw materials (González and Zermeño, 1986; Quintero, 1985, 1986).

The establishment of priorities was no easy task for a country with the population size of Mexico. However, it has become apparent that the multitude of applications made possible by biotechnology cannot be coped with simultaneously. Accordingly the applications selected for a recent study on the evaluation of opportunities in biotechnology, which was financed by the National Council of Science and Technology, are: food, agriculture and health (Quintero, 1985, 1986).

Taking into account the above factors and other elements considered as important for the scientific and technological policy of the last 15 years in order to make sure that research has an economic and social impact, (NPTSD, 1984; NPST, 1978) as well as the situation concerning biotechnology, (Quintero 1985) we consider that the following types of co-operation are the ones which would have the greatest potential for success.

\section{Vocational Training}

High level technical training is mainly oriented towards interdisciplinary education and research programmes which integrally cover the different stages of the development process of biological technology. The sectors which should be mostly emphasised are: design, sizing and operation of biological reactors as well as recuperation and purification of products. This type of training should preferably be given in research laboratories of the production sector as well as in technological development centres.

\section{RESEARCH AND DEVELOPMENT}

R\&D collaborations should be aimed at the realisation of research projects in previously mentioned applications. The possibilities offered by biotechnology for the co-existence of differing levels of technology would allow different countries to participate in precise activities throughout the project according to their respective scientific and technological capacities. As a consequence, third generation and alternative biotechnology provide several applications in which the processes must be adapted to socioeconomic and environmental conditions, and in which some of the stages of the project must be realised at the site of the application.
To take care of this, the country has provided research and technological development centres with experience in pilot and commercial level projects allowing specific agreements of collaboration to be agreed. Some of these centres have highly qualified staff who belonged to international research groups at the time these groups were realising considerable achievements in third generation biotechnology.

\section{APPLICATIONS IN PRODUCTION}

Establishment of new undertakings in selected applications. The most appropriate option for multilateral co-operation is considered to be joint ventures as this would imply an intermediate investment level compared to the establishment of a branch and the financial risks would be shared.

This option not only allows the partners to share the technology, but also offers the possibility of gathering together human, technical and material resources to continue with research and development activities. In our opinion, this is very similar to previous statements that multilateral co-operation should be founded on shared interests and in a mode of equality of rights and duties.

Finally, the options for co-operation that have been mentioned in the case of Mexico should be based on third generation and alternative biotechnology. The advantages and the disadvantages of the analysis of some of these options is shown in Table 8.

\section{Table 8. Types of Associations for the Production Sector.}

\begin{tabular}{lll}
\hline \multicolumn{1}{c}{ Type } & \multicolumn{1}{c}{ Advantages } & \multicolumn{1}{c}{ Disadvantages } \\
\hline $\begin{array}{l}\text { Association } \\
\text { via licence }\end{array}$ & $\begin{array}{l}\text { Cost and risks are low for the } \\
\text { technological partner. }\end{array}$ & $\begin{array}{l}\text { Financial profits limited for the } \\
\text { technologist }\end{array}$ \\
& $\begin{array}{l}\text { Greater control for the financial } \\
\text { partner }\end{array}$ & $\begin{array}{l}\text { Risk that the technology is not } \\
\text { adequate for the socio-economic } \\
\text { and environmental conditions }\end{array}$ \\
Joint ventures & $\begin{array}{l}\text { Shared financial risks } \\
\text { Access to patented technological } \\
\text { information. }\end{array}$ & $\begin{array}{l}\text { Whatever disadvantages remain } \\
\text { after defining the following: }\end{array}$ \\
& $\begin{array}{l}\text { The optimization of resources to } \\
\text { develop new technologies. }\end{array}$ & $\begin{array}{l}\text { - Proposals } \\
\text { - Objectives }\end{array}$ \\
& $\begin{array}{l}\text { The access to reputation, market } \\
\text { distribution network and } \\
\text { knowledge of local culture. }\end{array}$ & $\begin{array}{l}\text { - Adequate methods to evaluate } \\
\text { tangible and intangible assets }\end{array}$ \\
\hline
\end{tabular}




\section{Bibliography}

Vocational Training Guidance, Conacyt, 'Evaluatión de programas de posgrado del pais, en la área de alimentos’, México, D.F. January 1985.

González, R. L. and R. Zermeño, 'El desarrollo tecnológico y su promoción', 'El caso de la biotecnologia en México, presented to the Cuban Seminar II on the interferon, at the Cuban Seminar I on Biotechnology, La Havana, February 22, 1986.

Leal, H., 'La utilización microbiológica de desperdicios lignocelulósicos. Potencialidades y perspectivas', in R. Quintero (Ed.), Prospects of biotechnology in México, Foundation Javier Barros Sierra and the National Council of Sciences and Technology, México, 1985, pp. 93114.

National Programme of Sciences and Technology, National Council of Sciences and Technology, México, 1978.

National Programme of Technological and Scientific Development 84-88, Federal Power Executive, México, August 1984.

Quintero, R., 'Biotechnology in México: Needs and opportunities', presented at the Symposium: Development, Achievements, Aspirations and Problems of the Biotechnological Sciences in México, organised by The Society for Industrial Microbiology, 43th Annual Meeting, San Francisco, California, August 11-15, 1986.

Quintero, R., 'El desarrollo de la biotecnologia en México: Evaluación de Oportunidades', National Council of Sciences and Technology (in preparation).

Quintero R., 'Prospectiva de la biotecnologia en México', in R. Quintero (Ed.), Prospects for biotechnology in México, Foundation Javier Barros Sierra and the National Council of Sciences and Technology, México, 1985, pp. 461-468.

Quintero R., 'Role of Government in food, science and technology in México', presented to the Symposium on Food Sciences in México organised by the Institute of Food Technologists, 46th Annual Meeting, Dallas, Texas, June 15-18, 1986.
Robert, M. L., 'El Cultivo de tejidos vegetales en México', in R. Quintero (Ed.), Prospects of biotechnology in México, Foundation Javier Barros Sierra and National Council of Sciences and Technology, México, 1985, pp. 367-373.

SCFI, 'Panorama de la Inversión Extranjera en México', Department for Social Communication, México, 1986.

Viniegra, G., 'La biotecnologia en la agroindustria alimentaria', in R. Quintero (Ed.), Prospects for biotechnology in México, Foundation Javier Barros Sierra and National Council of Sciences and Technology, Méidco, 1986, pp. 115-130. 


\subsection{The Andean Countries}

\section{B. Carlos Aguirre}

\subsubsection{Andean Technology Policy: Its Nature and Far-Reaching Effects}

The Technological Policy adopted in 1969 by the Andean Group (GRAN), was defined to handle the demands generated by the economic integration process, whose goals were: the opening of possibilities to link technology to the building of a large market, the subordination of foreign investments and technology transfer to national and subregional interests and to link technology to the very process of production and services as one of its main factors.

The Andean Technological Policy was an essential element of the idea which tried to assert a process based on domestic habilities, displaying its own capacities and promoting the utilization of local production factors as an important component of an independent development model. Handling problems related to foreign investment, patent rights, technology transfer, information, permitted a step forward to the understanding of the matter. It also made possible to enact new rules on these matters allowing the definition of the action to stimulate technological development.

The Andean Programmes for Technological Development (PADT's) are the tools of the Andean Technological Policy and have become a new experimental area within the GRAN (Andean Group). Thanks to their execution, it was possible to realize that the integration process can take upon itself different co-operative forms to reduce the possibilities of conflict that can arise because of the complementarity that creates them. They lead to the interaction and the union of efforts that outline the Andean Group as a new unit of international co-operation.

${ }^{1}$ This document was prepared for the European/Latin-American Seminar on Biotechnology which, under the auspices of the European Economic Community, held in Brussels, Belgium, between the 27th and 29th April 1987. This document represents the opinions of the authors and does not necessarily reflect the views or opinions of the Cartagena Agreement, nor those of the member countries of the Andean Group. The present document is based on works done by experts of each Andean country, propositions by the Cartagena Agreement to the Andean Council of Science and Technology, and the results of a cooperation programme carried out since 1975.
This instrument eventually became one of the most typical contributions of the Andean Group. As a matter of fact, through their execution it was possible: to constitute multinational teams of experts and technicians; to obtain external financial resources; to reduce the differences among the projects; to exchange specialized information; and, to develop new techniques and methods for technology transfer.

As indicated before, the Andean Technological Policy was steered to demand knowledge from an ambitious project of subregional industrialization and a growing market. However, the far-reaching effects of a joint industrialization were partial and could not cope with the proper characteristics of an incomplete industrialization of the Latin-American region. The enlarged economic space, a key factor for technological development, did not trigger the expected demand of technology.

The strategic scope established by the Technological Policy of the Andean Group intended the combination of many financial, commercial and fiscal elements, but there were multiple divergences among the public powers, and between them and the private sector - a very common problem in the Andean countries. The lack of concertation seriously restrained the complete application of the Andean Technological Policy.

\subsubsection{Guidelines for a Reorientation of the Andean Scientific and Technological Integration}

NEW CHALLENGES

The application of the Andean Technological Policy advanced with the achievements and limitations already noted. In the meanwhile, and after a period of dynamism and growth, the integration process went through phases of stagnation and even regression.

Simultaneously, there is an unprecedented acceleration toward the technological change in the more developed countries, favourable to the upheaval of a new pattern of industrialization which tends to ignore the comparative advantages of developing countries.

On the other hand, as a counterpart to the crisis, the modernization gaps within the countries constitute a great challenge from social, productive and technological points of view. 
In spite of the growing attention placed by the governments of the Andean countries on science and technology, the answers are still insufficient for a National Policy to face problems such as those cited. The new technological elements playing a role deepen the differences between the Andean countries and the more developed countries. The intrinsic weakness of the existing scientific community, the fiscal crisis and the public debt, exacerbates the brain-drain and the dismantlement of the subregion's research centers.

\section{Reorientation of the Scientific and Technological Integration: Bases for a New Concept of Joint Action}

A series of orientations directed to consolidate the obtained results, overcome limitations and face the new challenges at national, sub-regional and international levels, have occurred over the last three years in the Andean Group.

The 'Reorientation Programme of the Andean Integration Process' (1983) contains a conceptual basis that should be mentioned. It points out that integration should offer the countries new prospects and alternatives for their development processes in fields necessitating efforts beyond the national boundaries and, therefore, requiring to be approached by a joint and concerted action. It also underlines the necessity to work with a flexible and pragmatic criterium in order to complete the application of the existing tools with all the possible forms of co-operation leading to a major interrelation among the countries.

Science and technology will help the development of this idea of reorientation. Two central aims are at the base of the new Andean technological strategy:

a) 'To create a joint capacity of scientific and technological response to the challenges of the countries' development and subregional integration process'

The problems, already described, show the advantages of association. The current crisis makes it urgent to unite efforts. In the technological field, it is more and more obvious that isolated positions are insufficient. A joint action is the new support for integration. Besides, scientific and technological co-operation is a must for the
Andean countries, since none of them can establish an independent and viable scientific and technological community.

It is worthwhile to insist here upon the elements of an Andean scientific and technological community. To achieve this, it is imperative to combine human, institutional and financial resources, not only those of the member countries, but also those of an international cooperation.

A pragmatic and urgent effort of permanent harmonization must be made to identify areas susceptible of integration.

b) 'To contribute with science and technology to the carrying out of sectorial strategies for the Andean integration process'

The sectorial strategies for integration enable to identify scientific and technological requirements. From them and through adequate programming and planning, the appropriate mechanisms and instruments to them can be recognized. Among the strategies, the following should be mentioned:

Food safety, within it new prospects for research and application of biotechnology: improved seeds, production of animal vaccines, nitrogen fixation, development of a variety of plants resisting diseases, etc.

Different political decisions give priority to the necessity to develop, appraise and protect renewable and unrenewable natural resources.

On the other side, the industrial sector strategy points out common methods to develop the agro-industry sector. This is due to its potential not only in the expansion of the production of existing goods, but also in the incorporation of new products responding to the basic needs of consumption, and the restriction on imports of final products and basic materials which can be substituted by subregional natural products.

The capital goods sector, a little behind but having a great potential for development in the subregion. It must be taken into account because of its implications on the use of skilled labour, major autonomy of industrial development, commercial potentiality, margin to continue the substitution of imports, and beginning exports on an extended market.

Electronics and telecommunications sector. Because of its numerous links to other areas, such as industry when it results in capital goods, it is one of the 'most promising' themes to work on science and technology. 
Priority is given to the evaluation of potential partners investing on projects for development and production of equipment and the constitution of Andean multinational enterprises.

\subsubsection{Fields of Action of the New Andean Technological Policy}

To reach the enumerated goals, the Andean Strategy for Scientific and Technological Integration has suggested a series of policies focused on fields of action that permit a kind of viable programming, that is to say ready to be applied under Andean realities. The carrying out of these policies should integrate efforts and resources around key matters, and give to the Andean Group a more specific outline when working on science and technology, and using for its development the economic space of the five member countries. Thus, new opportunities are open because of the deliberate utilization of a subregional space for products and sectors carriers of technology.

Three areas of action have been defined and will permit the organisation of the GRAN's efforts on science and technology:

\section{A) MANAGEMENT APPLIED TO THE DEVELOPMENT OF TECHNOLOGICAL} INNOVATION

The lack of an adequate management makes it difficult to apply technology to production. What has been tested is more intuitive than systematic. At present, it is clear that to obtain a real benefit from the research results, it is necessary to combine commercial, financial, etc. market mechanisms, as well as feasibility studies and technology transfer. This stage will require higher expenses. 'The enterprise, in general terms, must play the role of a technological innovation promoter and open the access to more appropriate and modern technologies'. It must be said that without an improvement of the management applied to innovation, no concrete results can be obtained.

\section{B) TECHNICAL AND INFORMATION AREA}

As indicated by the Andean Strategy for Scientific and Technological Integration, one of the areas requiring a major emphasis is the one which will permit 'to collect, process, and offer to the countries technical and economic information at subregional and international levels'... 'to prospect on trends of technical and economic change through branches and products' and 'to support the strategical thought of the subregion'.

Confronted with technical change, it is necessary nowadays to adopt a watchful and prospective attitude, more rigorous, exigent and permanent, as part of the subregional strategy, including the setting up of alternative models for development, taking into account the new technologies and the availability of subregional natural resources. The definition of best elements in order to determine a future technological pluralism, must consider the improvement of traditional technologies.

It has been underlined that 'the creation of information susceptible to support the concrete decisional process, in the pre-feasibility studies, is of vital importance. It requires the combination of structured information on alternative technologies, their economy and their economic conditions of access. This information is not spontaneously available. It must be created. Data must be organized to produce information, and so to say, likely to modify representations and behaviours. The constitution of technical, commercial and economic information must be made at the very foundation of the new activities.

\section{C) Science, Research And Advanced Technologies Area}

The present scientific and technological revolution is influencing multiple aspects of production, health, education and services, which are matters, because of their nature, of great interest for the Andean Group.

The encouragement given to science in the subregion acquires a different perspective. It becomes the condition to assimilate the present current of technological advances. There is talk of an industry based on science. The development of intellectual factors will be the key of competition between countries and group of countries. In the more developed countries, the scientific policy is gaining consideration after a period of stagnation.

In the light of a series of new demands that the sectorial strategies of the Andean Group would lay on scientific and technological areas, it is easy to remark that it is impossible to step forward without a good dose of organization, programming and effective support in the field of personnel training and its utilization through research activities. 
The 'Caracas Programme', approved by Decision 183 of the Cartagena Agreement Commission, claims to fulfill the void on those matters, setting up arrangements and compromises through harmonization and concertation.

A proposition of interest consists of structuring around the Programme a strong supporting movement to the scientific disciplines that serve as a basis for advanced technologies, depending on common needs, that is to say, scientific research and training of personnel.

Therefore, the human resources policy becomes a ruling principle of the Andean strategy as announced at the Cartagena Agreement, '...the unique policy compatible with a shifting future and the dynamics of the technical change, is the training of specialists who should be given a solid scientific knowledge and good practice in research methods. These are the right tools that will enable a fast adaptation to scientific changes, technological innovations and exchange of researchers...'

\subsubsection{The Andean Programme of Biotechnology}

The Cartagena Agreement has promoted since 1986 the programming of the Andean Strategy for Scientific and Technological Integration in concertation with ruling organisms of scientific and technological policy of the member countries, which constitute the Andean Council of Science and Technology.

The new stage, expected to be started in 1987, proposes to re-appraise the meaning of integration, especially its potential economic space, as a means to promote technological innovation within the subregion and to use this process to fortify the Andean integration.

The effort displayed till now to structure the Andean Programme of Biotechnology is an important part of the framework. To this purpose, there are national and community experiences, which will be analyzed in this document.

In general, the programme will try to organize joint capabilities on Biotechnology, especially in areas of social and economic interest to the Andean countries, such as the agriculture, health and food safety areas.

In the management area of biotechnology innovation, the programme will include financial incentives and a growing market. These actions allow the promotion and establishment of Andean multinational enterprises or similar forms of association, with the participation of the private sector and research institutes. Special attention will be placed on problems such as technology transfer and intellectual property.

The programme must consider the degree of advancement of the results already obtained in the Andean countries. Information on opportunities and sources, where a subregional action is advisable, will be collected and analyzed. The programme's basic activity is the analysis and evaluation of economic, technical and commercial information.

An immediate requirement is to promote the education and training of personnel research techniques. The establishment of networks and specific projects of $R \& D$ is part of the initial effort to identify requirements and common means for training.

\subsubsection{National and Subregional Experiences}

\section{NATIONAL EXPERIENCES}

The outline of the Andean Programme of Biotechnology is based on the experience of each member country in the biotechnology field.

At national level, there is a group of important activities in execution or planned at short or middle term, not only to formulate policies but also programmes and projects.

BOLIVIA

The development of biotechnology in Bolivia has not so far reached the level of the other countries of the subregion. However, at the Academia Nacional de Ciencias and the Universidad Boliviana, there is a group of researchers working together with those of the private sector, which constitute the basis on which a short-term nationwide programme is being discussed.

It is convenient to indicate as background that various efforts have already been displayed to establish a critical mass of re-searchers on which the programme will be based on.

Particularly, the activity developed by the National Co-ordination Committee for the development of biological sciences, has increased the scientific level of experts on biology through national and international courses and lectures, fellowships and training. At present, there are in Bolivia experts concentrated mainly at Instituto de Genética Humana, founded in 1972, Instituto de Investigaciones Biológicas of the Academia 
Nacional de Ciencias, founded in 1961, Department of Biology of the Universidad Mayor de San Simón and at the Facultad de Bioquímica y Farmacia of the Universidad Mayor de San Andrés.

At the industrial sector level, the pharmaceutical industry, although in the initial phase of formation has an important potential within a reduced number of national laboratories: INTI, VITA, ALCO, SIGMA and others, which have a high technological level. In the pharmaceutical field, Bolivia can develop biotechnology for the production of antibiotics through available natural resources.

There is also an important potential for biotechnology development and its application on farming. On the other hand, within the framework of a subregional project, Bolivia acquired important experience in the application of biotechnology to the mining and metallurgical sector.

Within the framework of policies and strategies for the development of the biotechnology programme, the Academia Nacional de Ciencias of Bolivia proposes to prepare the right ground for the management of a larger international co-operation, both regional and North/South, according to the programmes previously developed by CONDECIB and enlarged with new specific projects, which will integrate the scientific development sectors to productive areas of the nation.

The specific projects will constitute a coherent whole through which products and services of national and subregional interest will be obtained. They will contribute to the development and strengthening of science in the country and the Subregion.

The basic activity of these programmes or subprogrammes will be made up of specific projects for research and development of products and services. The programmes will be carried out by means of subcontracts between both the ruling and the executive organisms.

In its initial phase, the programme will analyze the establishment of an information network, the development of legal tools permit-ting the protection of the obtained results, and the organization of biotechnology laboratories so as to increase the interactions among them.

The general goals of the programme will be: a) To promote integration and links among the activities to be developed on biotechnology in the country, allowing the technological advance for development, implementing the definition and execution of biotechnologies and supporting the definition and execution of joint actions in order to find solutions to local and regional priority problems, through the obtainment of process products and services.

b) To generate projects of regional interest, which will permit the obtainment of international funds in order to try to solve the problems which action will have to face within the national borders, giving a remarkable social and economic impact enabling to clear up and solve problems through biotechnology techniques.

c) To develop diffusion and demonstration mechanisms directed to both state-controlled and private companies in order to promote investments.

d) To fortify the scientific and technological infrastructure of the country in order to carry out the programme for the benefit of Bolivia.

Regarding present research work in Bolivia, the Instituto de Genética Humana is carrying out a research programme, sponsored by the O.E.A., on Americanae Camelidae with the objective to implant vicuna embryos in llama uterus.

Another programme, in execution at the present time, is molecular biotechnology on diarrhoea diseases (enteropathy) and the transmission of viruses; to combat the drug resistance of the pathogenic strains through plasmids.

The Instituto de Biologia of the Academia Nacional de Ciencias, is carrying out a study on the neurobiological effects of snake venoms, and later, will prepare serums and vaccines.

COLOMBIA

The National Programme of Biotechnology set up by COLCIENCIAS endeavors the creation of a working mechanism with a high degree of participation and consultation with both the scientific community and the national productive sector. It also attempts the establishment of relations of active exchange and co-ordination with other countries of the region which have similar problems as those of Colombia, and also with countries in 
which biotechnology is well developed, marking the international trends whose social and economic impact must be analyzed and made known at the right time.

The basic activity is the permanent evaluation of the programme's progress, the redefinition of its objectives and priorities in accordance with the results, new trends, identification of needs, studies of feasibility and new opportunities.

The programme's basic activity as well as the whole series of necessary and essential activities for its perfect development, must rely on sufficient financial and human resources besides a definitive planning in order to reach the objectives. For this reason, each one of the essential activities has been structured as a subprogramme defined with concrete and specific goals and its proper order of priorities to give an answer to the needs of the Nationa1 Programme.

Another of the Programme's essential actions, already structured as subprogramme, is the establishment of an interaction between the productive sector and the scientific and technological sector. To fulfill this requirement it is necessary to undertake an aggressive policy of reciprocal diffusion between both sectors by means of a series of seminars attended by international experts, and later on, to promote activities resulting in an effective transfer of knowledge, technique, methods and services between the sectors above mentioned.

Concerning the international relations, the corresponding subprogramme promotes the exchange with outstanding centres, binational and multinational projects which encourage the national research activity, courses, congresses, and any other scientific meeting in order to satisfy specific needs of the research groups; organizes and diffuses any information received from abroad and from international organisms to the scientific community of the country; establishes contacts with technical missions of the embassies and, through them with other science and technology organisations of the countries represented; and keeps an active relation with regional and international programmes on biotechnology.

Up to now, the following activities have been considered as necessary for the efficient execution of the research projects:

a) Training of human resources. b) Establishment of a scientific and technological information and documentation network.

c) Setting up and running of a system of evaluation and control of the programme's development and other projects.

d) Monitoring and analysis of world-wide development trends of biotechnology, and anticipation of its economic impact.

e) International relationships and regional integration. Co-ordination with other national programmes.

f) Setting up and running of communication mechanisms between both the scientific and technological and the production sectors. Encouragement of a university/industry co-operation.

g) Enterprise management and development.

h) Projects for scientific and technological development.

i) Economic projects

Each one of the activities mentioned above will give their support to research projects. The activities have been chosen after consultation with the scientific community and some representatives of the national productive sector according to the country's needs and priorities and the presence of active groups in the different areas (see Chart 1).

The establishment of priorities for the development of biotechnology products and their production at commercial level, should be based on detailed economic surveys and on the predominating needs of the country and region. Studies envisaged by the National Programme will start soon.

However, there are certain product lines and services unquestionably essential because of their strong demand or immediate application and, therefore, receiving financial support from COLCIENCIAS through specific projects for development and research, which will be at short and middle term the object of negotiations for technology transfer and adaptation.

These lines are: development of vaccines; production of antigens, monoclonal antibodies, diagnostic kits for tropical diseases; plant micropropagation through tissue or cell culture; improvement of the symbiotic and asymbiotic fixation process of nitrogen in plants; biodegradation of organic polluants; recovery of biogas and biofertilizers; production of single-cell proteins for animal feed; production of enzymes for industrial use, lactic starters, organic acids and antibiotics. 


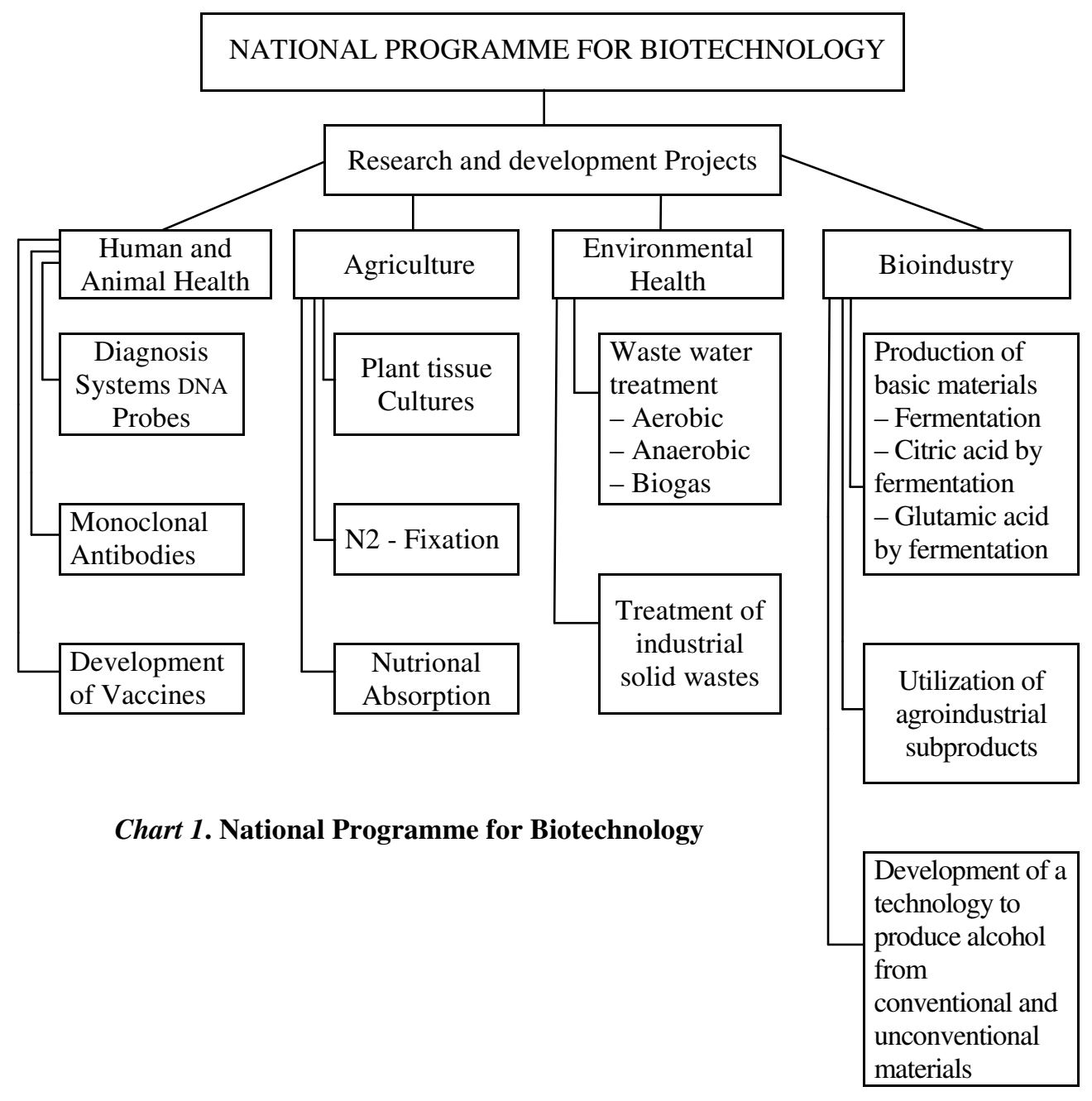

In the middle-term, there are also, at nation-wide level, projects with significant economic prospects such as: the animal reproduction through genetic techniques; the production of hormones, diagnostic kits for plant viral diseases, secondary metabolites from plant cell cultures, biopesticides for the biological control of epidemics, and bacterial leaching processes of certain metals.
ECUADOR

The National Council of Science and Technology (CONACYT) has promoted activities on biotechnology since 1983. At the very beginning an advisory group was created, composed of researchers of institutions working in biotechnology fields.

This group has helped to define priority areas and research projects which need to be developed. On the other side, it has supported the analysis of propositions made by international organisations, which have urged the country to adhere to development programmes on biotechnology. In the policy guidelines proposed by CONACYT, biotechnology is considered as a scientific and technological priority to solve some of the serious problems the country is facing, taking into account the unprecedented development of this sector at international level.

The policy guidelines will be concretized in a National Plan which, on the one hand, will gather the activities developed in the "Grupo Ecuatoriano de Biotecnologia' and, on the other hand, will determine actions directed to the production, application, adaptation and diffusion of biotechnology in the agro-food and industrial production; and will also attach health and environment preservation problems.

The National Plan for Biotechnology Development will contain harmonized programmes as part of the actions to be carried out in order to reach objectives and goals.

Among the planned programmes, the following ones can be mentioned:

a) Manpower Training Programme, through which a review and harmonization of the study plans on the basic sciences will be done at medium and high levels. It will support and fortify the disciplines of basic sciences in order to provide a basis for the training of human resources in biotechnology, such as: cellular biology, molecular biology, biochemistry, biophysics, virology, enzymology, genetics, microbiology and immunology, at postgraduate level. It will permit the identification of Master and Ph.D. programmes on biotechnology, which will be followed by Ecuadorian experts, in the countries of the region and in the developed countries. 
b) Research and Development Programme, through which the following points will be carried out: the evaluation of scientific and technological potential; the survey of research needs on biotechnology, giving priority to research Unes; identification of research projects on biotechnology which could be carried out by combined action of both the university and the industry; backing the foundation of a Biotechnology Research Centre whose objective will be, on the one hand, to stimulate the execution of research projects on problems of social interest, encouraging sectorial biotechnology production, and, on the other hand, to enrich the manpower training programmes and provide technical advice on governmental decisions; supporting research projects planned by institutions and research centres, which are presently developing surveys.

c) Programme to encourage international and technical co-operation, aimed to fortify the participation of the country in research projects on biotechnology, at regional and international levels.

From a strategical point of view, CONACYT intends to defineate the scientific and technological policies in the sector and the National Plan, suitable for being applied to the country's conditions and according to the evaluation of the scientific and technological potential, in co-ordination with the 'Grupo Ecuatoriano de Biotecnologia', which should be changed into a Technical Committee.

Concerning the research at present on execution, see Chart 2. Besides, the following institutions of public and private sectors are developing research, some of them at industrial and semi-industrial levels:

- Instituto Ecuatoriano de Investigaciones Agropecuarias: Merismatic Culture.

- Instituto Nacional de Higiene: production of human vaccines.

- INEXA S.A.: merismatic cultures.

- Latin-ReCo S.A.: food production.

- PRONATEC S.A.: Natural extracts.

- Centro de Adiestramiento Lechero S.A.: Lacteal fermentations.

- LEVAPAn S.A.: Development of fermentation processes.

- Laboratorios farmaceuticos Ecuatorianos (LIFE) S.A.: Production of animal vaccines.

- ALCOLESA S.A.: Alcoholic fermentation of molasses.

\begin{tabular}{|c|c|c|}
\hline \multicolumn{3}{|c|}{ Chart 2. Current Projects } \\
\hline Institution & Executive unity & Research fields \\
\hline $\begin{array}{l}\text { Universidad } \\
\text { Central del } \\
\text { Ecuador }\end{array}$ & $\begin{array}{l}\text { Faculty of } \\
\text { Medical Science }\end{array}$ & $\begin{array}{l}\text { - Histocompatibility } \\
\text { - Immunology and infections } \\
\text { - Development of Bioreactors } \\
\text { - Purification of plant dyes } \\
\text { - Purification of fuels }\end{array}$ \\
\hline $\begin{array}{l}\text { Universidad } \\
\text { Tecnica }\end{array}$ & $\begin{array}{l}\text { School of } \\
\text { Chemical } \\
\text { Engineering }\end{array}$ & $\begin{array}{l}\text { - Fermentation in solid material } \\
\text { - Dairy technology } \\
\text { - Meat technology } \\
\text { - Fruit and vegetable technology } \\
\text { - Post-harvesting studies of perishable } \\
\text { products }\end{array}$ \\
\hline $\begin{array}{l}\text { Universidad de } \\
\text { Guayaquil }\end{array}$ & $\begin{array}{l}\text { Faculty of } \\
\text { Natural } \\
\text { Sciences }\end{array}$ & $\begin{array}{l}\text { - Larval development of Macrobrachium } \\
\text { penamensis } \\
\text { - Sexual maturing of Bocachico (Bocaccio) } \\
\text { - Sexual diphorism and reproduction of } \\
\text { Aeuides mivulatus, in aquaculture } \\
\text { - Culture of Mytella guyamensis mussel } \\
\text { - Phytoplankton culture } \\
\text { - Sellfish of commercial interest }\end{array}$ \\
\hline $\begin{array}{l}\text { Armada del } \\
\text { Ecuador }\end{array}$ & $\begin{array}{l}\text { Oceanografic } \\
\text { Institute } \\
\text { (Division of Sea } \\
\text { Sciences) }\end{array}$ & $\begin{array}{l}\text { - Sea phytoplank and primary production } \\
\text { - Sea zooplankton } \\
\text { - Sea Benthos }\end{array}$ \\
\hline
\end{tabular}

In order to accelerate the biotechnology development, it is required, on the one hand, to encourage the training of human resources, strengthening in this way the country's scientific level through postgraduate courses in the countries of the region and the developed countries, and, on the other hand, to set up a teaching and permanent research programme at under- and postgraduate levels for the education and training of national researchers.

On that account, it is expected in Ecuador to initiate in 1988 the postgraduate programme on molecular and cellular biology as basic sciences in order to develop biotechnology.

At last, research projects to be carried out in the middle term are:

- Pharmaceutical products: Nation-wide development of the industrial production of pharmaceuticals; study of plant active principles and 
their application in the pharmaceutical industry; 'in vitro' production of antibodies from hydridoma to determinate: a) bacterial and viral antigens through etiopathogenic studies in animals; b) vaccine production from characterization of surface antigens; c) detection of blood markers of malignity for diagnosis of tumoral diseases; d) therapy methods using monoclonal antibodies finked covalently to drugs in order to attach malignant cells.

- Food products: Liquid and solid fermentations for the production and industrial transformation of food; in high-protein food, it is planned to carry out genetic modifications of the quinoa to increase its nutritive value; microbial culture collections: implementation of a microbial culture collection for the maintenance and distribution of strains of industrial interest; aquaculture: culture of sea organisms to improve production and nutritive value of shrimps, oysters and fish; biomass processes: production of biomass to obtain animal feeding-stuff biological control of insect vectors: studies of molecular biology, cellular biology and cytogenetics for the control of the life cycle of insect transmitters of malaria, oncocercosis, trypanosomiasis; plant culture: production of vegetable clones to obtain plants with high productivity and higher resistance to diseases.

- Genetic engineering: Interferon production for the treatment of cancerous diseases. Diagnosis of hereditary diseases through recombinant DNA techniques.

- Environment pollution: Treatment of industrial wastes, especially waste waters.

PERU

In 1986, the Peruvian National Council of Science and Technology (CONCYTEC) created the Consulting Commission of Biotechnology to analyze and propose activities for the application of biotechnology in the country.

Peru is far away from having a critical mass of researchers in this field. The country requires an adequate co-ordination of the international organization and the existing research activities for the development of this field allowing it to reach the phase of goods and services production and to improve the standard of living of the population.
In Peru, there is a deep gap between the industry sector and the universities; that is why initial actions of mutual benefit should be started, and whose quality and quantity would be gradually improved and increased. On that account, the teaching centres could offer quality control and advisory services, permitting an ever growing exchange and a real activity of co-operation in the future. A possible form of this co-operation is the establishment of industries which, rooted in academic institutions, can benefit from the human resources, equipment international advisory and consultancy available for those institutions, and contribute to their entire work on teaching, research and services.

An important aspect to be considered for the development of biotechnology in the country is the manpower training. In this direction, the National Programme must first contemplate the strengthening of different systems of advanced education (postgraduate courses, professional specialization, training, etc.), as well as trainee researcher exchange and the utilization of international and regional co-operation for that purpose.

The Consulting Commission of Biotechnology considers four sectors in which the application of biotechnology in Peru is of great importance:

Biomedical and Veterinary Sector. There are good reasons to back the biotechnology development in the health sector. The programme embraces promising technologies, of fast development, not requiring large investments for their implementation, depending on the existence of a critical mass of skilled specialists, and could be established in the present centres wherein biologists, chemists, pharmacists, veterinarians, biochemical physicians, microbiologists, immunologists and other researchers are educated and further trained.

It is likely to aim to a nation-wide production of diagnostic elements of biotechnological origin that will substitute, more or less quickly, expensive culture techniques and for which basic material is still imported.

With regard to therapeutic products, agreements could probably be concluded to ask national companies to take upon themselves the production and commercialization of bioproducts and to assume the development and production of products according to the needs in the near future.

Concerning vaccines, the World Health Organization and the PanAmerican Health Organization, working jointly with National Institutes of 
other American countries, will probably offer consulting services, support the technological development, set up production lines, quality control, etc. The areas of major interest are the following:

- Diagnosis of enteropathy, tuberculosis, acute respiratory diseases, transmitted by vectors and parasites;

- Thermostable vaccines and new vaccines;

- Other biological products such as antidotes, insulin and plasminogen activator.

Agro-Food Sector. This is a prior-right sector because of the agricultural situation of the country.

In several points of this sector, the in situ application of biotechnological processes is feasible, which could incite the development of rural industries, with a very large social impact. The application of these processes would also increase the production and productivity of the land. However, the promotion of a biotechnological agriculture will require a good control of its production and an appropriately expanded work from the corresponding governmental organisms.

In the agro-food sector, there are already some experiences and preliminary results which should be encouraged for obtaining short-term success, including their transfer to other countries of the region. Experiences and results within the following areas:

1. in vitro cultures;

2. micropropagation and genetic stabilization of plants;

3. production of basic seeds;

4. bioconversion of materials and agro-industrial wastes into animal

5. feeding stuff, enzyme production, alcohols and other chemical substances;

6. production of biogas and biofertilizers;

7. nitrogen-fixing micro-organisms and mycorrhyzal fungi;

8. production of diagnostic systems for plant viruses.

Chemical and Pharmaceutical Industry Sector. Considering the import balance of basic materials for the chemical and pharmaceutical industries, it is essential to substitute imports and to develop the following areas:
1. alcohol production as raw material for chemical industries (chemistry of alcohols);

2. production of solvents (butanol, isopropanol, acetone, etc.);

3. production of antibiotics through fermentation and biosynthetic methods (penicillins and semi-synthetic cephalosporins, aminoglycosides and rifampicin);

4. production of organic acids (citric, acetic, lactic, fumaric and others);

5. production of essential amino acids (lysine, methionine and glutamic acid) and vitamins (riboflavin and ascorbic acid);

6. production of steroids (cortisone, prednisone) and other molecules obtained from yams;

7. production of alkaloids and other substances through vegetable cell cultures.

Other Sectors. The following four areas are important:

1. metal extraction from metallic sulphates through bacterial

2. leaching;

3. tertiary recovery of petroleum

4. biodegradation of pollutants;

5. monitoring of environmental pollution.

Generally speaking, it is extremely important to carry out in these sectors a national evaluation of economic, political and technical nature.

In order to set up a programme, the Consulting Commission has proposed:

a) To carry out an evaluation of the national biotechnology, developing its prospects.

b) To analyze biotechnology abroad at three levels: Developed Countries, Third World Countries, the Andean Countries.

c) The elaboration and regulation of a policy responding to a national demand and adjusted to the situation of the country, in order to reach results enabling the improvement of the standard of life of the Peruvian consumer. The regulations must include a 'Patent Register' for the protection of biotechnological processes which do 
not have a directly human and social incidence, and, of course, underline the priority of working areas.

Besides the Commission has proposed:

- To create a National Network of Biotechnology as an institutionalized system of co-ordination and intercommunication, in accordance with the existing national laboratories.

- To recommend the creation of a special fund for biotechnology research and development, giving to the ITINTEC a part $(2 \%)$ of the resources provided by the industry, and thus harmonize research teams, activate the laboratories of the National Network and encourage researchers. This fund would be managed by the CONCYTEC.

- To promote meetings and communication among entrepreneurs, researchers and users of biotechnology to make effective the utilization of the National Network.

- It is necessary to clarify to what extent basic materials and scientific equipment, essential for the development of biotechnology, represent a significant point in the Peruvian import balance. A strategy must be planned to put an end to this dependency in order to develop the national production of these basic materials and scientific equipment.

- The permanent problem of imports has also been discussed. By general consent, CONCYTEC should try to speed up the regulations concerning customs clearance so as to be able, at least, to receive radioactive materials with preserved good specific capacity, really fresh biochemical supplies, laboratory reactives, biologically active and special strains.

\section{VENEZUELA}

The National Programme of Biotechnology was set up in 1984, after the President of the Republic created by Presidential Decree No. 240 the National Commission for Genetic Engineering and Biotechnology, within the National Council for Scientific and Technological Research, to act as an advisory organism to the presidency of the Republic and to define policies and elaborate plans for the development of genetic engineering and biotechnology.

The Programme's main objectives are the following: a) To promote scientific and technological research in genetic engineering and biotechnology areas.

b) To formulate and co-ordinate the National Plan for Genetic Engineering and Biotechnology.

c) To co-operate with organisms whose task is to promote, plan and finance the scientific and technological development of the country in this area.

d) To attempt the establishment of scientific and technological networks of information on genetic engineering and biotechnology.

e) To spur the training of human resources in this area.

f) To co-operate with organisations which represent the Republic on international matters; especially when relationships in the biotechnology area are concerned.

With the aim to get the Programme started, a strategy has been adopted to sort out projects, including the establishment of research cooperative groups in agriculture, agro-industry, and medicine areas, in which the participation of the teaching and the industry sectors is expected.

The principal projects of the biotechnology Programme, already selected, are the following:

Agriculture. Production of potato and yucca mother plants and other products, through tissue culture techniques, somatic hybridization, induction and selection of mutants.

Obtainment of pathogen-free plants using tissue culture techniques, followed by massive clonal propagation and development of diagnostic reactives for pathogen detection.

Industry. Purification technology of glucose and fructose syrups. Design and evaluation of processes for the production of fructose syrups.

Agro-industrial waste recovery for the production of protein-rich animal feed.

Enzymatic degradation of lignocellulose wastes.

Biomedicine. Studies of diagnosis, prophylaxis and epidemiology of diseases such as: leishmaniasis, trypanosomiasis and leprosy. Research in 
this field will include pathogen isolation and culture, cloning and antigen identification, obtainment of monoclonal and polyclonal antibodies, etc. Biochemistry and immunology studies are also planned.

Another group of studies in this area are: Cancer and AIDS diagnosis, therapeutics and epidemiology. Research in this area could be aimed to gene isolation, recombination, production of RNA and DNA probes, oncogens, transformation factors, etc.

SubregionAl ExPERIENCES: PADT-COBRE AND THE MINING-

MEtallurgicAl Programme

The Commission of the Cartagena Agreement, by Decisions 86 and 87, approved the Andean Projects for Technological Development in the Copper area (PADT-Cobre), whose activities started in 1973 and came to an end in 1981. The general objectives of PADT-Cobre were the following;

a) To form specialists teams, competent enough to generate and improve technologies applied in the area, from laboratory level to the planning, design, maintenance and operation of industrial plants.

b) To create in Bolivia and Peru laboratory facilities for the analysis, evaluation and development of existing studies on leaching of copper ore.

The projects executed within the PADT-Cobre framework, in which Peru and Bolivia participated, were:

Project I: Copper-oxide ore treatment through leaching with sulphuric acid and cementation with scrap iron.

Project II: Bacterial-acid leaching of copper ore in columns or wastes.

Project III: Copper recovery from copper sulphate solutions through ionexchange electro-deposition.

NOTEWORTHY RESULTS IN BOLIVIA

a) Equipment, fitting up, and operation of the laboratory belonging to the Department of Special Metallurgical Projects of the SubDirection of Projects of COMIBOL, in Oruro.

b) Fitting up of the Krupp pilot plant type 11 for copper recovery through ion-exchange electro-deposition. c) Education and training of 23 specialists, among them engineers and technicians on acid-leaching technologies; and, on the planning, design, building and operation of pilot and industrial plants for copper treatment through hydrometallurgical methods. This technical team has up-to-now elaborated two studies of feasibility 'Corocoro' and Solivar', and two of pre-feasibility 'San Miguel' and 'Telemayu'.

Noteworthy Results IN PERU

a) Equipment, fitting up and operation of the laboratory of the Department of Metallurgy Research of CENTROMIN, in La Oroya.

b) Plan, design, fitting up and operation of the Pilot Complex of Toromocho which is composed of 8 copper ore columns with more than 150,000 MT, reaching, some of them, an extraction rate of $88 \%$ and a throughput of $3.5 \%$ per month; a cementation plant of nearly 15 MT per month; and a Krupp plant for ion-exchange electrodeposition with a capacity of 14 MT of electrolytical copper per year. Approximately 400 MT of copper cement (worth US $\$ 470,000$ ) were produced in the cementation plant.

c) Education and training of 35 specialists, among them engineers and technicians, of CENTROMIN Peru, Ingemmet and Minero Peru.

In general, the following concluding remarks can be mentioned:

a) The development of PADT-Cobre has permitted the utilization of technologies in the copper hydrometallurgical area applied to the benefit of lower-grade copper ore in the following areas: chemical leaching, ferro-bacterial leaching, extraction by solvents, cementation, electro-deposition and crystallization.

b) As a result of the above mentioned development, technical and economic studies have been worked out, such as the planning, design, building and operation of the Pilot Complex of Toromocho in Centromin Peru.

c) The mastering of the technologies developed in Bolivia and Peru will enable their incorporation to the industrial and productive sector of both countries. 
d) The utilization of technologies developed in the subregion in the near future will allow the incorporation and development of new sources of foreign exchange. At the same time, they will have a growing effect, which will permit a larger industrial activity and the creation of 'satellite' services parallel to the establishment of new technologies.

e) The technological achievements attained through the concerted effort of the Cartagena Agreement and the Member Countries, in the present case Bolivia and Peru, are a clear example of what can be reached by means of a clearly defined technological integration policy provided with mechanisms and tools for its efficient application.

f) The adopted technologies open the way to recover copper and other valuable metals from lower-grade ore constituted by out-falls, effluent residues, wastes, etc. Two million tons of lower-grade ore has been estimated in Peru and Bolivia. The acquired technological knowledge will permit not only a more important income for both countries, but also a great contribution to fight environmental pollution provoked by traditional mining methods.

On basis of the experience above described, the Cartagena Agreement began in 1985 the development of the Andean MiningMetallurgical Programme (PMMA), whose general objective is to strengthen the technical and economic integration of the mining-metallurgical sector of the Andean subregion.

Particularly in the bio-hydrometallurgical area, work is at present carried out on technology transfer of bacterial leaching, obtained during the PADT-Cobre, and its application for polymetallic extraction. On the other side, research on the application of other hydro-metallurgical technologies, which will permit the recovery of other metals, is on the way.

These activities are possible because of the consolidation of the research and application centres for this technology in the Member Countries, and of course the training of human resources.

The technologies constituting this programme, will be applied in deposits chosen by the Member Countries.
With regard to financing, it is necessary to indicate the support for technical co-operation, not refundable, from the government of the Federal Republic of Germany, thanks to an accord with the Cartagena Agreement.

The ANDEAN CounCIL FOR SCIENCE AND TECHNOLOGY AND THE CONCERTATION OF ACTION ON BIOTECHNOLOGY

The Andean Council for Science and Technology (CACYT) strives to promote, at subregional level, an adequate scientific and technological capacity to satisfy the demands for economic and social development of the Member Countries (Decision 213).

The CACYT is composed of top authorities responsible, in each one of the countries, for the scientific and technological system and the orientation of activities considered in the 'Caracas Programme for Co-operation on Research and Scientific and Technological Education and Training' (Decision 183).

During its second meeting (La Paz, 1984) the CACYT recommended to enter upon biotechnology all together, and also sup-ported the creation of a work team composed of Colombia and Venezuela in order to elaborate preliminary actions, initiating a process of concertation and programming.

To achieve its goal, this task took form at the 'Cucuta Meeting', celebrated between both countries in September 1986; further details will be given in the next section.

Another source of discussion for concertation on biotechnology during the Fourth CACYT (Caracas, 1986) were the topics identified in the national plans for Science and Technology, by means of a document prepared by the Cartagena Agreement.

The Fourth CACYT adopted the idea of 'problem-areas' in order to identify action lines and to programme, at the first phase, joint activities on biotechnology.

In the health area: Tropical diseases, malaria, Chagas' disease and leishmaniasis were considered as targets for biotechnology applications.

In the agriculture area: The improvement of productivity through nitrogen fixation and micropropagation of pathogen-free plants were considered as priority lines. 
In the agro-industry area, priority was given to the improvement of nutrition through the production of protein-rich food.

In the natural resources area, an adequate utilization of natural resources will allow work on biotechnological research, and especially in fields related to promising products, treatment of waters and wastes.

In the energy area, the development of new sources, such as those generated by biomass, was considered as a priority for the first stage.

The Fourth CACYT recommended that the programming of scientific and technological activities on action lines above mentioned, must arise from the necessity to link research and production, and to take advantage of the Andean growing market to boost intensive products in technology, and fixing the financial mechanisms to obtain them.

\section{The Colombo-Venezuelan Meeting on Biotechnology in Health} AND AGRICULTURE AREAS

The Colombo-Venezuelan Meeting on Biotechnology in the health and agriculture areas, sponsored by the CACYT, was held between the 18th and 20th September 1986. Delegations of each Member Country presided by the top governmental authorities on scientific and technological policy, the Ministry of Science and Technology of Venezuela and the Director of Colciencias. Representatives of the Cartagena Agreement, EEC and BID attended the meeting too.

The participants contributed to the elaboration of specific project outlines intended to apply biotechnology in the health and agriculture areas through the creation and support of a series of co-operative networks to which other Member Countries would be later invited to participate in (see Chart 3).

The Programme's main objectives will be the expansion of the scientific and technological capacity on biotechnology and the potential market for the products resulting from its application; obtainment of products and services of significant economic and health interest for the subregion; and the co-operation on education and training of human resources to attain these goals.

\section{Chart 3. The Cucuta Meeting: outlines for specific projects \\ Biotechnology on Health}

Project I Leishmaniasis

Utilization of biotechnology for the development of detection techniques of leishmaniasis. Subprojects

1. Standardization and production of leishmania for diagnosis and prognosis of leishmaniasis.

2. Employment of DNA probes for identification and classification of leishmaniasis in vectors, for epidemiological control.

3. Use of monoclonal antibodies for identification, diagnosis and prognosis of leishmaniasis.

4. Isolation and characterization of specific antigens of leishmaniasis for diagnosis

Project II Creation of New Techniques for Diagnosis of the Chagas' Disease

Project III Diagnosis of Malaria

Subproject A: Entomological diagnosis.

Subproject B: Human blood cell screening.

Project IV. Animal Health

$$
\text { Subprojects }
$$

1. Bacterial and viral agents affecting bovine reproduction, brucellosis, bovine viral diarrhoea, bovine rhinotracheitis.

2. Hemoparasites, babesia and anaplasm.

3. Vesicular diseases, vesicular stomatitis and foot-and-mouth disease.

4. Viral agents provoking diarrhoea in porcines, bovines (rotavirus, reovirus).

5. Viral agents affecting poultry raising.

\section{Biotechnology on Agriculture}

Project I Tissue Culture

Subprojects

1. Selection and programming of promising banana clones of regional interest for Colombia and Venezuela.

2. Production of healthy potato plants for sowing.

3. Development of methodologies for clonal propagation of cacao.

4. Development of a technology for pelleting embryos produced 'in vitro'.

Project II Diagnosis and Prevention of Viral Diseases in Food and Industrial Cultures

To that effect, it has been suggested the creation of an integrative programme embracing the different aspects of co-operation in the area, and precluding the arise of a package of independent specific projects. A twofold objective is in mind to face mutual deficiencies which would hinder the 
success on the intended projects, and allow the introduction of new products as soon as areas of interest for regional concertation are detected. The programme will probably last four years in order to enable the harmonization of the goals fixed in projects initially chosen and those which could be introduced in the programme's first stage.

The programme is subdivided in three subprogrammes: (a) human health; (b) animal health; (c) education and training of human resources and scientific exchange. The first two subprogrammes embrace a series of specific projects in their respective areas. Priority was given to these projects because of the available information in the First ColomboVenezuelan Meeting on Biotechnology, but the introduction of projects for co-operation by well-known laboratories in both countries in areas not considered within the first stage, will be accelerated.

Every financed project will be directed by a co-ordinator appointed by the heads of the participant laboratories, and its execution will be periodically evaluated according to international rules, employing as far as possible technical commissions and the mechanisms established to follow up programmes for international co-operation by CONICIT and COLCIENCIAS, including the help, if necessary, of international experts.

The manpower training and scientific exchange programme will embrace the usual activities in this area trying to harmonize the respective needs of the specific projects and, in more general terms, the goals of a programme for integrative development of biotechnology. To that effect, mechanisms to ease the research exchange between Colombia and Venezuela will be established, and also the use of courses and training programmes of common interest.

The three subprogrammes will be run by an 'ad hoc' sharing Committee created by CONICIT and COLCIENCIAS and will oversee the accomplishment of objectives and the attribution to each sub-programme of the necessary resources.

The Biotechnology Programme of THE ANDEAn Corporation For DEVELOPMENT (CAF)

In order to contribute to the development of biotechnology in the countries of the Andean Group, through support to the research areas and spurring the creation of structures which will permit to link research results to the producing activity, the Andean Corporation for Development adopted a programme that will enable:

a) To promote communication among specialized research centres and to stimulate the exchange and harmonization of research and information.

b) To back the development of specific projects of applied research with the purpose to settle the ground for a more self-sustained development.

c) To support the constitution of operative structures that will bridge research sectors and users. (For instance, facilitating the association of research groups, farming centres and private enterprises.)

d) To support the establishment of enterprises specialized in the culture, propagation and commercialization of plants obtained by biotechnology applications.

e) To organize programmes for the education and training of the personnel, to ease technology transfer and advisory.

In the first phase, the programme will concentrate on the tissue culture area.

Selected research centres or companies carrying out or conceiving biotechnology projects will be supported. Choice or selection of projects will basically depend on the degree of their practical use.

Support will include personnel training and specialization, as well as technical assistance and consulting services. It will also include the equipment and the supply of research material. Concerning training and equipment areas, an important task has been planned: the search of support of international organisms in order to reinforce the CAF possible contributions.

At later stages, and after evaluation of the initial actions, new areas of biotechnology and genetic engineering will be introduced according to applicability and utility criteria.

The programme is expected to carry out the following main activities:

1. The establishment of an inventory of the subregional capacity in biotechnology, including:

a) Research areas.

b) Availability of laboratories. 
c) Availability and needs of skilled personnel.

d) Degree of application and present and potential use of biotechnology in the productive sector.

2. Selection or choice of programmes or projects, actual or in course of preparation.

3. Organization and outset of the projects.

4. Organization of a specialized seminar at subregional level.

5. Intervention before international organisations to obtain support on personnel training, consulting services and equipment.

6. Evaluation of the programme's results after the first year of operation.

The program will last two years and cost US\$1.0 million that will finance the following activities:

a) Inventory of the subregional capacity in the biotechnological sector.

b) Further development and identification of biotechnology programmes or projects.

c) Organization of meetings and specialized seminars at subregional level.

d) Promotion of participation of specialized international agencies in the programme.

e) Budget support to specialized centres on biotechnology in each country of the subregion.

The programme will be financed with resources of the Fund for Development of Genetic Engineering and Biotechnology in the Andean Group. The Assembly of Shareholders of the Andean Council for Development (CAF) has been urged to create the above mentioned fund, and to grant it US\$1.0 million from the accumulated net income of the CAF on the 31 st December 1986

The programme will be conducted by a unit specially created to that effect and composed of the Head of the Programme, one or several consultants, according to needs, supplied without any cost for CAF by specialized governmental or international agencies, and a secretariat.

\subsubsection{Andean-European Co-operation on Biotechnology}

A future Andean-European Co-operation in the biotechnology sec-tor may rely on the Agreement for Co-operation signed by both integration groups. To that effect, it is convenient to identify the main points of the above mentioned Agreement.

The Agreement has a global and integrative conception of cooperation which is defined as 'a broad economic co-operation to contribute to the development of the Parties respective economies and to raising their standards of living'. It is no longer something as punctual as the supports the EEC was offering to certain sectors in the past. The Agreement's global task is to spur more adequate stages according to the degree of maturity of both integration processes: it opens an ambitious outlook with far-reaching effects.

A 'more equitable distribution' of development potentials encloses a redistributive criterium maintained by the Andean Group and must lead to the planning of operation in which science and technology transfer would play an important role; and this because of the arrangements and commitments for teaching and transmission stated in the Agreement. The Agreement must therefore serve as an ambitious instrument for redistribution at subregional level.

To recognize that the Andean Group is made up of developing countries, and within it of less-developed countries, is to give to Bolivia and Ecuador a special treatment, above all in the education and training.

The co-operation for development enunciated in the GRAN/EEC Agreement recognizes the necessity to co-ordinate EEC member states efforts to back integration projects, in the present case scientific and technological. For the Andean Group it implies a larger capacity of harmonization and concertation so as to enable the integration projects to seize major opportunities which will probably be carried out by means of the European effort for co-ordination. The resulting rationalization should be considered as a growing and profitable potential which will depend on a more active and efficient position of the Andean Group during the execution of the Agreement.

Scientific and technological co-operation was sometimes confined to certain activities with detriment to others, to public agents 
disadvantaging the private sector. The Agreement explicitly embraces co-operation in the fields of science and technology, industrial development, agro-industry and farming, mining, fisheries, infrastructure, transport and communications, energy and tourism. The possibility to form joint ventures was not considered by the GRAN/EEC co-operation in the past. This leads to the necessity of seeking synergetic effects. Science and technology, as proposed by the An-dean strategy, must be the common denominator to all the sectors affected by modernization processes within the framework of the Andean Strategies for Science and Technology. Knowledge becomes the key to the whole integration process in various areas.

\section{Concluding Remarks}

a) We face an Agreement whose potential must be ambitious in its far-reaching effects. It may be used, within the present crisis, to transfer of knowledge and capacity necessary for the Andean Group for a more self-sustained development.

b) It is important to point out mechanisms or tools from the GRAN/EEC Agreement to make viable the knowledge and capacity transfer, and realized through the co-operation above indicated or in exclusively detailed activities.

c) The Agreement requires an explicit and feasible action framework for scientific and technological co-operation.

d) Completing this idea, a strong support would be given to the relationship of horizontal co-operation among the GRAN member countries in order to create a joint action through resources, capacities and abilities from the EEC.

The GRAN and EEC Member States must come to understand each other's experiences in science and technology. Priority is placed on the better understanding of the rationalization and canalization of recent resources in order to create a new and more integrative cooperation scheme.

GRAN is stepping towards a scheme of harmonization and concertation of needs and will, soon be ready to initiate this task. The subregion's 'harmonized' demands are already known, particularly in the subregional personnel education and training area which could become one of the most important channels for capacity transfer from the EEC to GRAN.

An unavoidable subject which has been discussed for a certain time by the GRAN member countries and in consequence has been approved as a Special Fund by Decision 183, is the organization and setting up of a financial mechanism to support joint actions. The precise identification of mechanisms for co-operation will come to light from the experiences and opinions exchanged during the European/Latin-American Seminar. 


\section{HEALTH IN THE THIRD WORLD: \\ THE ROLE OF INTERNATIONAL CO-OPERATION}

\section{Luiz Pereira da Silva}

Expectations of the benefits from the introduction of new biotechnologies on the health of people in the third world is reflected in the immense publicity given to them not only in the specialized press but also in the mass media.

Therefore, it is not necessary here to re-emphasize the new possible applications to health sciences provided by DNA recombinant techniques, molecular genetics, monoclonal antibodies and other modern techniques for the diagnosis, prevention and treatment of human diseases.

Taking for granted that most if not all of the people in the audience are aware of these potential benefits, the speaker is more inclined to discuss a few general points related to the introduction of new biotechnologies in the third world. By assuming an 'against the stream' attitude, the speaker is conscious of the fact that he will probably be considered as having conservative views. He accepts this blame and asks for the comprehension of his younger colleagues.

The speaker will try to define some problems which he thinks are specific to third world conditions, to raise some questions on the introduction of new biotechnologies and to develop arguments in favour of particular policies he thinks must be followed by govern-mental agencies, either national or international to provide a rational basis for the use and development of biotechnologies. Finally, he will try to define the type of international co-operation that he thinks could contribute to accelerate socio-cultural progress in the third world and would lead to an improvement in the infra-structure necessary for the development of health policies.

\section{Specificity of Third World Problems}

The first thing to define is the existence of specific problems of health in the third world. They consist first in the nature of the health problems: malnutrition, high incidence of infectious and parasitic diseases, high rates of maternal, neonatal and infantile mortality, low quality and insecurity of housing and working conditions, with high incidence of accidents. Most of these problems, which drastically decrease the expectation of life and seriously deteriorate the living standards are determined by social and economical structures. Medical care measures are only of limited effect and correspond to the use of traditional products like antibiotics and chemical drugs.

The second important feature of health problems in the third world is the inadequacy or absence of the structures necessary to provide health care: hospitals, welfare centres, and the low (or insufficient) qualification of the staff responsible for health care. In respect to the subject discussed here, namely the introduction of modern biotechnology in health sciences and in medical practice, one important deficiency is the absence of national pharmaceutical and chemical industries for drugs and pesticides in most countries of the third world and the weakness or absence of a biological industry for vaccines, sera and blood products and derivates. As a consequence, all the medical measures of the health policies in the third world, from the public health level to the private clinical medicine are entirely dependent on the importation of technology in the form of drugs, products, machines and equipment.

\section{A Rational Policy for the Introduction of New Biotechnologies}

With this picture of the health problems in the third world we will try first to describe some errors and illustrate how they can be avoided.

1. New biotechnologies cannot, in any case, replace measures at the social-economical level responsible for the basic problems of health.

2. New biotechnologies are not obligatorily giving the best solutions for health problems in substitution to traditional biotechnology.

3. New biotechnologies cannot (or are difficult to) be introduced independently of the complex economical and technological infrastructures necessary for their functioning.

4. New biotechnologies cannot be employed out of context of a solid scientific environment and a precise evaluation of interdisciplinary and technological interactions. 
5. New biotechnologies will not be an area in which can proliferate small new enterprises full of original ideas and opening fantastic opportunities for imaginative young people.

6. New biotechnologies applied to health will not be an area of activity from which important financial benefits are to be expected.

After having considered all of these negative views on the use of new biotechnologies in the third world, the speaker will discuss some positive ones which are important:

1. Some of the important problems of public health in the third world would benefit enormously from the introduction of new biotechnologies, like for the diagnosis and prevention of hepatitis, malaria, AIDS and other diseases.

2. Most of the countries in the third world, in addition to a majority of poor people, have also a fraction of the population with relatively high socio-economic conditions, and consequently health problems, equivalent to those of developed countries.

3. The absence of strong local industry occupying areas of economical activity and using traditional technology liberate countries of the third world from conservative pressure of lobbies.

A rational policy on the introduction of modern biotechnologies in health sciences and in medical care in the third world must take into consideration both the positive and negative constraints discussed above. According to the speaker's point of view it must respect some basic points:

- Development of scientific and technological education, scientific and technological research without any dicotomy but looking for equilibrium and association of both activities;

- Acurate planning of investments to provide, through the development of economical and technological backgrounds, the opportunity for the flowering of different innovation;

- Stimulate the participation of the scientific community through an open and large debate on selecting priorities and choosing technological alternatives;
- Define social priorities and integrate public health programs in a general project of socio-economic development.

\section{International Co-operation}

The difficulty in defining a rational model for the development of international co-operation in the area of new biotechnologies is the difficulty in defining the protagonists. Since technologies are finally to produce goods and since the production of goods is a function of Industry, 'new biotechnological products' are as result produced by the different branches of the 'Industrie de pointe' in Pharmacy, Chemistry, Mechanics, Electronics, etc. As we know these industries are nowadays developing a tremendous international commercial war for conquering markets. To create artificial needs is often more important than to satisfy a real necessity. Marketing is more decisive than scientific accuracy.

The past experience of the third world of co-operation in Industry is quite negative. The example of what happened with the pharmaceutical industry in Latin America in the 1960s is illustrative. During the Second World War, and in the years just after, many Latin American countries had developed a promising pharmaceutical industry. This, however, collapsed when confronted with the multinational enterprises invading the market during the economical 'boom' of the 1960's which offered a series of new products like antibiotics, neuroleptics, tranquillizers, etc. (which, of course, were all covered by patents).

If we wish to avoid the repetition of this phenomenon with new biotechnologies we need to have very clear ideas on the mechanisms by which international co-operation and technological and commercial exchange must be oriented. For the moment there is no reason for an excess of optimism, since all the available indicators point to an undesirable evolution and this for a series of reasons:

- New biotechnologies and their derived products applied to health sciences and medical care are more and more the 'affaire' of gian chemical-pharmaceutical enterprises, which are normally more interested in selling products than in transferring know-how. In the 1970s we observed the creation of a large number of new small enterprises dealing with biotechnology, especially in the USA but also in Europe, nowadays most of them have disappeared or have 
been absorbed by the giant industrial conglomerates either national or multinational.

- To regulate the exchange of technologies between developed countries and to conciliate conflicts arising from the industrial and commercial activities of national and multinational giant enterprises, European countries have created structures at the supranational level, like the EEC, which have all the political support from national governments and which are provided with the necessary social, political and economical authority to guarantee and support their role.

- Apart from some political tribunes in United Nations, there is no equivalent international organisations to regulate the interactions and exchanges among developed and underdeveloped countries with the exception of those in charge of the police supervision at the financial level like IMF.

- In these conditions it is easy to realize that free direct interactions between industrial protagonists, bringing together, on the one side experienced giant enterprises and on the other inexperienced small and poor companies will more often generate good business for the first than useful technological transfer for the second.

- Therefore, the natural tendency of trade, interactions and 'cooperation' will be (and already is in many respects) the invasion of nascent markets in the third world countries by commercialized products, either imported or produced by local subsidiaries of multinational enterprises. They will satisfy the needs (real or artificial) of the fraction of the population referred to above as being similar to the consumer society present in developed countries.

If following this model, transfer of new biotechnologies will reinforce economical and technological dependence, create artificial social needs, create foreign commercial exchange imbalance and deform the priorities of national health policies.

The only way that third world countries have to protect them-selves against all these negative consequences of 'free exchanges' and 'open borders' is to refuse them and to regulate the international co-operation according to their national interest and health policies.

\section{Conclusion}

The speaker has already defined some of the main principles he thinks must be followed by third world countries in order to favour a rational introduction of modern technology obtained from developed countries.

If we assume that all men are alike and that all of them would benefit from a general improvement in the health of the third world, then it is possible perhaps to express some wishes concerning practical recommendations that could be addressed to the EEC to favour know-how transfer in the area of new biotechnologies.

- Creation of permanent bilateral structures between EEC and the equivalent regional inter-governmental organizations, for the study, regulation, financial support and control of technological transfer projects.

- Developing and amplifying the already existing programmes of scientific co-operation between third world and European laboratories. Give priority to institutions of the third world directly involved in research in health sciences to allow them to elaborate new adapted techniques and products.

- Developing programmes of scientific and technological training for third world students giving preference to projects conducted in local laboratories and institutions. The organization of permanent summer schools with a minimum of permanent administration and the participation of relevant European technicians and scientists would be a welcome formula.

- Elaborate programmes to drain the surplus of trained people in Europe to work for periods of one to a few years in laboratories of the third world with financial support from the EEC or international agencies. In this respect, a welcome initiative would be to stimulate well-trained young Europeans, during their military service, to go to work in third world laboratories.

All these and other possible initiatives might be developed in coordination with WHO and their regional agencies. A dose interaction with parallel projects related to agriculture would certainly increase their impact. 


\section{CONCLUSIONS AND ANALYSIS}

Bernardo Sorj

The three days of discussion confirmed the importance of biotechnology for Latin America not only in such fields as tropical medicine and nutrition which are vital to basic welfare, but also in areas directly contributing to economic growth and development.

Biotechnology has a role to play in strengthening Latin America's growth prospects and trade performance by:

- improving crop yields;

- favouring import substitution in agriculture and industry;

- extending the pharmaceutical industry into new areas;

- and, perhaps above all, capturing the creativeness and entrepreneurship of Latin America's smaller technology-based firms.

If these hopes are realised biotechnology will feed into structural adjustment efforts and so contribute to relaunching growth, and overcoming the debt problem.

But these hopes will not be realised overnight:

- there is a shortage of scientists able to place the necessary expertise at the service of Latin American industry;

- research institutes and universities cannot keep pace with the demand;

- information concerning available technologies which could be adapted to the needs of Latin American industry and agriculture is lacking;

- smaller firms possessing such technologies in Europe and elsewhere may, because of their size, lack the means to establish contacts with counter-part firms in Latin America.

This situation poses a challenge to research institutes, industry, governments, regional organisations in Latin America and to the European
Community. SOBELA was an impressive demonstration of the will of all parties concerned to meet this challenge.

Where do we go from here, now that a certain number of contacts have been made? What can Europe and Latin America do, working together as partners, to further co-operation in the field of biotechnology? How in particular can the Community, by virtue of its own experience in promoting cross-national research on biotechnology and more generally of economic co-operation help assure a follow-up which is worthy of the many valuable interventions made at the seminar?

There are at least three fields which call for immediate action:

A. Information. The improvement of the two-way flow of information between Europe and Latin America on new developments in biotechnology: the Commission is ready to explore possibilities for improving data bases, facilitating exchanges between research institutes, organising specialised seminars and conferences to ensure that researchers in our two continents are informed of each others efforts, within the normal constraints imposed by commercial considerations;

B. Training. Latin America is producing an increasing number of scientists but their number falls short of that required by the rapid growth of biotechnology.

The Community and its Member States can help overcome this problem by:

- making available experts to work with Latin American research institutes and biotechnology-based enterprises;

- arranging traineeships for Latin American scientists with Community firms and research institutes;

- providing assistance for Latin American biologists to pursue advanced studies in Europe;

- improving information on training possibilities throughout the Community.

C. Industrial Co-operation. These three days' discussion have shown that both sides have an interest in joint ventures and other forms of 
collaboration between firms and research institutes on either side of the Atlantic. Such arrangements are among the most effective instruments for technology transfer.

The Commission has recently proposed to the Council that henceforth the Community should do more to promote industrial co-operation with enterprises in our partner countries in Latin America and elsewhere in the developing world.

We will examine together in the coming months how best these ideas can be applied to the field of biotechnology.

You can rest assured that the European Commission will do whatever is within its power to support those efforts which you, who are dose to the reality of industry and research, decide jointly to undertake.

Together we will examine the kind of instruments by which we could develop and implement joint initiatives in the fields covered by this seminar.

For us this seminar has served as a valuable learning experience, an example of the kind of initiative which can help bring researchers and industrialists in Europe and Latin America closer together.

The many suggestions put forward will help us to develop new forms of co-operation not only in biotechnology but also in other advanced fields where Europe and Latin America can learn from each others' experience.

\section{SOBELA Analysis}

Advanced technologies pose new challenges for developing countries and their relationships with the developed world. How can high technology be integrated into a development strategy? What is the best basis for cooperation between Europe and Latin America in the context of a global market challenged by Japan and the USA?

It is the belief of the Editors that the SOBELA seminar and this volume provide some valuable indications of how the preceding questions might be addressed.

SOBELA was organised in two parts: the meeting itself and a number of satellite visits to European countries by members of the Latin American delegations. Proposals for possible co- operation were evaluated by a questionnaire distributed to Latin American delegates both before and after SOBELA. The following table shows the level of response.

\begin{tabular}{|lccc|}
\hline Table 1. Questionnaire replies. & & & \\
\hline Country & Delegates & Replies & Percentage \\
\hline Andean Pact & $9(11)^{*}$ & 4 & 45 \\
Argentina & 10 & 6 & 60 \\
Brazil & $17(26)^{*}$ & 11 & 65 \\
Mexico & 5 & 3 & 60 \\
Totals & $41(52)^{*}$ & 24 & 59 \\
\hline * The number in parentheses includes journalists and governmental representatives, not \\
directly involved in biotechnology.
\end{tabular}

The number of co-operation proposals advanced by each delegation attests to a broadly similar level of interest. If numbers are extrapolated to include all delegates from Latin America some 200 proposals for cooperation may have been initiated.

\begin{tabular}{|l|c|c|c|}
\hline \multicolumn{3}{|l|}{ Table 2. Co-operation proposals by delegation. } \\
Country & Total & Extrapolated total* & Average proposals per delegate \\
Andean Pact & 28 & 58 & 6.4 \\
Argentina & 23 & 38 & 3.8 \\
Brazil & 36 & 56 & 3.3 \\
Mexico & 10 & 17 & 3.4 \\
Totals & 97 & 169 & 4.1 \\
*extrapolation to 100\% rate of reply for each delegation. \\
\hline
\end{tabular}

The following table summarizes proposals on a country by country basis.

\begin{tabular}{|lccccccccccccc|}
\hline \multicolumn{10}{|l|}{ Table 3. Co-operation proposals, synopsis. } \\
\hline \multicolumn{1}{|c}{ Countries } & $B$ & $F$ & $G R$ & NL & IRL & $I$ & $P$ & $E$ & $G B$ & $D$ & $L A$ & Total \\
\hline Andean Pact & 6 & 4 & - & 2 & 1 & 4 & - & 2 & 1 & 5 & 2 & 27 \\
Argentina & 6 & 7 & - & 1 & - & - & - & 1 & 7 & 2 & - & 24 \\
Brazil & 12 & 11 & 1 & 7 & - & - & 2 & 1 & 1 & 2 & - & 36 \\
Mexico & 2 & - & 1 & 2 & - & - & - & 2 & 1 & 1 & 1 & 10 \\
Totals & 26 & 22 & 2 & 12 & 1 & 4 & 2 & 6 & 10 & 10 & 3 & 98 \\
\hline
\end{tabular}

The above figures reflect the special efforts made by Belgium, France and the Netherlands who organised visits within their countries for members of the Latin American delegations. Although the United Kingdom did not host any visits it is notable that a strong tradition of co-operation served as the basis for a number of proposals. 


\begin{tabular}{|lccccc|}
\hline Table 4. A sectorial analysis of replies. & & & \\
\hline \multicolumn{1}{|c}{ Countries } & Health & Agro & Energy & Others* & Total \\
\hline Andean Pact & 8 & 6 & - & 13 & 27 \\
Argentina & 10 & 4 & - & 10 & 24 \\
Brazil & 4 & 24 & 1 & 7 & 37 \\
Mexico & 1 & 4 & - & 5 & 10 \\
Totals & 23 & 38 & 1 & 35 & 38 \\
\hline * Refers essentially to training programmes in relevant fields. \\
\hline
\end{tabular}

There is a clear division of interest among the Latin American states, with Argentina and the Andean Pact focusing on Health Care and Brazil and Mexico focusing on Agriculture. Almost half of the proposals related to agriculture and a quarter to health care.

The type of European institution interested in co-operation with Latin America is indicated in the following table.

\begin{tabular}{|lccc|}
\hline \multicolumn{4}{|c|}{ Table 5. European Institutions interested in proposals. } \\
\hline \multicolumn{1}{|c|}{ Countries } & Private & Public & Total \\
\hline Andean Pact & 3 & 24 & 27 \\
Argentina & 11 & 13 & 24 \\
Brazil & 21 & 16 & 37 \\
Mexico & 4 & 6 & 10 \\
Totals & 39 & 59 & 98 \\
\hline
\end{tabular}

Overall there was a balance between private and public sector proposals for co-operation. The Brazilian delegation, which included a significant number of entrepreneurs showed the greatest tendency to private industrial co-operation.

It is still unclear how many of these early overtures of interest will ultimately become manifest as contractual agreements. This will depend in some measure on the active involvement of states and individuals in initiatives discussed in the concluding remarks.

A most important consequence of SOBELA was the stimulation of an identity amongst those Latin American institutions involved in biotechnology. Strong institutions, both public and private, are of fundamental importance in promoting and sustaining European/ Latin American co-operation. It is important to note that the timing of SOBELA in April 1987 was critical, coming just as Latin American countries were taking the first steps in the establishment of private and governmental enterprises in the field of biotechnology. Brazil had just launched the
Association of Biotechnology Enterprises (ABRABI). The National Secretariat of Biotechnology of the Ministry of Science and Technology, in its second year, was defining its programme of activity. Argentina, with a lesser degree of institutionalisation, had a government body responsible for promoting biotechnology, and a forum for encouraging the interaction of entrepreneurs. Mexico has long had government sponsored activities in biotechnology, but no private industrial sector of note. The Andean Pact countries are only now formulating their biotechnology programme.

The first important, and unforeseen, role of SOBELA was to crystallise the institutionalisation of Latin American biotechnology. The seminar functioned both as a Latin America/Europe meeting and as a rare Latin American forum, where representatives from the differing Latin American states were together able to discuss strategy. Thus SOBELA stimulated not only inter-continental co-operation, but also intra-continental co-operation. The massive Brazilian delegation probably had a stimulating effect on the other Latin American delegates, especially in the sense of emulating the Brazilian association of enterprises with its large private sector representation.

SOBELA fulfilled a second role in indicating a 'modus operandi' for European/Latin American co-operation that may surmount many of the problems encountered in such international co-operative ventures. The inclusion of representatives from government, industry and research institutions allowed the different influences to counterbalance and complement each other. Too often there is a tendency for policy makers to be rhetorical, entrepreneurs narrow minded and academics unrealistic. In Latin America, political instability and sometimes ideological pressures, can increase those tendencies. It is fundamental that all sectors work together to ensure the continuity and efficacity of international co-operation.

As an exercise in awareness SOBELA filled a third role, allowing Latin American and European delegates to evaluate the advantages of cooperation. Latin American delegates were most enthusiastic as exemplified by the following comments:

- 'We felt that Europe is capable of confronting America and Japan at the scientific and technological level'

- 'SOBEla was the first but important step in a difficult, time consuming, process' 
- 'European-Latin American relations should be based on a fair exchange by which the first receive technology, and the second an important consumer market'

- 'The formation of human resources is a central interest for Latin America and a precondition for the effective absorption of European technology'

- 'We need to create direct links between European and Latin American entrepreneurs'

- 'We need greater selectivity in the field of industrial co-operation, taking into consideration existing infrastructure, markets, technical capacity and patent laws'

- 'We need to study the mechanisms by which Europe increases the links between enterprises and universities'

- 'We need to consolidate realistically our national programmes of biotechnology in order to make clearer what we need and have to offer'

- 'We need to discuss negotiation models capable of satisfying the expectations of both sides'

- 'We discovered that Europe has technologies that will find their ideal application in Latin America'

- 'European documents related to legal problems, regulation and promotion of biotechnology should be diffused and a workshop organised on specific topics of common interest'

- 'I was impressed by the diversity of interest and idiosyncrasies of the various European countries, and at the same time by their conviviality within a common framework

- 'SOBELA was important for us (Andean Pact) because we are in a stage of definition of our national programme and priorities'

- 'The interpersonal relations established during SOBELA will be central to our future co-operation with Europe. SOBELA expressed the will of the Commission to increase links with Latin America.
These efforts should have continuity through open communication channels, and the realisation of new meetings'

\section{The Challenges}

The quality and quantity of contacts that were established between Latin American and European biotechnology entrepreneurs, and the facility with which they were set up indicate that the biotechnology sector is particularly well placed for the development of economic co-operation between the two continents, especially between small and medium scale enterprises (SMEs). The reasons for this lie in the special nature of biotechnology based SMEs. Relatively small amounts of capital are needed to launch a joint venture operation, and importantly company directors often have an academic back-ground with international languages and experience.

In a sector where industrial and academic skills are highly integrated it is possible to exploit the well established international programmes in scientific training and research to the benefit of science based commercial development. SOBELA raised the prospect of using biotechnology as a tool for promoting international co-operation. Many problems still exist and will need to be resolved if effective inter-continental partnerships are to be effected. It will be critical that in such relationships a fair exchange is effected: for European firms, a reasonable return on investment and presence in a developing world market, and for Latin American countries and organisations, the production of essential goods within the framework of a favourable technology transfer and co-operation environment.

In order to advance the interests of both sides further exchange and experience is required. The controversial topic of patent legislation must be confronted. This topic is a subject of debate in Latin America, and indeed the world press. The USA has recently adopted a most hostile stance towards Latin American latitude on the patents issue. Internal debate is moving towards a consolidation of opinion and in some states, Mexico for example, legislation is being enacted to give full patent protection to pharmaceuticals and food products. Europe should seek active participation in these discussions, at European Commission, national governmental and industrial levels, thus shaping Latin American positions for the future. This will not be achieved by confrontation and polarisation, but by exchanges of opinion and political concertation. 
Europe's presence in Latin America is mediated predominantly by large companies. There is however much scope for the active participation of European SMEs, which are usually more open to the technology transfer schemes expected by Latin American countries.

Increasing co-operation between European and Latin American SMES is a difficult objective to realise, not least because of limited information, provincial attitudes, and simple ignorance of the scope of possibilities for international co-operation. On the basis of arguments presented in drafts of this volume the European Commission will explore ways to make available the information, interface operational units and concertation activities needed to transform the spirit of SOBELA into a permanent and expanding reality.

SOBELA was not simply a seminar on biotechnology in Europe and Latin America held in April 1987. It is an ongoing activity, in which Europe is demonstrating its capacity to be the active partner and focal point for the constant effort needed to turn around the economies of developing countries through the medium of high technology. 